MONITORING VARIATION OF SURFACE RESIDUAL STRESSES

IN THE SHOT-PEENED STEEL COMPONENTS

BY MAGNETIC BARKHAUSEN NOISE METHOD

A THESIS SUBMITTED TO

THE GRADUATE SCHOOL OF NATURAL AND APPLIED SCIENCES

$\mathrm{OF}$

MIDDLE EAST TECHNICAL UNIVERSITY

BY

SERDAR SAVAŞ

IN PARTIAL FULFILLMENT OF THE REQUIREMENTS

FOR

THE DEGREE OF MASTER OF SCIENCE

IN

METALLURGICAL AND MATERIALS ENGINEERING

JULY 2010 
Approval of the thesis:

\section{MONITORING VARIATION OF SURFACE RESIDUAL STRESSES IN THE SHOT-PEENED STEEL COMPONENTS BY MAGNETIC BARKHAUSEN NOISE METHOD}

submitted by SERDAR SAVAŞ in partial fulfillment of the requirements for the degree of Master of Science in Metallurgical and Materials Engineering Department, Middle East Technical University by

Prof. Dr. Canan Özgen

Dean, Graduate School of Natural and Applied Sciences

Prof. Dr. Tayfur Öztürk

Head of Department, Metallurgical and Materials Engineering

Prof. Dr. C. Hakan Gür

Supervisor, Metallurgical and Materials Eng. Dept., METU

Prof. Dr. Bilgehan Ögel

Co-Supervisor, Metallurgical and Materials Eng. Dept., METU

\section{Examining Committee Members:}

Prof. Dr. C. Hakan Gür

Metallurgical and Materials Engineering Dept., METU

Prof. Dr. Tayfur Öztürk

Metallurgical and Materials Engineering Dept., METU

Prof. Dr. Riza Gürbüz

Metallurgical and Materials Engineering Dept., METU

Prof. Dr. Bülent Doyum

Mechanical Engineering Dept., METU

Dr. İbrahim Çam

Central Laboratory, METU

Date: 05.07.2010 
I hereby declare that all information in this document has been obtained and presented in accordance with academic rules and ethical conduct. I also declare that, as required by these rules and conduct, I have fully cited and referenced all material and results that are not original to this work.

Name, Last name: Serdar SAVAŞ

Signature: 


\author{
ABSTRACT \\ MONITORING VARIATION OF SURFACE RESIDUAL STRESSES \\ IN THE SHOT-PEENED STEEL COMPONENTS \\ BY MAGNETIC BARKHAUSEN NOISE METHOD
}

\author{
Savaş, Serdar \\ M.Sc., Department of Metallurgical and Materials Engineering \\ Supervisor: Prof. Dr. C. Hakan Gür \\ Co Supervisor: Prof. Dr. Bilgehan Ögel
}

July 2010, 81 pages

Shot peening is a cold-working process by which residual compressive stresses are being induced in the surface region to increase the fatigue strength and the resistance to stress-corrosion cracking. This study covers non-destructive measurement of surface residual stresses in the shot-peened steel components by a micro-magnetic technique, named as Magnetic Barkhausen Noise (MBN) method. For this purpose, various low alloy steel specimens were prepared by a controlled shot peening process with different intensity, impact angle and coverage values. The measurements showed that a clear relationship exists between residual stresses and the MBN signals. Residual stress values determined by MBN technique were also verified by $\mathrm{X}$-ray diffraction measurements.

Keywords: Shot-peening, Residual Stresses, Non-Destructive Evaluation, Magnetic Barkhausen Noise 


\title{
ÖZ
}

\section{BİLYELİ DÖVME UYGULANMIŞ ÇELİK PARÇALARDAYÜZEY KALINTI GERILMELERINIIN MANYETIK BARKHAUSEN GÜRÜLTÜ YÖNTEMİ İLE ÖLÇÜLMESİ}

\author{
Savaş, Serdar \\ Yüksek Lisans, Metalurji ve Malzeme Mühendisliği Bölümü \\ Tez Yöneticisi: Prof. Dr. C. Hakan Gür \\ Ortak Tez Yöneticisi: Prof. Dr. Bilgehan Ögel
}

Temmuz 2010, 81 Sayfa

Bilyeli dövme işlemi, metallerin yorulma ve gerilmeli korozyona karş1 mukavemetlerini artırmak için yüzeyde basma nitelikli kalıntı gerilme oluşturmak amacıyla uygulanmaktadır. Bu çalışma, bilyeli dövme sonrasında çelik parçaların yüzeyindeki kalıntı gerilmelerin tahribatsız mikro-manyetik bir yöntem olan manyetik Barkhausen gürültüsü (MBN) tekniği ile ölçülmesi hakkındadır. Ölçümler için, kontrollü bir bilyeli dövme uygulaması kullanılarak, farklı dövme şiddeti, bilye püskürtme açısı ve yüzey kapsama değerleri kullanılarak elde edilen numuneler hazırlanmıştır. Yapılan ölçümler, yüzey kalıntı gerilmeleri ve MBN sinyalleri arasında belirgin bir ilişki olduğunu göstermiştir. MBN yöntemi ile belirlenen kalıntı gerilim değerleri X-Ray ölçüm yöntemi ile doğrulanmıştır.

Anahtar kelimeler: Bilyeli Dövme, Kalıntı Gerilme, Tahribatsız yöntem, Manyetik Barkhausen Gürültüsü 
To my family 


\section{ACKNOWLEDGEMENTS}

Firstly, I would like to express my gratitude to my supervisor Prof. Dr. C. Hakan Gür for his guidance, understanding and continuous support throughout the study.

I would also like to thank to Dr. İbrahim Çam for his guidance and help in Magnetic Barkhausen Noise measurements and to Emre Ergül for the technical assistance in chemical analysis of the samples.

My special thanks go to TUBITAK for the scholarship given for doing Master of Science which was very important throughout my study.

I wish to thank to Turkish Aerospace Industry (TAI) for their help and for the great opportunity to manufacture the samples for the study at NADCAP certified equipment.

My special thanks go to Sinem Adigüzel who was performed X-Ray Diffraction residual stress measurements in Atılım University.

I would like to thank to my friends Onur Rauf Bingöl, Hüseyin Ergün, Alp Aykut Kibar, Mert Akkuş, Murat Tolga Ertürk, Göksu Gürer and, colleagues H. İlker Yelbay, Sadık Bayramoğlu, Orcan Kolankaya and Seyhan Çamlıgüney from METU WTNDT / Nondestructive Testing Unit for their help, support and interest.

I would also like to thank to my colleagues and managers at GE Marmara Technology Center.

Finally, I would also like to express my special thanks to Nigar Savaş, Erhan Savaş, Arzu Savaş for their support and interest and to dedicate this study to my father Y1lmaz Savaş who always supported, encouraged and gave valuable hints during his life. 


\section{TABLE OF CONTENTS}

ABSTRACT

\section{CHAPTERS}

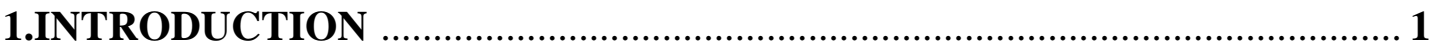

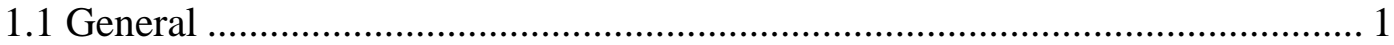

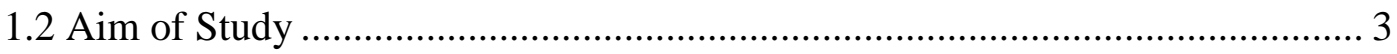

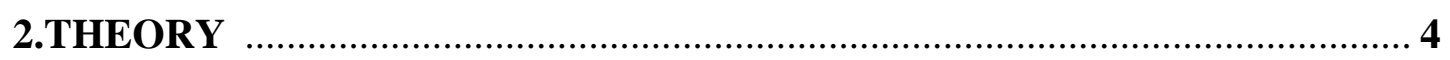

2.1 Theory of Magnetic Barkhausen Noise …................................................... 4

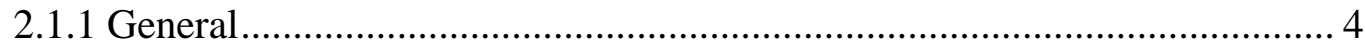

2.1.2 Applications of Magnetic Barkhausen Noise .......................................... 9

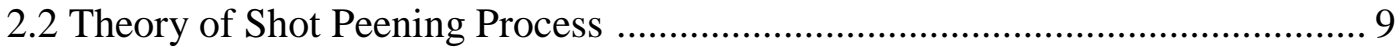

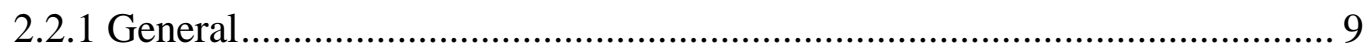


2.2.2 Equipments and Parameters................................................................. 10

2.2.3 Residual Stress Formation Mechanism ................................................ 22

2.2.4 Application and Benefits .................................................................. 23

2.2.5 Other Types of Shot Peening Process.................................................. 25

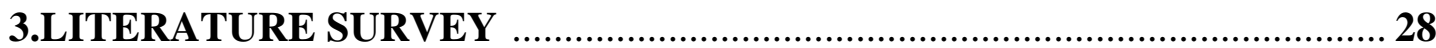

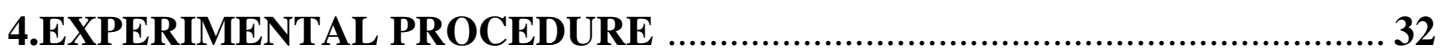

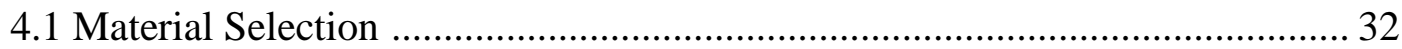

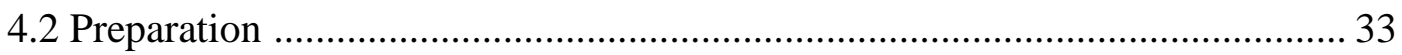

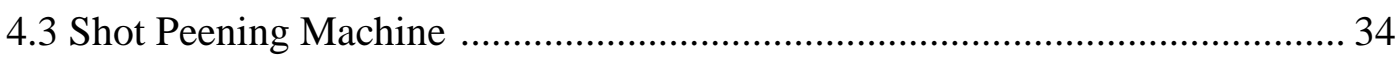

4.4 Determination of Shot Peening Parameters ................................................. 35

4.5 Calibration of Shot Peening Operation .......................................................... 36

4.6 Magnetic Barkhausen Noise Measurement ................................................... 37

4.7 Stress versus Barkhausen Curve ................................................................... 42

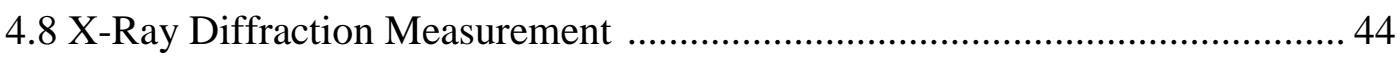

4.9 Electrical Conductivity and Magnetic Permeability Measurement ................ 47

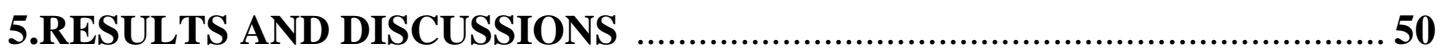

5.1 MBN Measurements with Rollscan System .............................................. 50

5.1.1 MBN Measurements Results of Shot Peened Samples with different Peening Intensity, Coverage and Impact Angles ........................................... 50

5.1.2 Random MBN Measurement Results of Shot Peened Samples in order to Evaluate Homogeneity of the Process ................................................................ 54

5.1.3 Conversion of MBN Measurements Results of Shot Peened Samples to

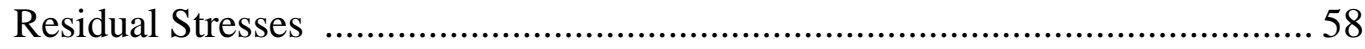

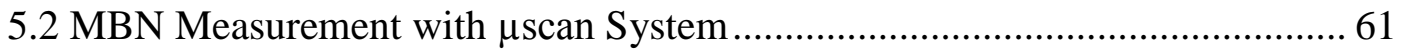

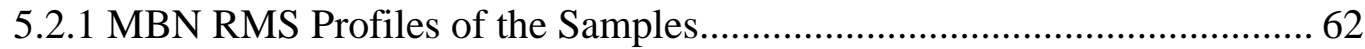


5.2.2 Frequency Distribution Profiles of the Samples ....................................... 64

5.2.3 Representative Hysteresis Curves of the Samples................................. 70

5.3 Verification of MBN with XRD Residual Stress Measurement Results 73

6.CONCLUSION 75

REFERENCES 78 


\section{LIST OF TABLES}

\section{TABLES}

Table 2.1: Nozzle life time changes under steel shot according to the coating material

Table 2.2: Fatigue life change in some components due to shot peening process ... 24

Table 4.1 Chemical composition of the sample

Table 4.2: Cycle time versus Almen intensity values

Table 4.3: $\mathrm{MBN}$ measurement results of shot peened $9.9 \mathrm{~A}$ and un-shot peened samples.(5 random data) $125 \mathrm{~Hz}$, magnetization 20, amplification 20, general purpose probe

Table 5.1: Random BN responses taken from shot peened samples with different angles and reference samples. (Max var. is max variation from the average) 53

Table 5.2: Random BN responses taken from shot peened samples with different coverage and reference samples. (Max var. is max variation from the average) ......53

Table 5.3: Descriptive statistical analyses of random collected data 57

Table 5.4: MBN data versus Stress value collected from the calibration sample .... 58 


\section{LIST OF FIGURES}

\section{FIGURES}

Figure 1.1 Fatigue failure of a gear tooth (left), crack initiation site on a gear tooth (right) 2

Figure 2.1 Barkhausen jumps 4

Figure 2.2 Random orientations of magnetic domains without magnetization (left), domain wall motion under an applied magnetic field (right) 5

Figure 2.3 Domain walls(a), tensile stress effect(b), compressive stress effect(c) .... 6

Figure 2.4 Surface (left) and encircling (right) MBN technique 7

Figure 2.5 Raw time domain data plot (a), RMS MBN profile (b), Amplitude versus frequency plot after application FFT (c), Pulse Height Distribution (d) 8

Figure 2.6 Shot peening operation 10

Figure 2.7 Examples of conveyor systems 12

Figure 2.8 Illustrating the "Intensity distribution" of a peening stream 12

Figure 2.9 Automatic Air Blast Machine 12

Figure 2.10 Straight bore (left), Venturi (right) 13

Figure 2.11 Steel shot codes according to their sizes 15

Figure 2.12 Types of Almen strips 17

Figure 2.13 Dimensions of Almen strips 17 
Figure 2.14 Almen strip holder

Figure 2.15 Almen strip curvature after shot peening ….................................... 18

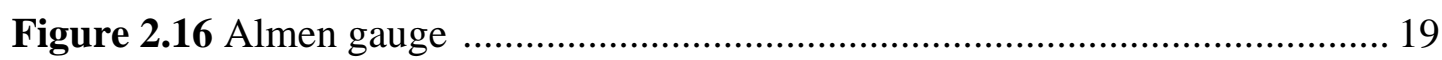

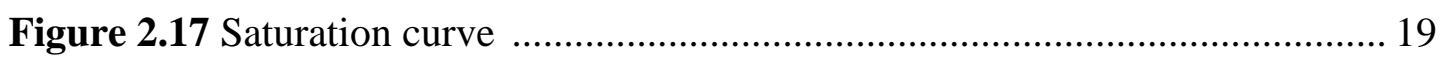

Figure 2.18 Determination of saturation in shot peening .................................... 20

Figure 2.19 Shot peening parameters affecting residual stress state ....................... 21

Figure 2.20 Streched surface in shot peening ….................................................. 22

Figure 2.21 Residual stress distribution after shot peening ................................. 22

Figure 2.22 Formation of wings by shot peening ............................................ 25

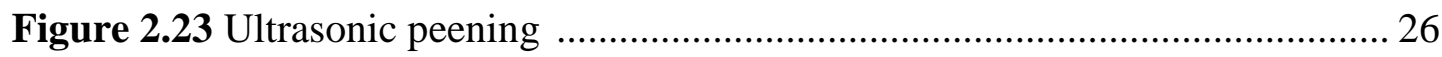

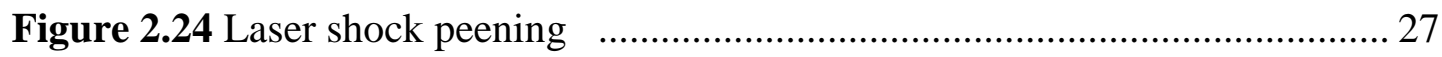

Figure 3.1 MBN change due to stress for three different materials ........................ 28

Figure 3.2 XRD and MBN measurement results from different shot peened samples

Figure 3.3 XRD and MBN measurement results from different shot peened AISI

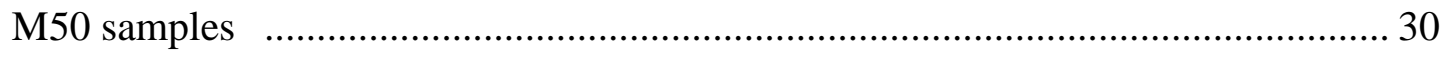

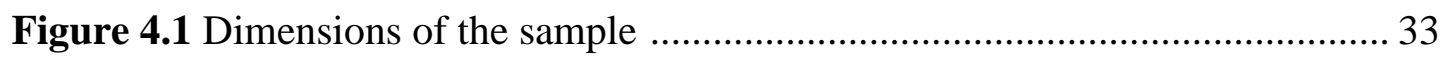

Figure 4.2 Representative micrograph of the starting material having ferriticpearlitic microstructure (100X) 33

Figure 4.3 A representative conventional air pressured shot peening equipment and nozzles used to manipulate the balls to hit the surface of the material. 34

Figure 4.4 Saturation curve which is arc height of Almen strip versus cycle time... 37 Figure 4.5 Stresstech Rollscan $\mu$ Scan 500-2 device Magnetic Barkhausen Noise Equipment 38

Figure 4.6 Magnetic Barkhausen Noise probes. Right: General purpose probe, Left: Probe has more powerful magnetization capacity than the general purpose probe. . 38 
Figure 4.7 RMS MBN Profile of shot peened with 9.9 A intensity value and un-shot peened samples with $125 \mathrm{~Hz}$ magnetizing frequency, magnetization 20, amplification 20 , general purpose probe (Figure 4.8 right). ( $\mu$ scan channel) 40

Figure 4.8 MBN response change according to magnetization and amplification (Amp: Amplification) (Un-shot peened sample)

Figure 4.9 (M: Magnetization) Comparison between un-shot peened and shot peened sample MBN response under different amplification values.

Figure 4.10 System where the calibration sample is applied to tensile and compressive loads in elastic range, a micrometer as $0.001 \mathrm{~mm}$ sensitivity.

Figure 4.11 Magnetic Barkhausen Noise change according to stress changes in the elastic region which will be used in conversion of Barkhausen responses into residual stress values.

Figure 4.12 Seifert XRD 3003 PTS X-Ray Diffractometer System 45

Figure 4.13 Database reference for the XRD residual stress measurements 45

Figure 4.14 Basis of XRD residual stress measurements (S: X-Ray Source, D: XRay Detector, N: Bisector of incident and diffracted beam, $2 \varphi$ : Bragg angle, $\psi$ : Sample is rotated in front of the x-ray source with a known angle $\psi[30]$. 46

Figure 4.15 Electrical conductivity measurement (Agilent 3458A Digital Multimeter) 47

Figure 4.16 Coiled toroid for permeability measurement (Agilent 4294A Impedance Analyzer) 48

Figure 4.17 Depth of the information vs. Barkhausen Noise frequency 49

Figure 5.1 Rollscan BN amplitude for different intensity (a), different coverage (b), and different angles (c) shot peened samples

Figure 5.2 Rollscan BN amplitude from different 10 points randomly selected from the different coverage samples and reference sample in order to see the homogeneity of the signal response from the samples 54 
Figure 5.3 Rollscan BN amplitude from different 10 points randomly selected from the different angle samples and reference sample in order to see the homogeneity of the signal response from the samples

Figure 5.4 Histograms of the random collected data (45, 90 degree; 100\%, 300\% coverage and USP (Un-shot peened) samples)

Figure 5.5 Normality analyses were done with three models and in all types models data were found as normal

Figure 5.6 The best fitted line is drawn. The graph is plotted as Stress versus MBN in order to calculate the formula by taking MBN responses as $\mathrm{x}$ of the formula ..... 59

Figure 5.7 The graph is plotted as Stress versus MBN to show intensity effect of shot peening.

Figure 5.8 The graph is plotted as Stress versus MBN show coverage effect of shot peening.

Figure 5.9 The graph is plotted as Stress versus MBN to show impact angle effect of shot peening (The result for 0 degree shows MBN response of reference sample)... 61

Figure 5.10 RMS MBN Profiles of shot peened samples with different intensity ... 63

Figure 5.11 RMS MBN Profiles of shot peened samples with different coverage .. 63

Figure 5.12 RMS MBN Profiles of shot peened samples with different impact angle

Figure 5.13 Frequency distributions of the samples with different intensity and the reference sample.

Figure 5.14 Difference between shot peened with different intensities and reference sample in amplitude with their distribution regarding frequency

Figure 5.15 Frequency distributions of the samples with different coverage and the reference sample.

Figure 5.16 Difference between shot peened with different coverages and reference sample in amplitude with their distribution regarding frequency 
Figure 5.17 Frequency distributions of the samples with different impact angle and the reference sample 68

Figure 5.18 Difference between the samples with different impact angles and reference sample in amplitude with their distribution regarding frequency. 68

Figure 5.19 RMS MBN Profiles taken by using different filtering options from the reference sample.

Figure 5.20 Microhardness measurement taken from the most severest shot peened sample.

Figure 5.20 Hysteresis curves of the samples shot peened with different intensities. 71

Figure 5.21 Hysteresis curves of the samples shot peened with different coverages.

Figure 5.22 Hysteresis curves of the samples shot peened with different impact angles 72

Figure 5.23 XRD residual stress measurement results 73

Figure 5.24 Validation of MBN with XRD measurements 74 


\section{CHAPTER 1}

\section{INTRODUCTION}

\subsection{General:}

All components are working under different types of stresses in their service conditions. The types and magnitude of the stresses are calculated and modeled by Finite Element Analysis (FEM) analysis at their design stage. However, till becoming their final shape, all the components are exposed many types of manufacturing processes. All the processes cause in different types of residual stresses formed in the materials. These residual stresses should be considered as an additional stress magnitude to the stresses due to service conditions. Therefore, tensile type of residual stresses is detrimental for the materials by decreasing the fatigue life and compressive type of residual stresses is beneficial because of its hindering effect on crack initiation and propagation.

Fatigue failure is so common in most metals and is mainly caused by the tensile stresses which favor crack growth near or from the surface of the material. These stresses cause in a drastically reduced performance of the component followed by catastrophic failures at an early stage of the component's life. The magnitude and the distribution of the residual tensile stress are both critical to the general behavior and performance of any components. Therefore, they should be considered at the design stage and also at the production stage [1]. 
In order to annihilate tensile residual stresses some special processes are applied on the surface of the components. By applying that processes it is aimed to obtain beneficial compressive residual stresses. Conventional shot peening is mostly used method for that purpose. By doing FEM analysis, the residual stress magnitude and distribution are tried to be interpreted with the mathematical models at the design stage. However, they have to be also measured experimentally because many conditions have to be taken as ideal in that analysis.

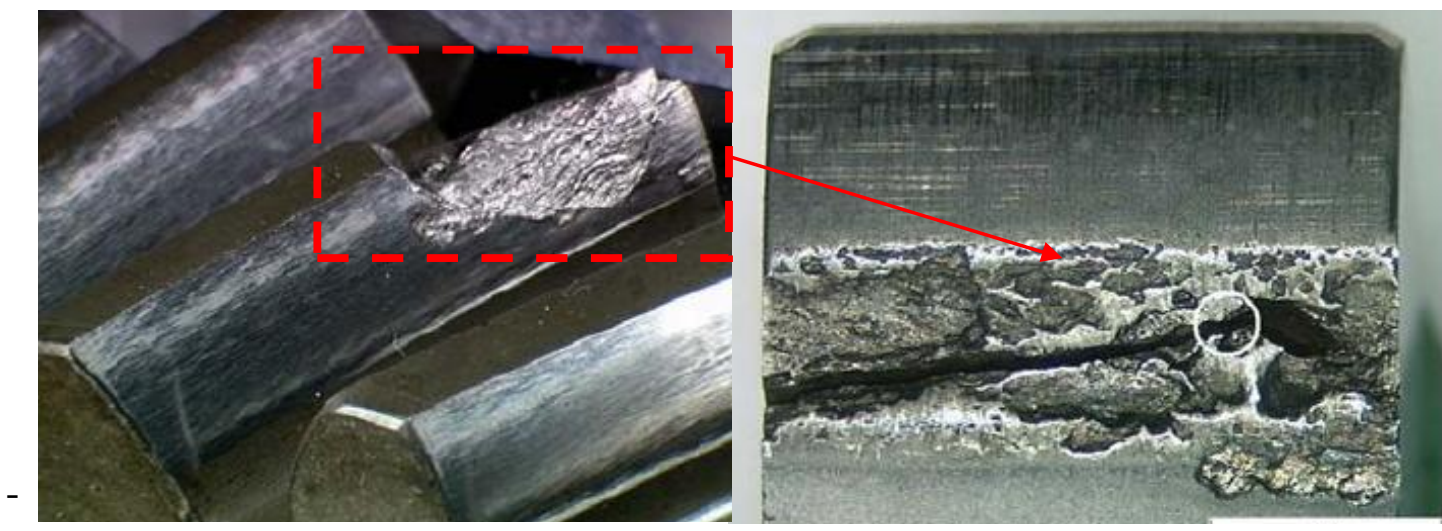

Figure 1.1 Fatigue failure of a gear tooth (left), crack initiation site on a gear tooth (right) [1]

There are different types of residual stresses characterization methods among that there exist semi-destructive and non-destructive techniques. One of the nondestructive methods is as a magnetic method, Barkhausen Noise technique which is working as the basis of variation in magnetic domains with stress [2].

Consequently, residual stresses are an important topic for designing, manufacturing and life of the industrial components. As stated before, residual stresses obtained after some production stages will be detrimental or beneficial which is changing according to their types. Conventional shot peening is an important process to obtain 
beneficial compressive residual stresses in order to annihilate tensile type of residual stresses and to increase the fatigue life of the industrial components.

\subsection{Aim of Study:}

Shot peening is a special cold working process which introduces residual compressive stress layer on the surface by projecting different types of peening media to the surface of the materials. That compressive stress layer provides prevention against stress corrosion cracking, and increased fatigue life to the materials. Therefore, determination of residual stress levels and the homogeneity of shot peening process on the surface of the materials are vital for service life of the industrial components.

Current common used residual stress determination methods are X-Ray diffraction and Hole-Drilling methods. There are also neutron diffraction and Raman spectroscopy methods for that purpose. As a magnetic method, Barkhausen noise technique challenges commonly used methods with its low cost, fast and nondestructive inspection capability in characterization of residual stresses.

The aim of this study, to characterize the compressive residual stresses formed on the surface of the materials by conventional shot peening operation non-destructively. By means of non-destructive residual stress characterization technique, there will be an opportunity to inspect all the shot peened components in the production sides continuously. In addition to characterization of residual stresses, the homogeneity of the shot peening operation can be controlled by a non-destructive inspection method. Currently, homogeneity of the shot peening is tried to be controlled by visual inspection and fluorescent penetrant methods. By those methods, whether or not the balls were hit to the areas which were desired to be shot peened. By obtaining a signal range that is corresponding to the stress values required by the specifications, homogeneity of the shot peening can be controlled with the basis of residual stresses instead of visual inspection which will be increased reliability of the components. 


\section{CHAPTER 2}

\section{THEORY}

\subsection{Theory of Magnetic Barkhausen Noise:}

\subsubsection{General:}

Magnetic Barkhausen Noise was discovered by Prof. Barkhausen in 1919. The magnetic flux density subjected to a variable magnetic field in time does not show a change that is strictly linear. There are abrupt, small, discontinuous changes in magnetic flux density called Barkhausen effect which can be seen when the magnetic hysteresis curve is observed, illustrated in Figure 2.1.[3]

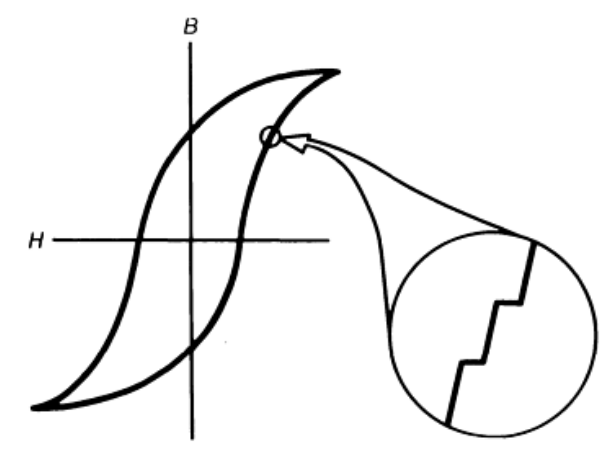

Figure 2.1 Barkhausen jumps [3] 
Ferromagnetic materials which were not magnetized consist of a large number of magnetic domains which are oriented in a random orientation (Figure 2.2 (left). When an external field is applied to the material, the domains aligned closely to the applied field tend to grow (Figure 2.2 (right)). The material is magnetized. When the applied field is removed, the domains cannot totally revert back to their original orientation due to some obstacles such as precipitates, grain boundaries etc. MBN is the irreversible jumps of the domain walls over those local obstacles. These jumps which are uneven and discontinuous changes in magnetization are associated with the sudden growth of a series of magnetic domains that have been temporarily stopped from further growth by such obstacles as grain boundaries, precipitates, dislocations. This explains the microstructure effect on MBN.
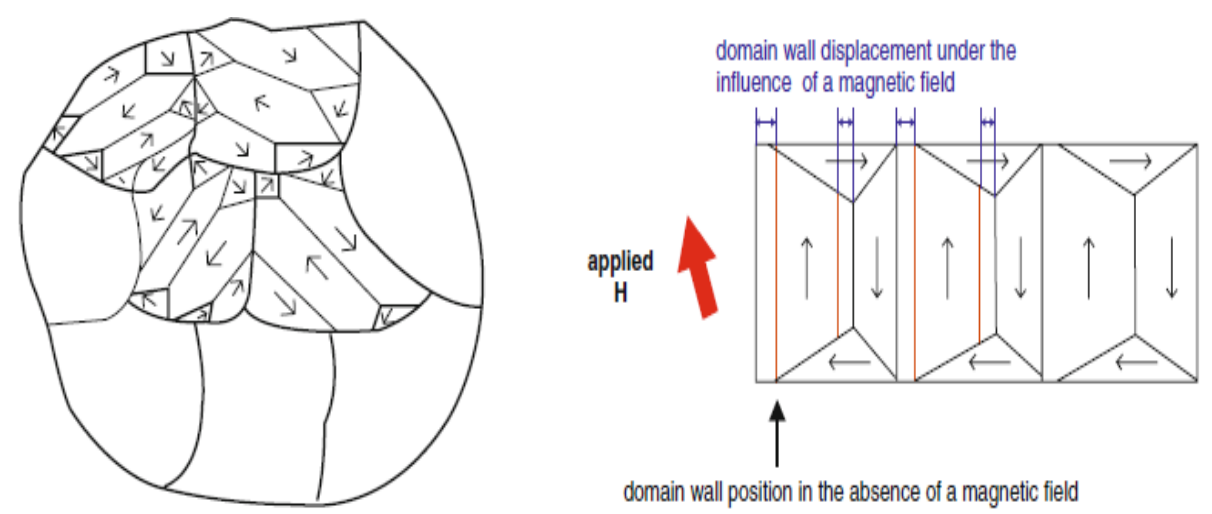

Figure 2.2 Random orientations of magnetic domains without magnetization (left), domain wall motion under an applied magnetic field (right) [4]

Ferromagnetic material which is subjected to a stress will cause in a change to its bulk magnetization, whether or not an applied field is present. This is because the affected domains by the stresses and the resulting strain in the material. A stress induced volume change occurs among the magnetic domains like when they are exposed an external magnetic field [5]. 
The domain walls are specified for steels with explanation that the walls separating regions of opposite magnetic moment are called $180^{\circ}$ walls, whereas the walls lying at $90^{\circ}$ to each other are called $90^{\circ}$ walls. These walls specified for Nickel are $109^{\circ}$ and $71^{\circ}[5]$. The main motion capability is coming from $180^{\circ}$ domain wall as seen in the literature. Tensile type or compressive types of stresses affect the size of the domain wall and with the change of the size the motion capability of the wall is changed. As the theory, tensile type residual stresses increases that kind of domain walls and compressive stresses decreases [5, 6, 7] (Figure 2.3). These are the changes occur when some elastic stresses like residual stresses affecting the material.

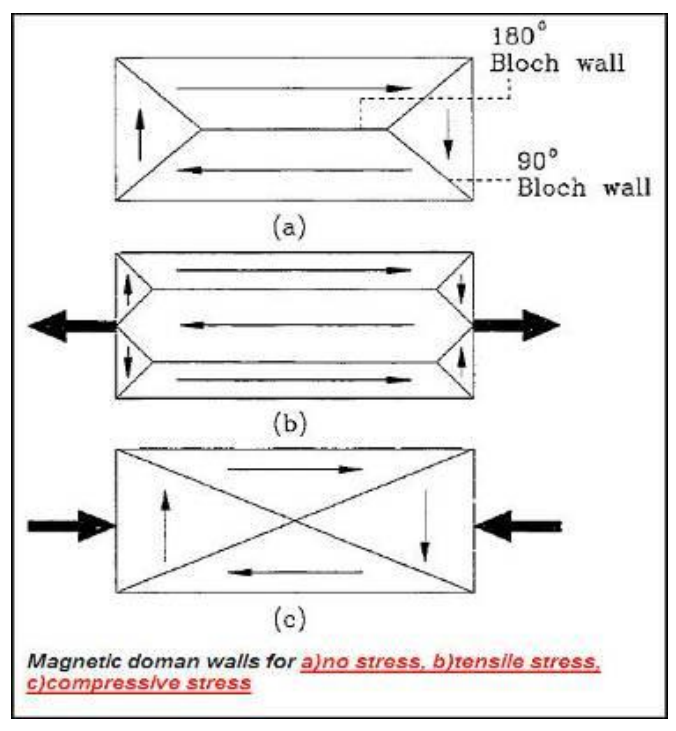

Figure 2.3 Domain walls (a), tensile stress effect (b), compressive stress effect (c) [6].

Two types of Barkhausen noise measurement technique can be performed. A detection coil can be placed on the surface of the specimen where the emission is termed as surface Barkhausen noise and a coil wrapped around the specimen is called encircling Barkhausen noise as shown in Figure 2.4 [8]. In this thesis work 
surface technique is used which is more appropriate method for industrial applications.
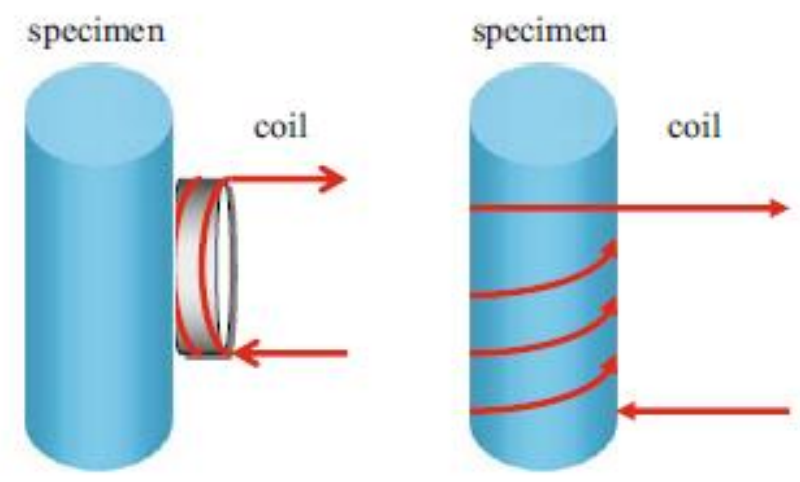

Figure 2.4 Surface (left) and encircling (right) MBN techniques

As instrumentation a small C-Shaped electromagnet is used for applying a controlled and time varying applied magnetic field to the specimen. That $\mathrm{C}$-Shaped electromagnet is the MBN probe used in commercial equipment which is also used in this thesis work. The abrupt changes of the magnetic domains are detected by an inductive search coil which is the sensor available on the MBN probe. These signals are amplified and recorded [3] (Figure 2.4).

The detected signals as a raw data are burst of noise like pulses in time domain (Figure 2.5(a)). The root mean squares (RMS) of the noise over several field cycles is obtained as MBN amplitude versus applied magnetic field strength, some smoothening algorithms can be also applied. These are two curves are usually mirror images in $\mathrm{H}=0$, which curve at the increasing magnetic field direction and vice versa (Figure 2.5(b)). One of them is used to evaluate the MBN variations between two different material conditions [9]. 
By the application of Fast Fourier transformation to the time domain data, amplitude versus frequency plot is obtained from the raw data and with this plot the variation of the MBN signal amplitude according to the MBN frequencies can be observed (Figure 2.5(c)). By means of this plot and usage of skin depth estimation, the information regarding which depth the variations coming from can be evaluated [9]. In addition to those plots, a pulse height distribution is also plotted which shows number of pulses coming at which pulse heights as voltage (Figure 2.5(d)) [9].

Finally, a representative hysteresis plot is also obtained during the MBN measurements. That is representative because a local part of the specimen can be exposed to a variable applied magnetic field and can form a local hysteresis curve from that magnetization. That curve can be used also in evaluation some material condition changes regarding microstructure and stress. This plot is also used in this thesis work and can be seen in Chapter 5.

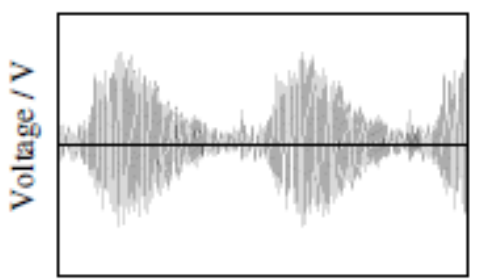

Time/s

(a)

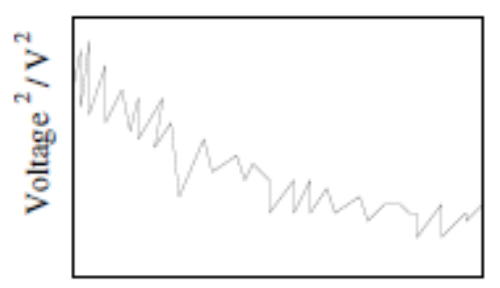

Frequency / Hz

(c)

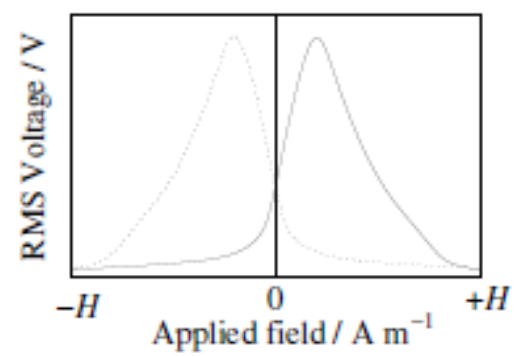

(b)

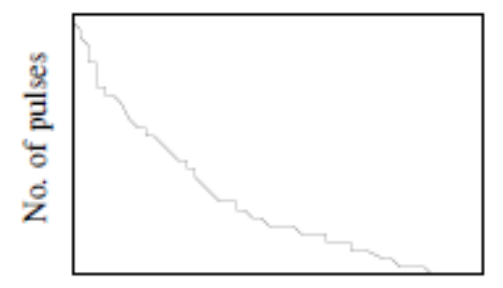

Pulse height / V

(d)

Figure 2.5 Raw time domain data plot (a), RMS MBN profile (b), Amplitude versus frequency plot after application FFT (c), Pulse Height Distribution (d) [9]. 


\subsubsection{Applications of Magnetic Barkhausen Noise Technique:}

Many common surface treatments which are grinding, shot peening, nitriding, carburizing and induction hardening that will cause in changes in stress and microstructural conditions of the materials can be characterized by using this technique. In addition to them, as a dynamic processes fatigue and creep causing some modifications both in stress and microstructure can be also monitored by MBN.

Practical application areas of MBN can be divided into three main groups [10]:

- Evaluation of residual stresses; provided microstructural variables can be reasonable controlled.

- Evaluation of change in microstructures; when stress variables can be reasonable controlled.

- Examination of the surface defects, processes and surface treatments that may involve modifications of both stress and microstructure conditions.

- Detection of grinding defects like burns and its process control

- Detection of surface defects in Cr-coating

- Measurement of residual surface stresses in steel mill rolls and steel sheet.

\subsection{Theory of Shot Peening Process:}

\subsubsection{General:}

Controlled shot peening is an operation which is used largely in the manufacture of mechanical parts. It should not be confused with sand blasting used in cleaning parts [11]. It differs from blast cleaning in primary purpose and in the extent to which it is 
controlled to yield accurate and reproducible results. Shot peening cleans also the surface being peened like sand blasting, but this function is incidental [12]. The benefits obtained from the shot peening operation are due to the effects of the residual compressive stresses and the cold work. The effect usually extends to about 0.13 to $0.25 \mathrm{~mm}$ but may extend as much as $0.50 \mathrm{~mm}$ below the surface [13]. By forming at the surface of a compressive residual stress layer in order to hinder enlargement the formed surface cracks at the operating condition the fatigue strength is increased. Improvements in fatigue strength through use of present shot peening practices can result in 10 to 100 percent in fatigue strength which means 100 to 1200 percent in fatigue life increase. Benefits obtained due to cold working include work hardening and testing the bond of coatings. Both compressive stresses and coldworked effects are used in the application of shot peening in forming metal parts which is mainly used in forming metal sheets for production of the plane wings.

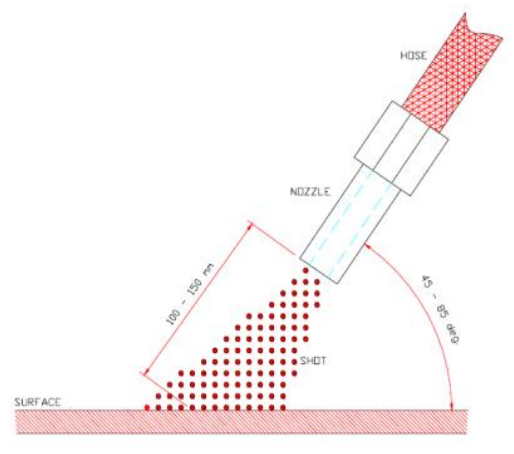

Figure 2.6 Shot peening operation

\subsubsection{Equipments and Parameters:}

\subsubsection{Shot Peening Machine:}

There are numerous types of shot-peening machines. The classical shot peening processes can be divided into two categories, dependent on the method used for how 
the shot is projected, compressed air or wheel. There are also ultrasonic and laser peening techniques which will be explained in chapter 2.2.1.

The choice between these two types of machine is dependent on the quality of the shot-peening that is desired to obtain and the properties of the component's material which is to be treated. Shot-peening machines can also vary considerably in the way based on the position of the component in the stream of shot. There are thus drumtype machines for shot-peening parts in bulk, rotating table machines for small parts in series, linear conveyors for helical springs, and overhead conveyors. By means of the computer-controlled machines now exist different surfaces of the part can be peened with varying intensities. Finally, for certain cases, the shot-peening of welded joints on off - shore pipelines for example, there are portable units [11].

In the wheel method, shot is propelled by means of a bladed wheel that works with a combination of radial and tangential forces to reach to the necessary peening velocity to the shot. The position on the wheel from which the shots are projected is controlled to concentrate the peening blast in the desired direction. Among the advantages of the wheel method of propulsion are easy control of shot velocity when equipped with a variable-speed drive, high production capacity, lower power consumption, and freedom from the moisture problem that can occur usually with compressed air [13].

The air blast method introduces the shot, either by gravity or by direct pressure, into a stream of compressed air directed through a nozzle onto the material to be peened. In addition to its economical advantage for limited production quantities, the air blast method can reach to higher intensities with small shot sizes, permits the peening of deep holes and cavities by using a long nozzle, consumes less shot in peening small areas on intricate parts, and has lower initial cost, especially when a source of compressed air is already available.[13] In this thesis the air blast technique is used to shot peen steel samples. 

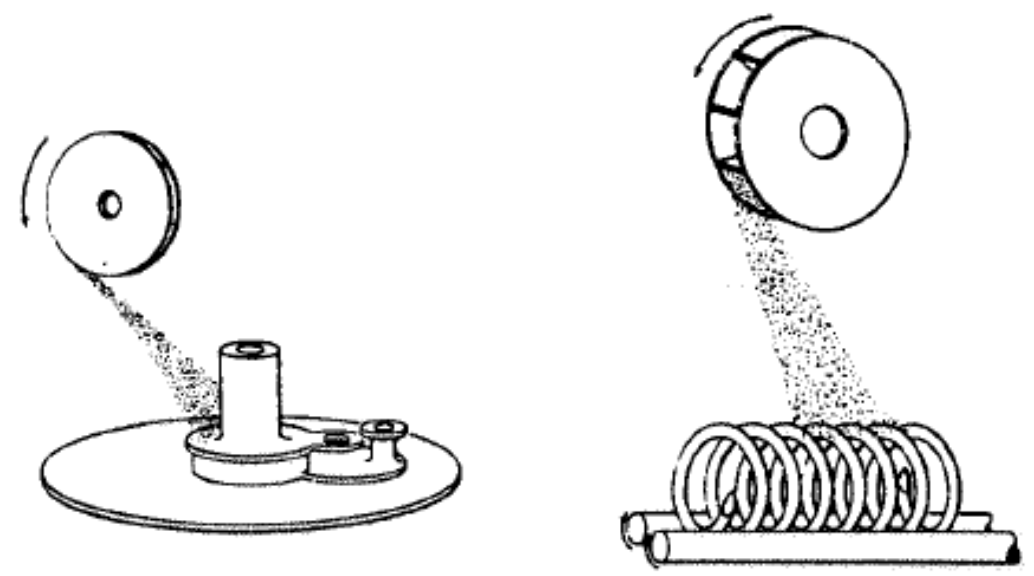

Figure 2.7 Examples of conveyor systems.

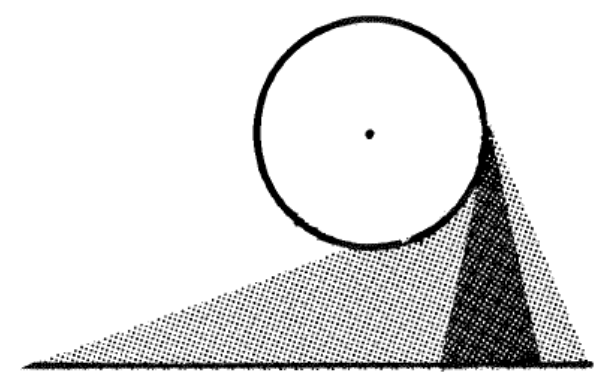

Figure 2.8 Illustrating the "Intensity distribution" of a peening stream.
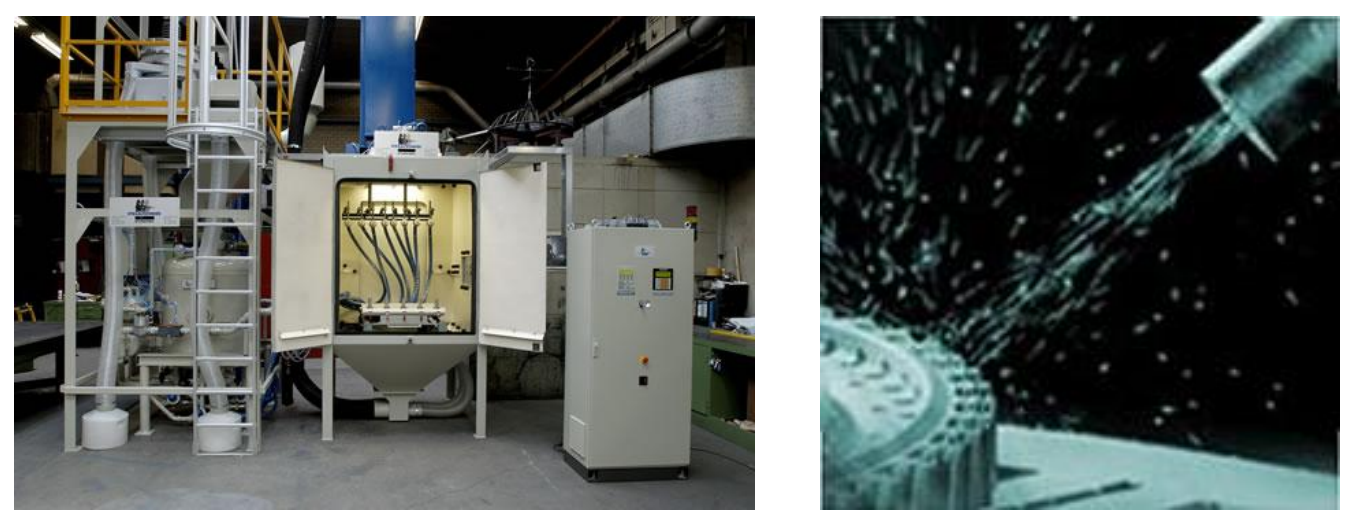

Figure 2.9 Automatic Air Blast Machine 


\subsubsection{Nozzles:}

The nozzles are used in the air blast technique. For shot peening, it is needed a blast nozzle that generates the required peening intensity while providing a cost-effective production rate. Pressure blast nozzles come in straight bore and venturi shapes. Both are sharply tapered from the point where the air and media enter the orifice. The rapid reduction in inside diameter and controlled expansion of the air that is moving through the tapered outlet work together to accelerate the shot. For maximum acceleration, the nozzle orifice should be about one-third the inside diameter of the blast hose [14].
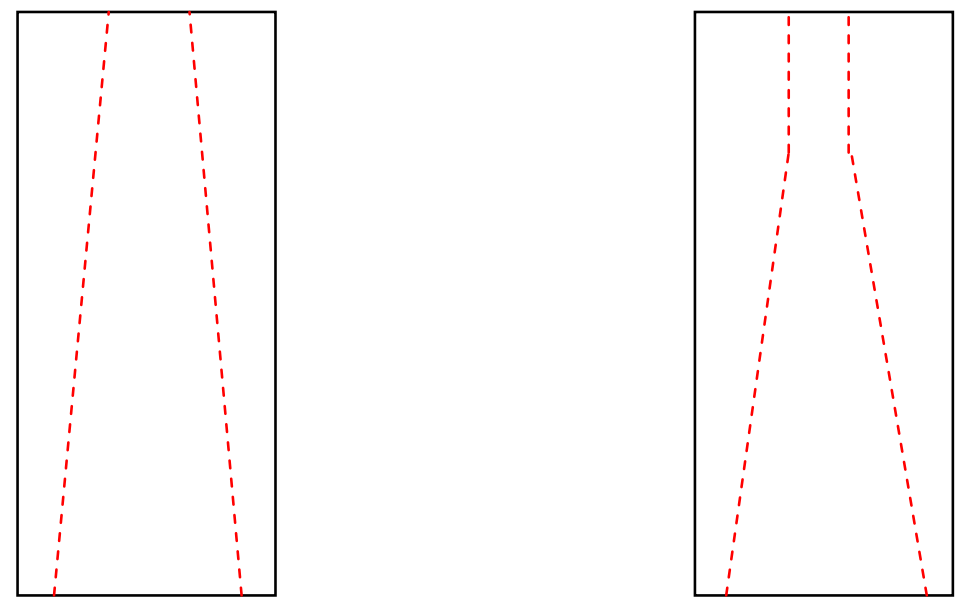

Figure 2.10 Straight bore (left), Venturi (right)

Inside a venturi nozzle, the inside diameter tapers outward past the orifice, allowing the mixture of air and shot to expand more uniformly before it exits the end of the nozzle. A venturi nozzle gives excellent peening intensity, but, more important, it delivers that intensity more uniformly across the blast pattern. In this thesis, the venturi type nozzles are used in the shot peening operation [14].

Because of the shot media the nozzles start to wear. Due to this wearing more air and media begin to flow inside the nozzle but the pressure inside the nozzle will 
decrease. More air flow exists through the nozzle, but due to the pressure decrease the shot media velocity so the peening intensity starts to fall.

In order to hinder wearing and increase service life inside of the nozzle is coated with wear resistant materials. This coating material is chosen according to the shot media type. Harder the shot media, more wear resistant has to be the coating material. In the table 1, typical coating material and the life of the nozzles are shown.

Table 2.1 Nozzle life time changes under steel shot according to the coating material [14]

\begin{tabular}{|c|c|}
\hline Nozzle Coating Material & Nozzle Life(Hours) Steel Shot \\
\hline Tungsten Carbide & 400 to 700 \\
\hline Silicon Carbide & 500 to 800 \\
\hline Boron Carbide & 1000 to 1500 \\
\hline
\end{tabular}

\subsubsection{Shot Media:}

Shot media has direct effect on the formed local plastic deformation on the surface so the amount and the depth of the residual stress formed at the surface and the subsurface. Therefore, it is so important to select proper shot media to proper material to be shot peened in order to obtain desired amount of the compressive residual stress. There are different types of shot media that can be also made from different type of materials.

\subsubsection{Shot Types and Materials:}

The geometry of the shot media is generally spherical. As the shot media is classified based on its material the following types of it can be used in shot peening operations

Chilled iron shots: This is a cast material. It is manufactured by melting suitably graded iron in a cupola, and at a critical temperature, pouring or projecting it in to a 
quench tank. By these means the metal is broken up in flight and shocked by the water as spherical shapes [15].

Due to the problems in manufacturing operation, the shape of some shot media can not be spherical, but they may be elongated or worm like. These kinds of shots are eliminated by screening operation. The advantages of the chilled iron shots are that it is cheap and hard. Its hardness is changed between 60-69 HRC [15].

The disadvantage is that it is broken in a short time period and this is an unwanted situation for the shot peening operation [15].

Steel shot: This is produced like chilled iron type, but the differences are that its raw material is scrap and it is melted electrically. Because it is wanted to have a high quality product, scraps have to be selected very carefully. All steel shot is produced to a range of sizes and subject to accepted grading standards. As seen in the Figure 2.11 , the sizes of the steel shots are coded with $\mathrm{S}$ and a number. The numbers are specified based on the diameters of the spheres in inches. For example, S230 which used in the experiments means that the diameter of the spheres is $230 \times 10^{-4}$ inches $(584 \mu \mathrm{m})$. Their hardness can reach up to 55 HRC [15].

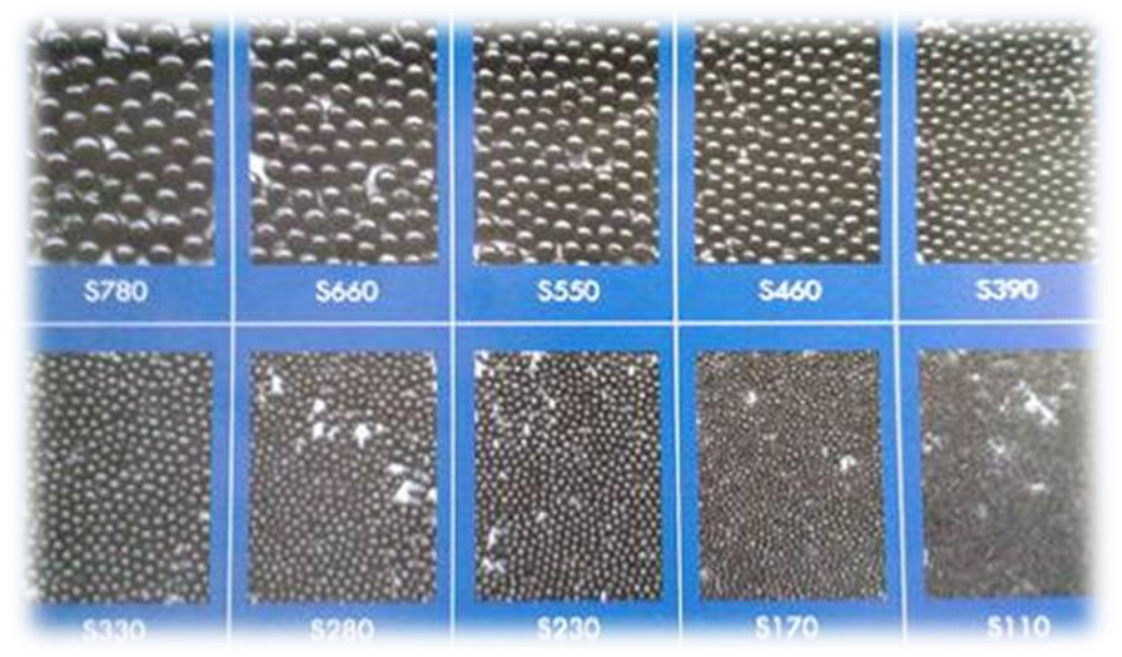

Figure 2.11 Steel shot codes according to their sizes 
Cut Wire shots: The starting material for cut wire shots is steel or stainless steel wire. The wire is cut into pieces of length which is equal to diameter and the resulting cylindrical shape is made at least roughly spherical by a conditioning process that involves impingement against a hard surface [16].

Glass Beads: These media particles are produced from the molten state. The specific gravity of glass beads is one third of the cast iron. Therefore, accelerating the glass beads is much easier than cast iron media by air. But the problem with the glass beads is that they lose easily their energy after emerging from the nozzles, so in order to lessen the kinetic energy loss the distance between the nozzle and the component has to be $50 \mathrm{~mm}$ to $90 \mathrm{~mm}$.

Ceramic Beads: This is a new type of shot media. The most common ceramic bead material is zirconium oxide with a glassy-phase aluminum oxide binder. It is manufactured by compaction and sintering of the materials initially in powder form. They are made in sizes of $0.2 \mathrm{~mm}$ to $0.5 \mathrm{~mm}$ [16]. Based on the researches of Niku Lari [11], ceramic beads are comparable with steel shots in peening operation.

\subsubsection{Almen Strips:}

Almen strips are developed and patented by John O. Almen and as a general view, thin metal strips that are used when quantifying of shot peening operation intensity which are explained in chapter 2.2.2.6 and 2.2.2.7 in detail. The Almen strips are standard components used before peening operation and have certain specifications on which people who want to do the shot peening have to concentrate. The Almen strips are made from plain carbon steel SAE 1070 and have hardness about 45 HRC. There are three types of Almen strips. They are N-type, A-type and C-type. They differ from each other with their thicknesses (Figure 2.12). Their length and width values are same (Figure 2.13).

The N-type Almen strips are used predominantly with glass beads and ceramic beads. The A-type Almen strips are widely used one and are used with cast shots and 
cut wire shots. The C-type Almen strips are used more rarely and are thicker than the other types.

The most rigid requirements are applicable for Almen strips and checking devices (Almen gauges) used in the aerospace industry. The generic requirements can be found in SAE specifications [17].

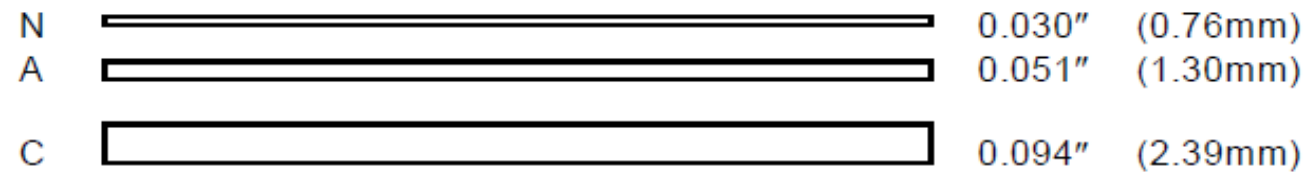

Figure 2.12 Types of Almen strips

$3^{\prime \prime}(76 \mathrm{~mm})$

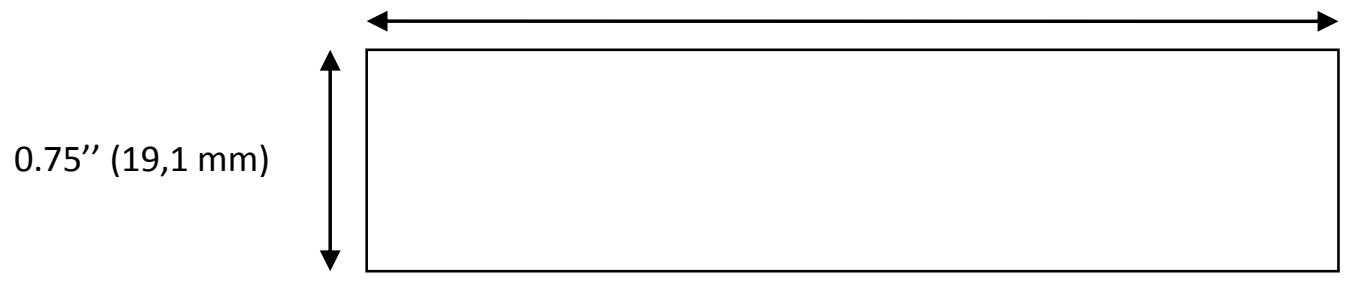

Figure 2.13 Dimensions of Almen strips

As be said above, the Almen strips are used for quantifying shot peening operation. The operation is applied on the strips by fixing them on a platform which is called Almen holders (Figure 2.14). In automatic machines which are controlled by software, in order to quantify the peening intensity at different directions on the complex geometry components, strips are shot peened by putting them under the nozzles in different positions. 


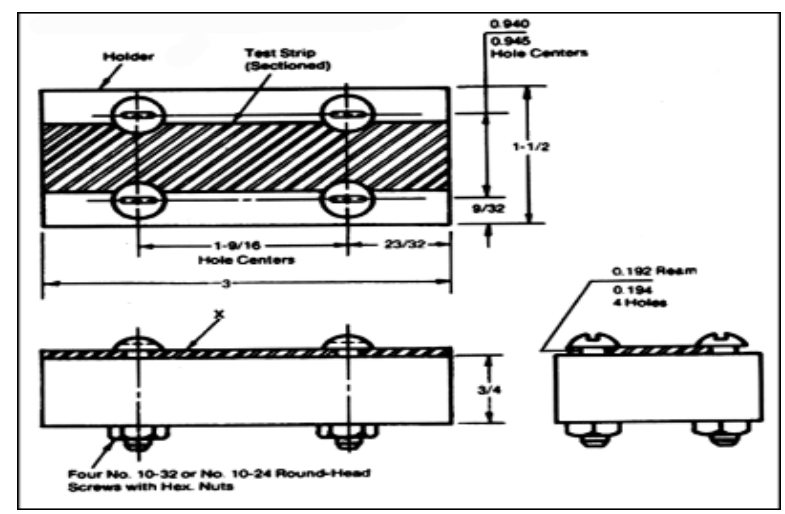

Figure 2.14 Almen strip holder

After shot peening operation due to the residual stress relief, strips become in a curved form Figure 2.15. By measuring this curvature, intensity of shot peening is quantified.

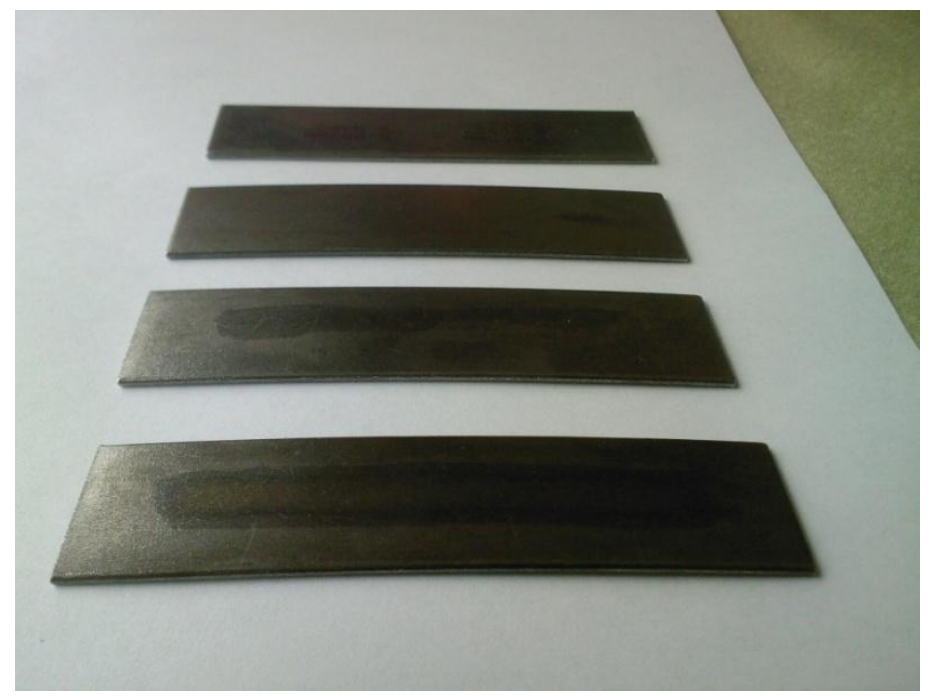

Figure 2.15 Almen strip curvature after shot peening 


\subsubsection{Almen Gauges:}

The measurement of the curvature is made by Almen gauges (Figure 2.16). For example, if the Almen gauge shows a curvature value which is 0.0064 inches which means the Almen intensity is equal to 6.4 .
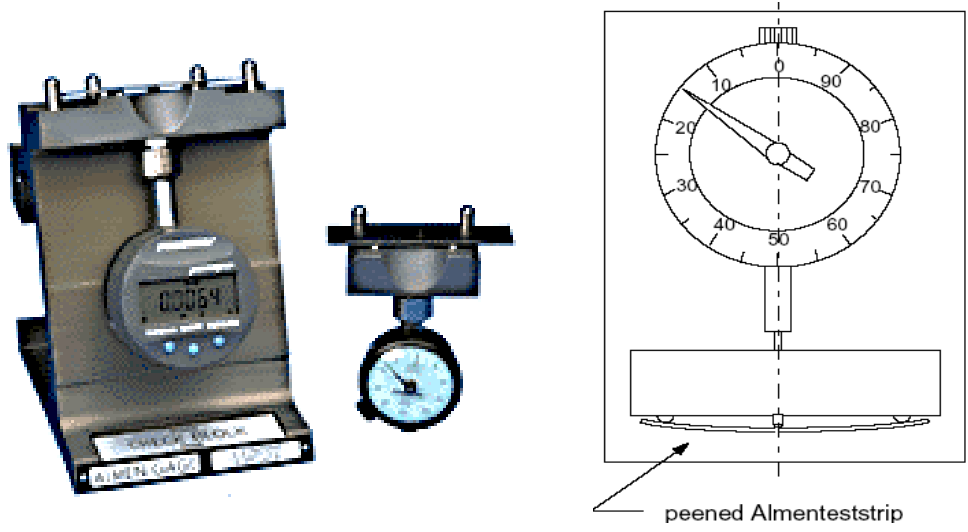

Figure 2.16 Almen gauge [16]

\subsubsection{Saturation Curves:}

When specifying the intensity of the operation Almen strips are shot peened in specified time periods and their curvature is measured by Almen gauge after every time period. By these measurements, the maximum curvature obtained with a certain air pressure and mass flow of shot media can be found. As a result, saturation point of the action can be found. At the end of the operation a curve is obtained which is Almen value vs. time (Figure 2.17). 


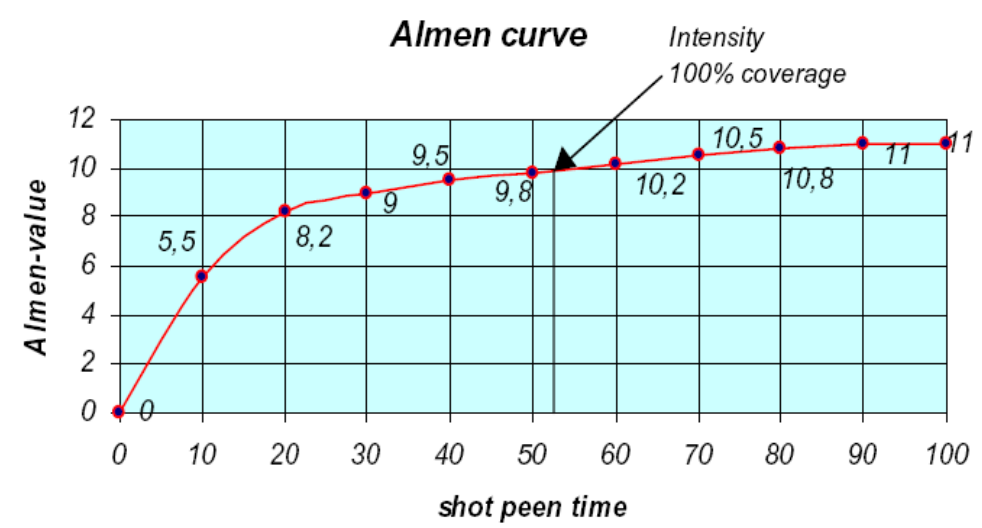

Figure 2.17 Saturation curve

Saturation is defined (in the military specification) as the time to produce a height that is increased by not more than 10 per cent if the peening time is doubled (Figure 2.18). $\mathrm{T}$ is the minimum time that meets the specification. Longer times than $\mathrm{T}$ would meet the specification as stated. Commercially we need the minimum time to achieve a specified Almen height which is defined as Almen intensity.

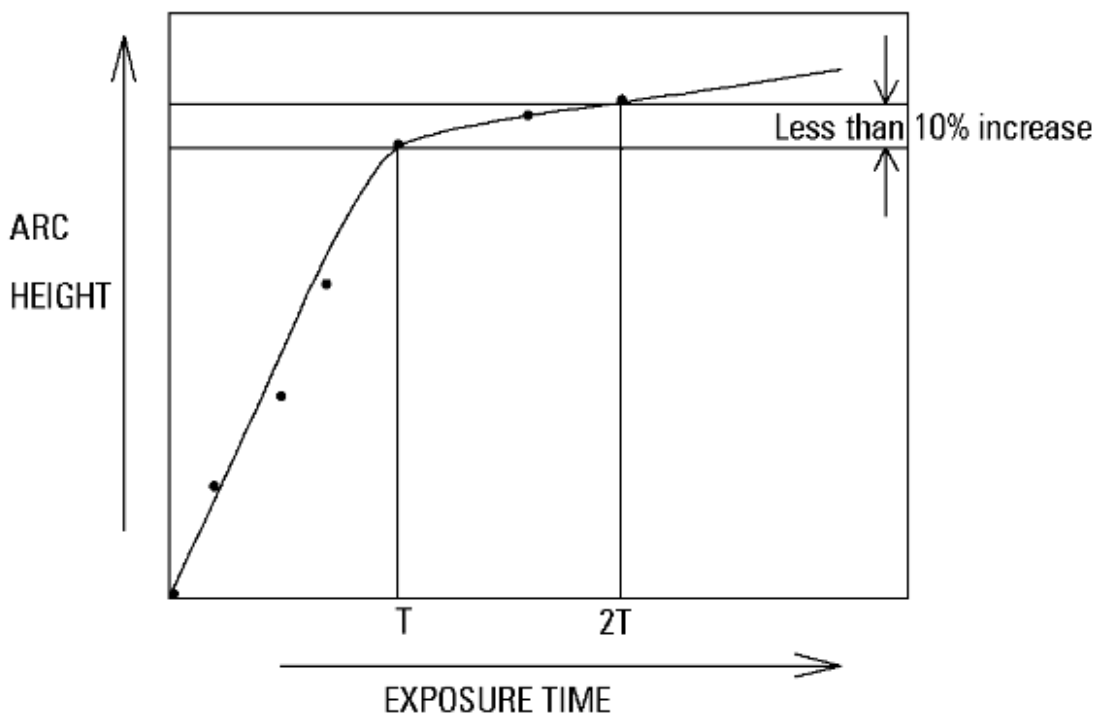

Figure 2.18 Determination of saturation in shot peening 


\subsubsection{Parameters:}

There are many parameters that affect the shot peening operation and the residual stress state form on the surface of the component. As seen in the Figure 2.19, parameters can be analyzed in three groups which are related shot medium, shot peening device, material that is shot peened.

\section{Residual Stress State after Shot Peening}

$\begin{array}{lll}\downarrow & \downarrow & \downarrow \\ \text { Shot medium: } & \text { Shot Peening Device: } & \text { Workpiece: } \\ \text {-Shot Shape } & \text {-Process time } & \text {-Geometry } \\ \text {-Shot hardness } & \text {-Shot velocity } & \text {-Hardness } \\ \text {-Shot size } & \text { - Impact Angle } & \text {-Deformation } \\ \text {-Shot mass } & \text {-Nozzle Diameter } & \text { Behaviour } \\ \text {-Deformation } & \text {-Nozzle Distance } & \text {-Temperature } \\ \text { Behaviour } & \text {-Mass Flow } & \\ \text {-Shot size } & \text {-Coverage } & \\ \text { distribution } & & \end{array}$

Figure 2.19 Shot peening parameters affecting residual stress state [18]

Every parameter written in the figure has direct effect on the residual stress state. In this thesis, especially the effect of the shot peening device parameters on the residual stress is observed. 


\subsubsection{Residual Stress Formation Mechanism:}

Shot peening is a cold working process performed at room temperature in which the surface of the work-piece following the impact of small spherical balls, usually made of steel, plastically deforms. The balls are projected against the surface being peened, indenting the work surface causing plastic flow within the surface zone (Figure 2.20) [18]. The effect usually extends to about 0.13 to $0.25 \mathrm{~mm}$ (0.005 to $0.010 \mathrm{in}$.) but may extend as much as $0.50 \mathrm{~mm}$ (0.02 in.) below the surface [13].

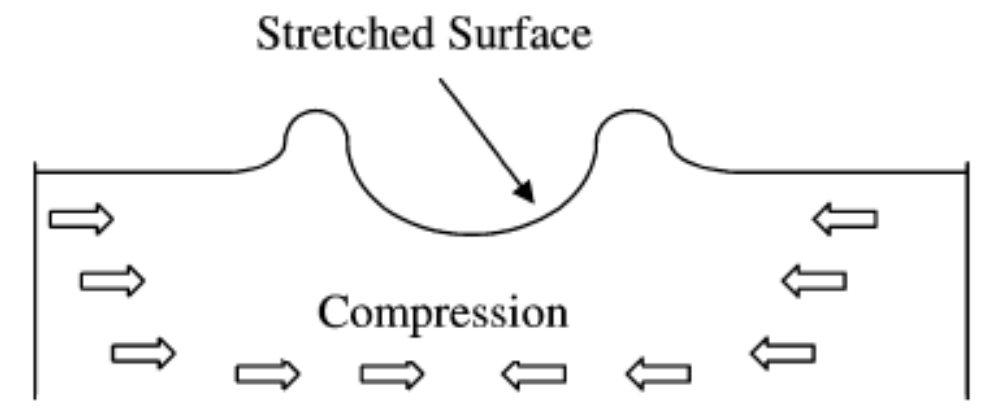

Figure 2.20 Streched surface in shot peening [19]

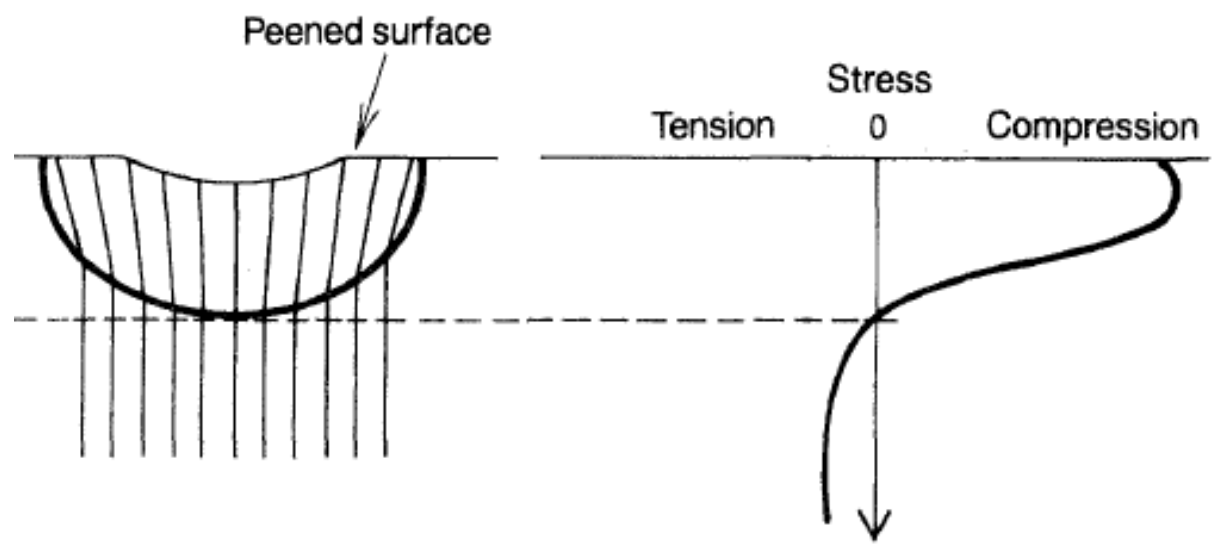

Figure 2.21 Residual stress distribution after shot peening [20] 
In order to obtain compressive residual stress layer the surface of the component must be acted by local plastic deformation which provides elastic stretching at the upper surface of the material. Inner part of the material imposes compressive stress in order to hinder the stretching formed at the surface. As a result, a compressive residual stress layer shown in Figure 2.21 is formed at the surface and a tensile residual stress field in order to balance the compressive layer. The maximum compressive residual stress produced at or under the surface of a part by shot peening can be as great as one half the yield strength of the material being formed. Moreover, parts formed by shot peening exhibit increased resistance to flexural bending fatigue [19]. Surface compressive stress may be several times greater than the subsurface tensile stress [13].

The magnitude of the compressive stress introduced that can be predicted is obviously a function of the shot medium, as well as the shot peening parameters related to shot peening machine and the shot peened material that are discussed in chapter 2.2.2.8 and can reach values as high as 50 to $60 \%$ of ultimate tensile strength of the material. Its depth largely depends on the peening intensity and the relative hardness of the impinging shot and the targeted component; practically, it can be from up to $200 \mu \mathrm{m}$ (hard materials, i.e. $700 \mathrm{HV}-60 \mathrm{HRC}$ ) to $1000 \mu \mathrm{m}$ (soft materials, i.e. $300 \mathrm{HV}-31 \mathrm{HRC})[1]$.

\subsubsection{Application and Benefits:}

Shot peening has wide application in the aerospace and automotive industry. Aircraft components, axial compressors, gears, brake parts, camshafts, chain side bars, coil springs, connecting rods, crank shafts, leaf springs, piston rods, turbine blades, valve springs can be given as examples for the parts that are shot peened in the industrial applications. The aim of the shot peening is especially increasing the fatigue life of the component. 
Fatigue failure is common in most metals and is most frequently caused by tensile stresses which make easier crack and micro fissure growth from or near the surface of the material. This is usually followed by a drastically reduced performance of the component followed by failure at an early stage of the component's life [1]. In order to hinder formation of the cracks the compressive type residual stresses are very useful. The compressive stress region at the surface and the near surface of the component increases the fatigue life of the components significantly. Some examples about the increase in fatigue life of some components can be seen in Table 2.

Table 2.2 Fatigue life change in some components due to shot peening process

\begin{tabular}{|c|}
\hline Coil Springs > $1000 \%$ \\
\hline Torsion Springs up to $600 \%$ \\
\hline Piston Rods up to $100 \%$ \\
\hline Wheel Hubs > $1000 \%$ \\
\hline Welding Seems up to $200 \%$ \\
\hline
\end{tabular}

In addition the fatigue cracking, shot peening has a hindrance effect against stress corrosion cracking (SCC). SCC is the cracking the cracking induced from the combined influence of tensile stress and a corrosive environment. The tensile stresses can be an applied stress or residual type stress. As a result, the formation of the compressive type residual stresses can delay crack formation and propagation.

By the hindrance effect against crack formation and propagation, shot peening can be used for some formation operations (Figure 2.22). The forming of wing skins by pressing or rolling can introduce the tensile stresses that are detrimental for the fatigue life and are responsible for the initiation and propagation of cracks. Because shot peening introduces compressive stresses, it is possible to form thin components like aircraft wing skins into shape, simply by using the peening technique. The result 
of the process is thin components with desired form and they contain inherent compressive stresses at both sides which are beneficial for them [21].

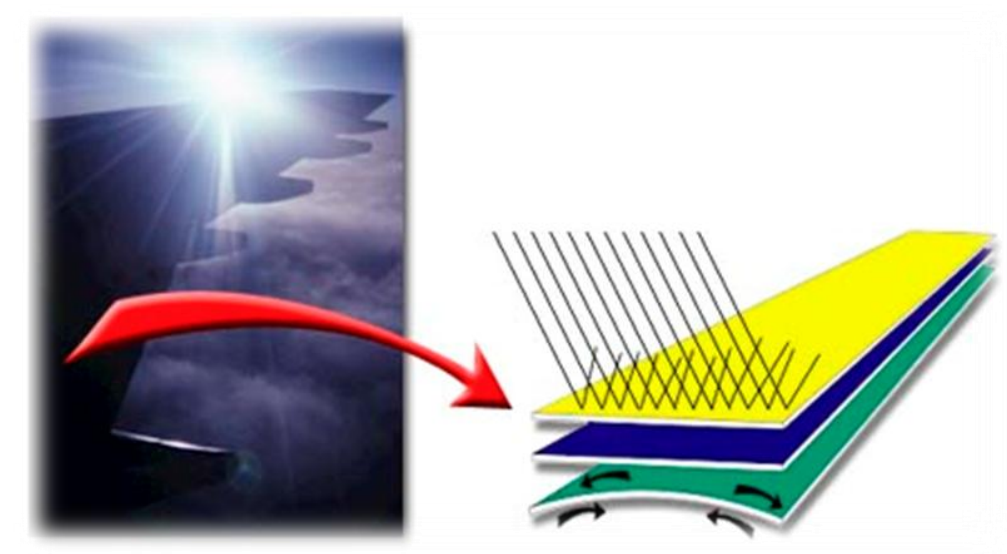

Figure 2.22 Formation of wings by shot peening

\subsubsection{Other Types of Shot Peening Process:}

\subsubsection{Ultrasonic Shot Peening:}

A piezoelectric transducer produces ultrasonic waves at $20 \mathrm{kHz}$. The waves are amplified when they travel through an acoustic booster which contains the parts to be treated and the shots.

The shots strike the vibrating walls and are reflected off the surface. Then, they collide with one another. The balls are scattered randomly throughout their encasing, i.e. molecules of gas. A homogeneous treatment is then obtained on the surface of the casing. Schematic view of the ultrasonic peening equipment can be seen in the Figure 2.23 [22]. 


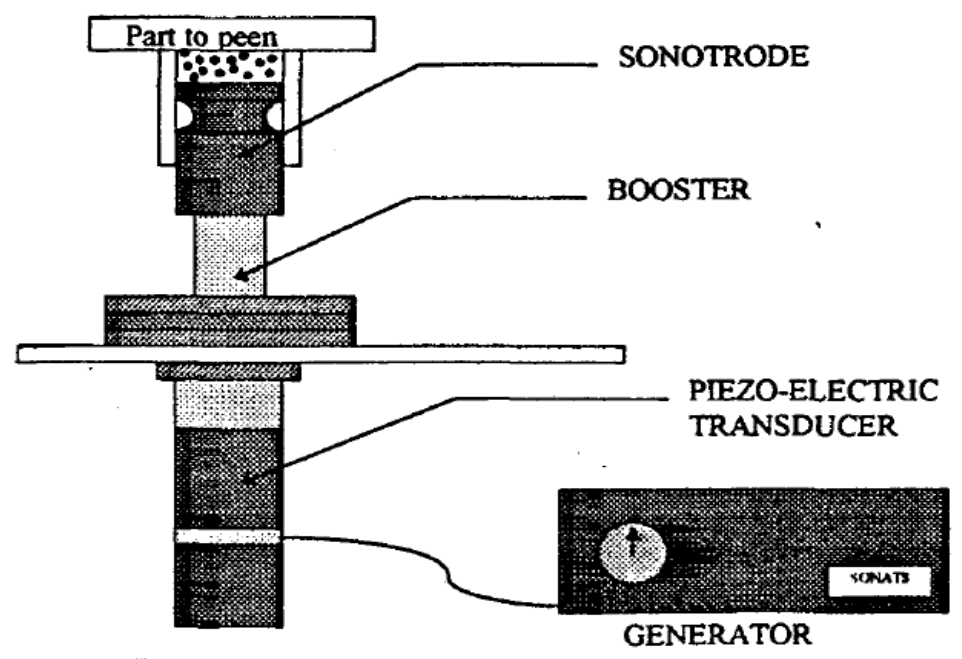

Figure 2.23 Ultrasonic Peening[22]

\subsubsection{Laser Shock Peening:}

Laser peening directs an intense beam of light to the critical surface. This creates high-pressure plasma that generates a shock wave which drives the compressive stress deep into the surface.

The water layer called a tamping layer whose purpose is to work as an inertial stop when the high-pressure plasma is formed. The plasma is formed in nanoseconds and water layer hinders it from expanding at forming area which provides a direct effect of the energy formed due to the plasma to the surface of the work piece.

The second point is the use of an ablative layer. Unlike a mask used in shot peening which hinders surfaces from being hit with shot-peens, an ablative layer is applied to the areas requiring laser peening. The ablative layer works as a sacrificial layer that 
hinders a slight burning of the surface that would be seen without an ablative layer. Schematic view of the laser peening equipment can be seen in the Figure 2.24 [23].
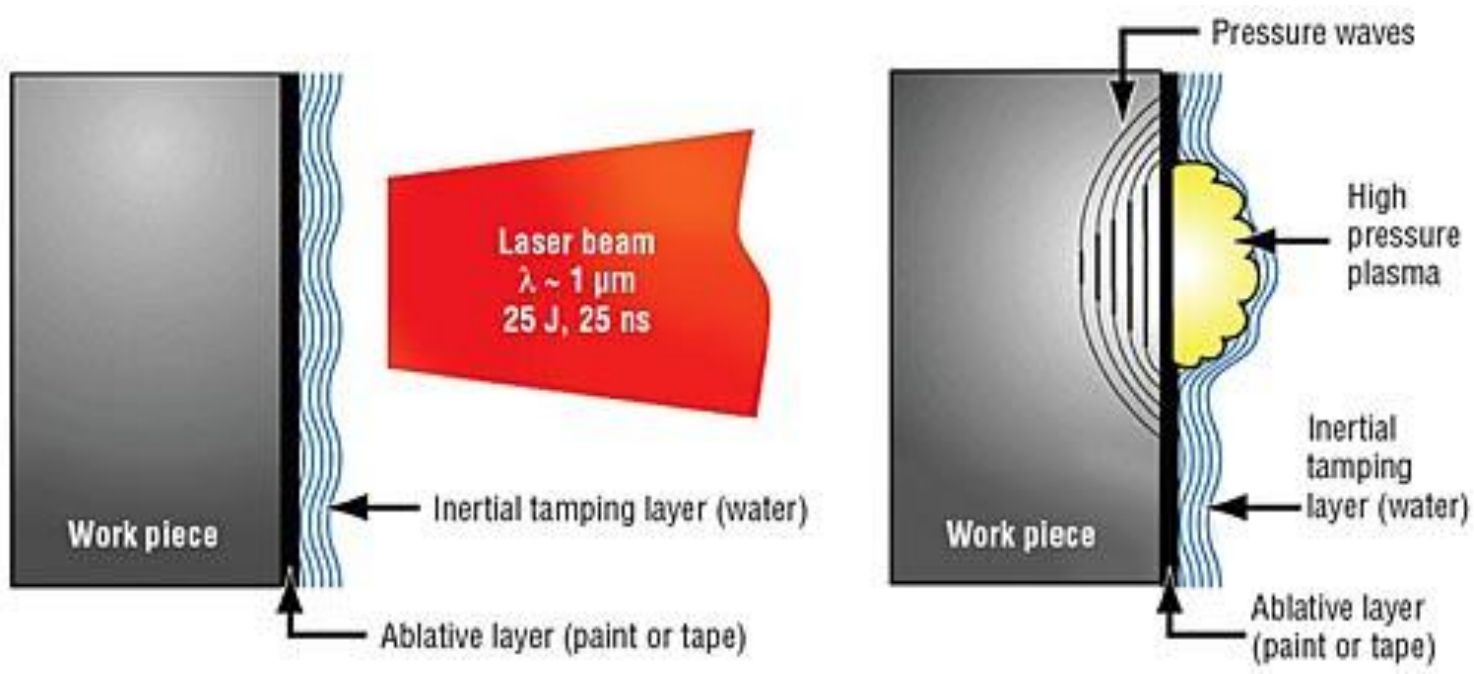

Figure 2.24 Laser Shock Peening [23] 


\section{CHAPTER 3}

\section{LITERATURE SURVEY}

This part focuses on the residual stress characterization of shot peened materials by Magnetic Barkhausen Noise technique and other residual stress measurement techniques.

L.Suominen and K. Tiitto has worked on the quality evaluation of the shot peened components by $\mathrm{MBN}$ and X-Ray techniques. They worked with 15-5 PH precipitation hardened, 4330 and 4340 high strength steels. The equipment used in the experiments was $\mu$ scan-500 commercial equipment. They showed a calibration curve which illustrates BN change according to stress change (Figure 3.1) [24].

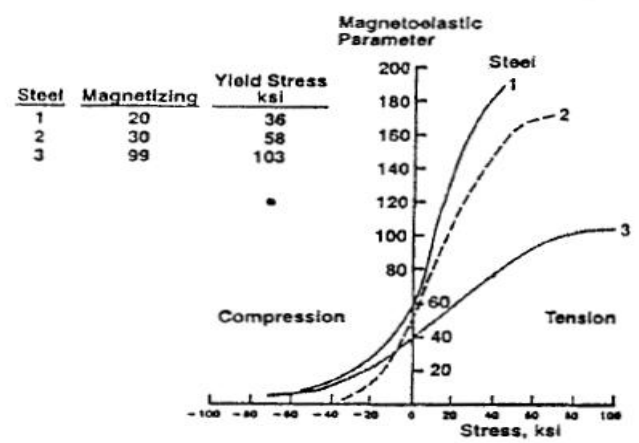

Figure 3.1 MBN change due to stress for three different materials [24]. 
They measured shot peened components with different intensities with MBN and XRay techniques. X-Ray technique measured the stress profiles of the shot peened components. MBN measurements also show a correlation with the intensity values and it is concluded with a potential of MBN technique to evaluate shot peening effect [24].

Wojtas performed a work regarding the qualitative and quantitative residual stress characterization of peened components. In the experiments, qualitative scanning of the samples by Barkhausen method was done. For quantitative measurement, X-Ray diffraction method was used. Also, by doing a calibration, stresses were also characterized by Barkhausen method. It is concluded that MBN method is very useful for fast scanning and sorting of shot peening operation at the production sites [25].

Jacob et al. performed an experimental work with 32CD4 steel blades and have undergone nitriding, grinding and shot peening operation and used for residual stress measurement by Barkhausen and XRD with surface removal method. They found correlated results of MBN and XRD techniques which are shown in Figure 3.2. They resulted in that the variation of $\mathrm{MBN}$ measurement is $3 \%$ against the variation in $\mathrm{XRD}$ technique is $8 \%$ [26]. 


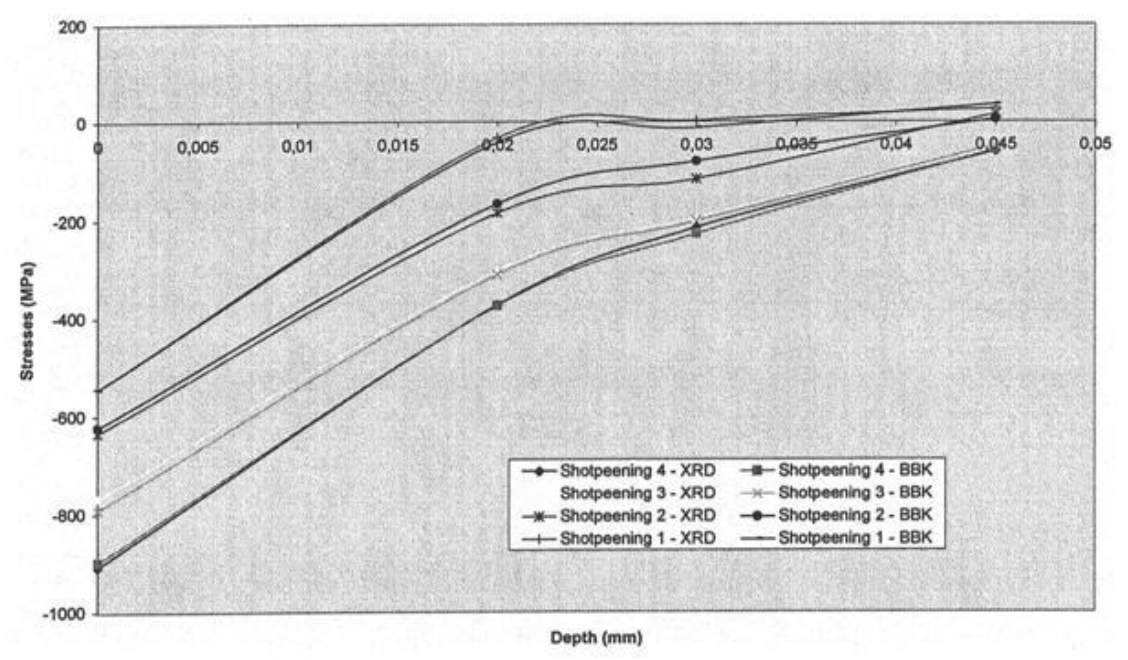

Figure 3.2 XRD and MBN measurement results from different shot peened samples [26].

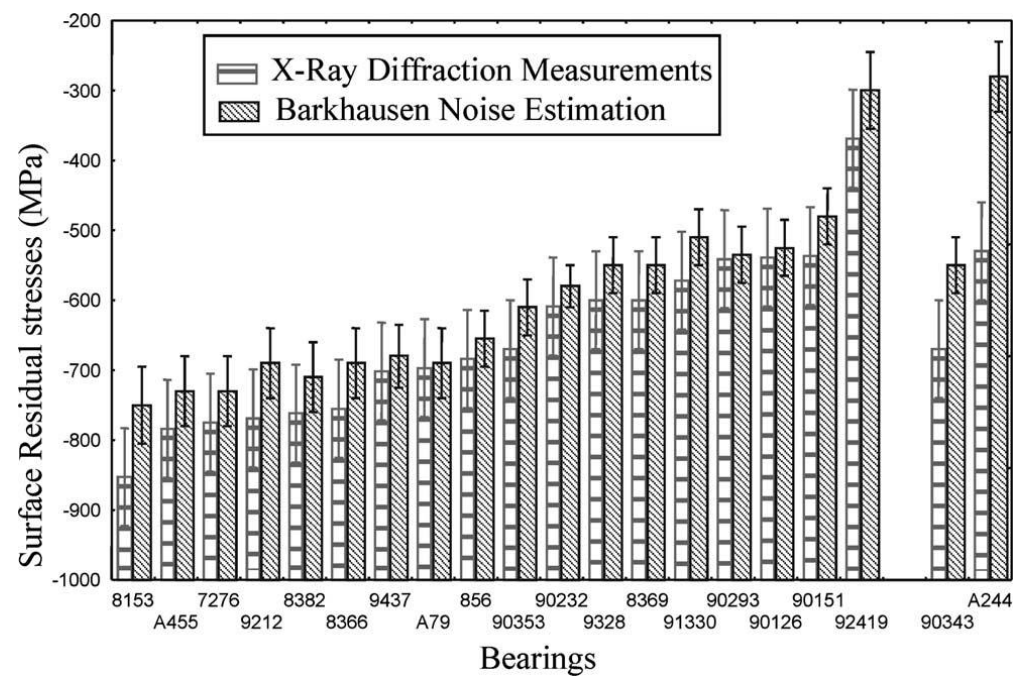

Figure 3.3 XRD and MBN measurement results from different shot peened AISI M50 samples [27]. 
Desvaux et al. performed residual stress measurements on aeronautic bearings. They used shot peening operation in order to simulate surface residual stresses at the bearing components. Material was AISI M50. They used XRD and MBN measurements for evaluation of surface residual measurements. In MBN measurements $20 \mathrm{kHz}-1 \mathrm{MHz}$ bandwidth was used. The results are shown in Figure 3.3 [27].

Zagar et al. performed residual stress measurements on shot peened with different air pressures which were 4, 6, 8, 10 bar and different time as 30s and 60s. Their variable in the shot peening operation was the air pressure and time. They did not evaluate the calibration stage of the shot peening operation. After peening they used MBN technique in order to evaluate the residual stress changes due to the change in air pressure and time. They were compared their results with a hole drilling equipment and they found 100-150 MPa differences between the two technique results [28]. 


\section{CHAPTER 4}

\section{EXPERIMENTAL PROCEDURE}

\subsection{Material Selection:}

First of all the material that was chosen must be a ferromagnetic material which can be iron, nickel, cobalt and their alloys. In this study, the material was chosen among the materials that are classified as steel. As mentioned before in the aim of the study that the main purpose is to show the measurability of the residual stresses formed in the component by Magnetic Barkhausen Noise method. Because this study can be taken as an introductory study for the works about residual stress evaluation by MBN, it is wanted to eliminate all the microstructural effect of the material and to achieve to monitor only the effect of the residual stresses. Therefore, a low carbon steel composition which is shown in Table 4.1 and its microstructure is shown in Figure 4.2 is selected for this study. Because of the high ferritic microstructure the permeability of the material is high enough easily to be magnetized and also with this high ferrite low pearlite microstructural property make it easy that to see the effect of the residual stress on the MBN of the material that is measured. In addition to these, the shot peening operation is done generally to the steels that have a carbon content which is lower and equal to $0.4 \%$. 
Table 4.1 Chemical Composition of the Sample

\begin{tabular}{|c|c|c|c|c|c|c|c|c|}
\hline \multicolumn{10}{|c|}{ Chemical Composition of the Sample ( \%, balance Fe) } \\
\hline $\mathbf{C}$ & $\mathbf{S i}$ & $\mathbf{M n}$ & $\mathbf{P}$ & $\mathbf{S}$ & $\mathbf{C u}$ & $\mathbf{C r}$ & $\mathbf{M o}$ & $\mathbf{N i}$ \\
\hline 0.077 & 0.241 & 0.6 & $<0.003$ & 0.019 & 0.328 & 0.126 & 0.041 & 0.146 \\
\hline
\end{tabular}

\subsection{Preparation:}

The specimens were cut from a slab that has $15 \mathrm{~m}$ x $120 \mathrm{~mm}$ x $19 \mathrm{~mm}$ (LxWxT) dimensions. The dimensions of the sample are $50 \mathrm{~mm}$ x $40 \mathrm{~mm}$ x $19 \mathrm{~mm}$ (LxWxT). Thickness of the sample were chosen as $19 \mathrm{~mm}$ in order to hinder any form change due to the residual stress formed because of the shot peening operation. As mentioned before, with the shot peening operation the thin sheets can be formed by means of the residual stress relief principle. The dimensions of the sample are shown in Figure 4.1.

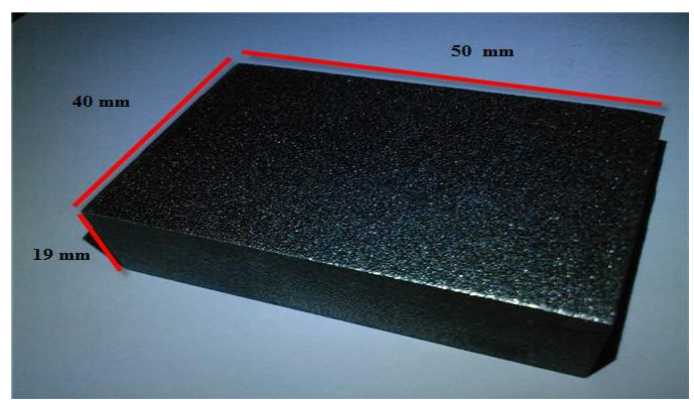

Figure 4.1 Dimensions of the sample

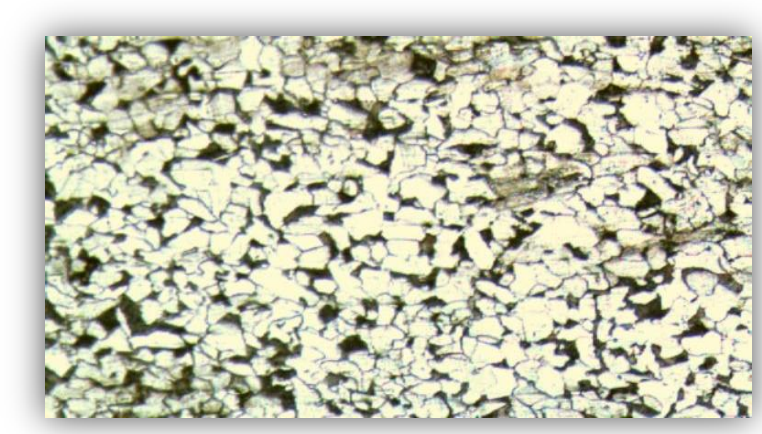

Figure 4.2 Representative micrograph of the starting material having ferriticpearlitic microstructure (100X) 
After cutting operation, metallographic examination was done. Hardness test was performed to the samples by taking five hardness values at every sample. Hardness of the sample is $215 \mathrm{HV}$. Stress relief heat treatment operation has been performed at $600{ }^{\circ} \mathrm{C}$ for $50 \mathrm{~min}$. Then the surfaces were polished again because before the shot peening operation the surfaces of the samples must be cleared from any type of chemicals. All of these operations were done. The MBN measurements of the unshot peened samples and in the end of the shot peening operation was applied on the surface of the samples.

\subsection{Shot Peening Machine:}

The NADCAP certified shot peening equipment existing in TUSAŞ-TURK Aerospace Industry was used for preparing samples. It is a conventional type of shot peening with an automated and manual part. Shot media is sent to the sample by means of pressurized air by controlling pressure and media amount with computer program.

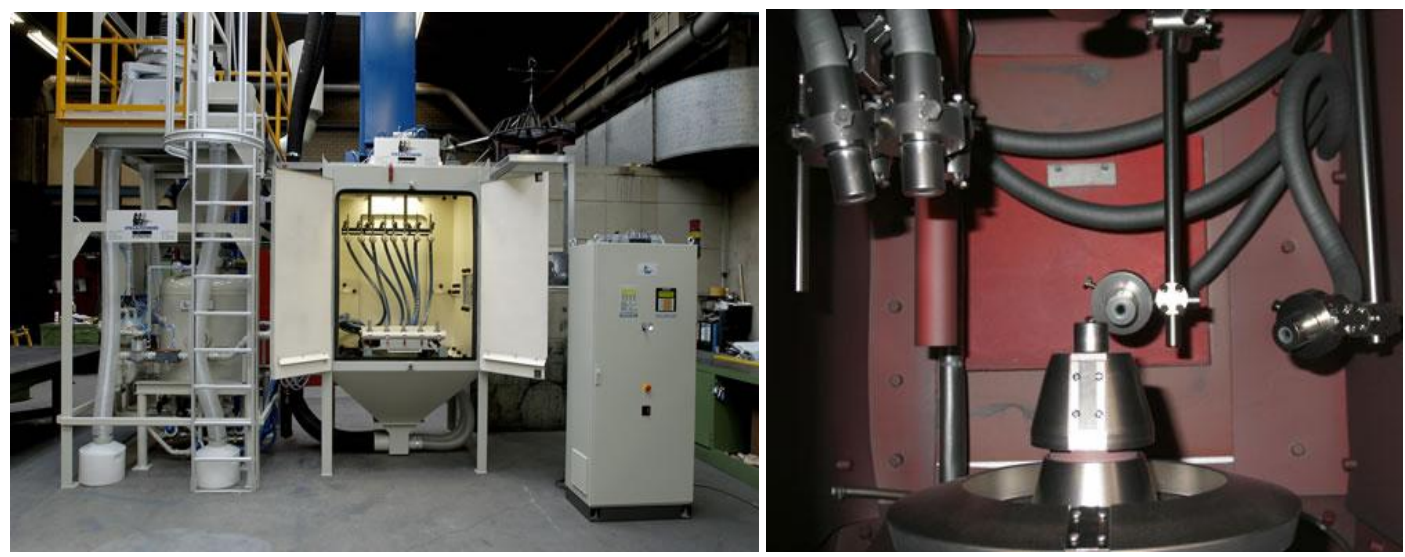

Figure 4.3 A representative conventional air pressured shot peening equipment and nozzles used to manipulate the balls to hit the surface of the material. 


\subsection{Determination of Shot Peening Parameters:}

Y of SP process is the residual stress state at the surface of the component after the shot peening operation.

The Xs, which is used as affecting parameters on $\mathrm{Y}$ of our process the residual stress state at the surface of the component after the shot peening operation that is our $\mathrm{Y}$ for shot peening, which is used for the response in 6 Sigma methodologies are shown at Figure 2.19.

There are many Xs and those are classified as three groups that are related to shot medium, shot peening device and the properties of component's material. In this study, the shot medium and the work piece material properties are constant parameters. One type of material were used in the experiments because at first it is aimed to find the shot peening effect on residual stress and MBN response change due to residual stress change. In other words, the goal is to show whether or not Barkhausen technique can characterize residual stress changes.

The type of shot medium was not be changed with another one because the device used in the experiments works continuously for TAI and the company decided to use same type of shot medium which is a steel shot type and coded as S230 which means that shot has a diameter equal to $230.10^{-4}$ inches. When it is converted into SI unit it is equal to approximately $0.05 \mathrm{~mm}$.

The parameters that are taken as variables for the experiments, are the parameters related to the shot peening device except the nozzle diameter and distance. Nozzle diameter and distance are fixed for the equipment utilized in the experiments. 


\subsection{Calibration of Shot Peening Operation:}

Calibration of the shot peening operation is done by shot peening the Almen strips and measuring their curvature by means of the Almen gauge. Shot peening intensity is calculated by measuring the curvature values. Parameters affecting the intensity of the shot peening is air pressure and media amount sent in one minute to the surface of the material. By changing the parameters, Almen strips are peened till finding desired Almen intensity value. In order to obtain intensity value, three Almen strips are peened with different peening time with the same air pressure and media amount per minute. A saturation curve (Figure 4.4) is plotted with these three Almen strip curvature (Table 4.2). Saturation time is calculated from the computer according to the requirements regarding the specifications. The saturation time is time needed to obtain $100 \%$ coverage of one Almen strip area. Time for $100 \%$ coverage for shot peening of desired component can be calculating by multiplying the time with (Sample area/Almen strip area).

Formula is as follows,

$$
\mathrm{T}^{*} \mathrm{~A} 2 / \mathrm{A} 1=\mathrm{t}
$$

A1: The surface area of the Almen strip (Figure 2.15)

A2: The surface area of the sample (Figure 4.2)

T: Time for obtaining 100\% coverage. (Figure 4.6)

$\mathrm{t}$ : Total time needed to obtain $100 \%$ coverage for the sample. 


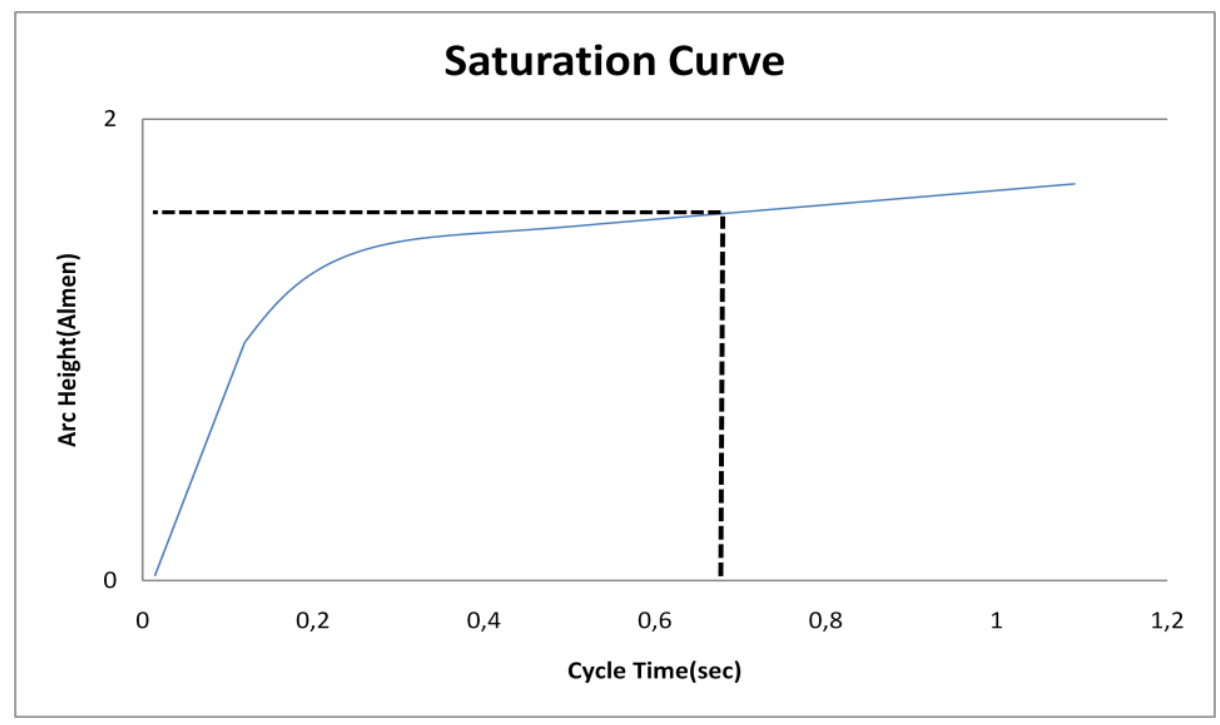

Figure 4.4 Saturation curve which is arc height of Almen strip versus cycle time.

Table 4.2 Cycle time versus Almen intensity values.

\begin{tabular}{|c|c|}
\hline$t(\mathrm{sec})$ & Almen \\
\hline 0 & 0 \\
\hline 10 & 12,80 \\
\hline 20 & 13,8 \\
\hline 40 & 15,3 \\
\hline
\end{tabular}

Because curvature values are so small values they are measured by sensitive Almen gauge (Figure 2.16)

\subsection{Magnetic Barkhausen Noise Measurements:}

\subsubsection{Equipment:}

Magnetic Barkhausen Noise (MBN) measurements were conducted by Stresstech Rollscan $\mu$ Scan 500-2 device (Figure 4.5) which consists of a sensor, a computer and software for data acquisition. During the measurements, excitation frequency of the 
magnetic field was $125 \mathrm{~Hz}$, magnetizing voltage was $10 \mathrm{~V}$, filtering was done mainly between $1-500 \mathrm{kHz}$ and the number of bursts (the number of magnetizing half cycles or Barkhausen Noise bursts that will be stored for signal analysis) was 374 . However, some other filtering options were tried in order to see the effect on the Barkhausen signal. Number of bursts is changing according to the filter used. The sensors used for the MBN measurements are shown in Figure 4.8.

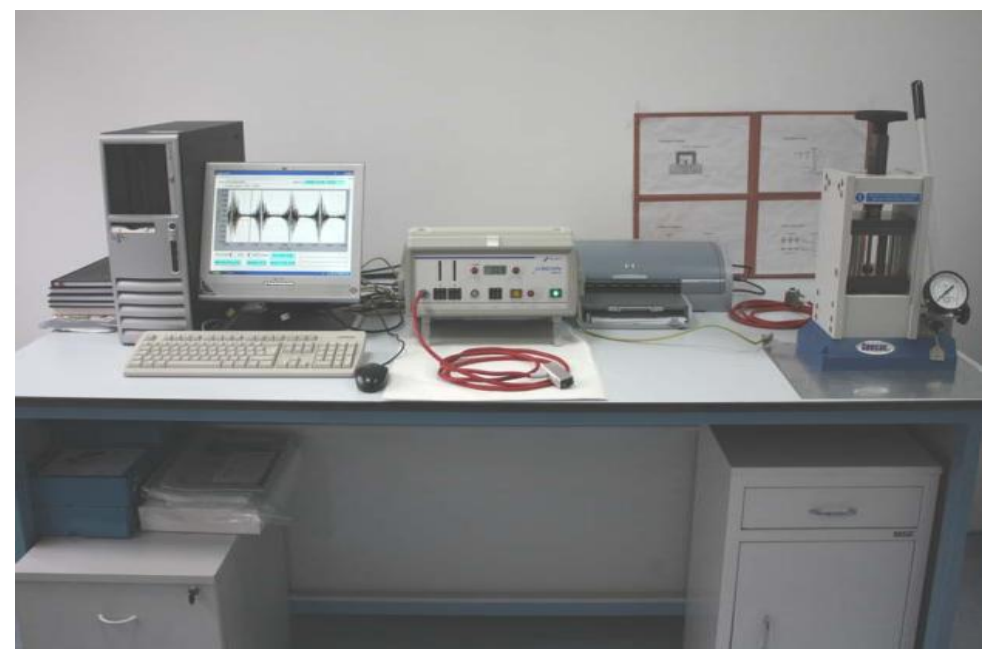

Figure 4.5 Stresstech Rollscan $\mu$ Scan 500-2 device Magnetic Barkhausen Noise Equipment
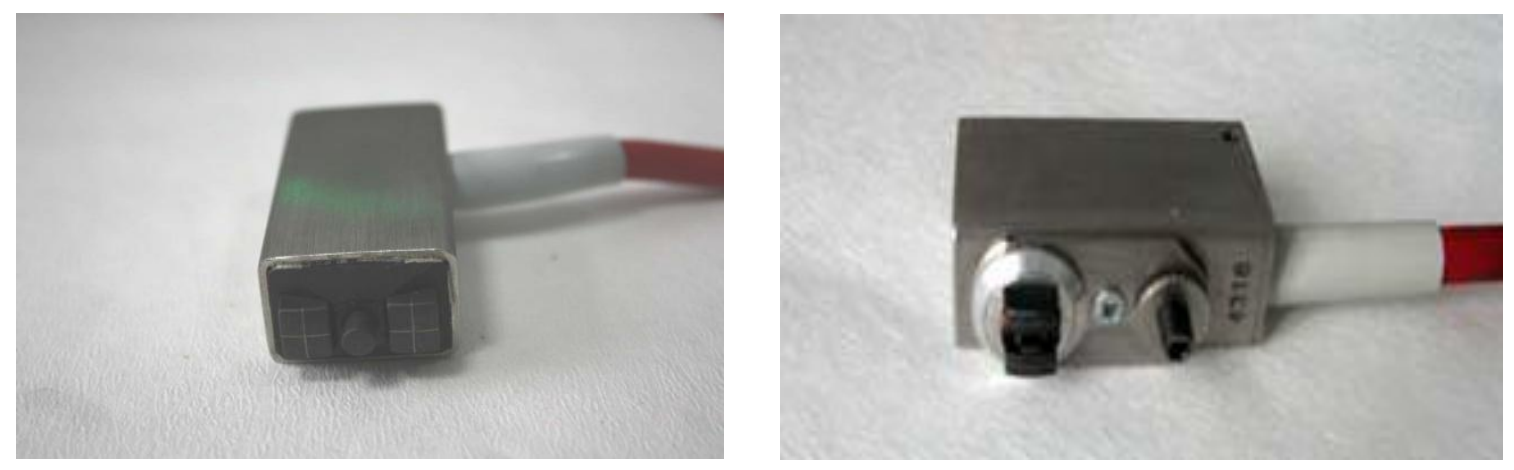

Figure 4.6 Magnetic Barkhausen Noise probes. Right: General purpose probe, Left: Probe has more powerful magnetization capacity than the general purpose probe. 
The magnetization capacity and sensing capacity for the probe at the left is higher than the right one because two measurements were taken with these two probe from the reference sample in the same settings. General purpose probe can measure 99 MBN amplitude where other probe can obtain 142 MBN amplitude with the same measurement settings. Because compressive stresses have an effect of decreasing Barkhausen signal, it is needed probes which can apply higher magnetic field strengths to the material in order to detect that compressive stress changes.

\subsubsection{First Experimental Study:}

This study were performed in order to show the capability of the Magnetic Barkhausen Noise equipment, which will be used in the experiments, for detecting the shot peening effect before starting detailed experimental study. This was a feasibility work for the MBN equipment is made to see the potential that are shown in the literature with a quick experimental study. In order to perform this first experimental work, a shot peened sample with the same peening intensity value and a reference sample were inspected with MBN equipment. The results are shown in Figure 4.7 and Table 4.3.

As seen in the results, there is a good potential to differentiate the shot peening effect with this equipment. In order to increase the magnetizing capacity of the measurement strength a more powerful MBN probe (Figure 4.8 left) is used in calibration and experimental work. 


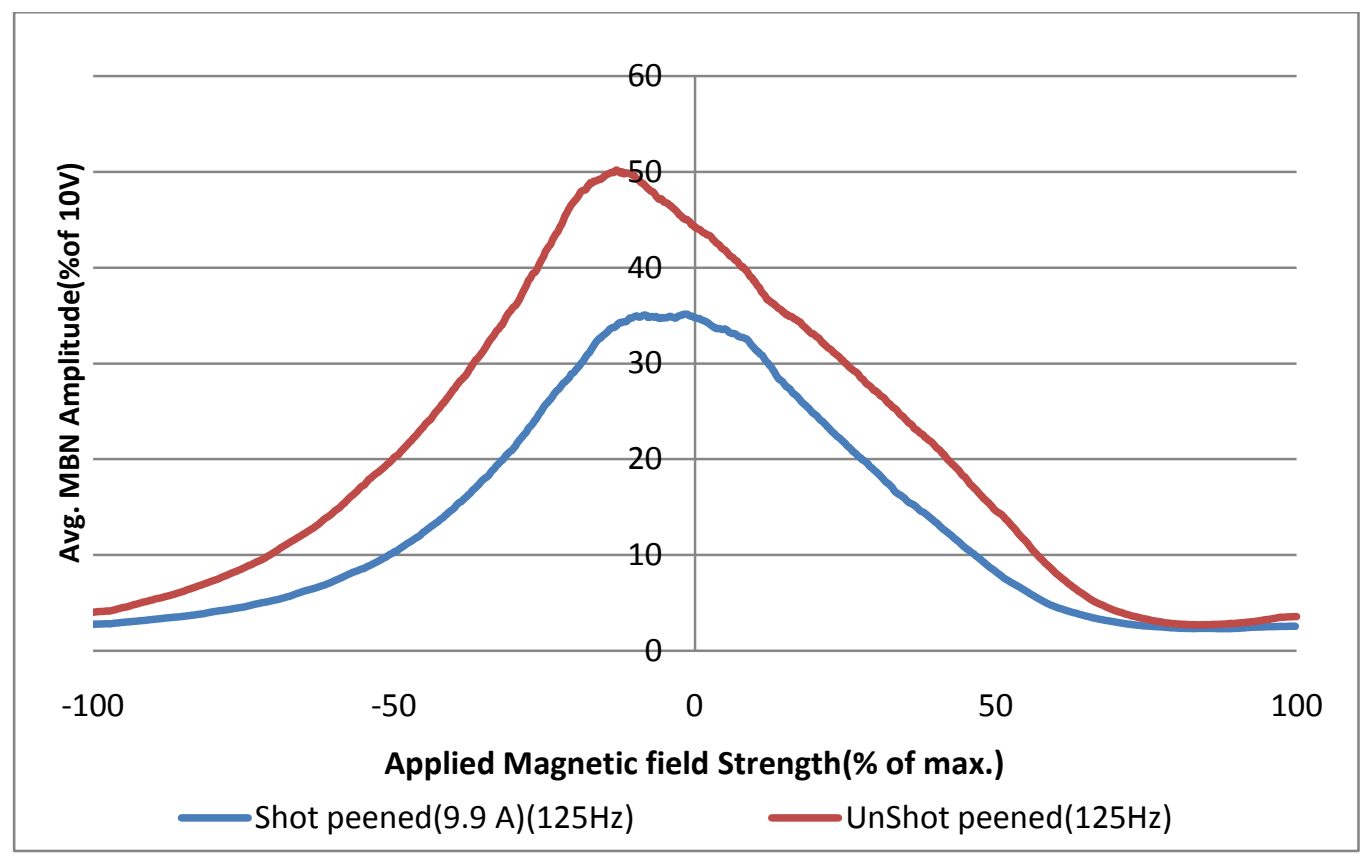

Figure 4.7 RMS MBN Profile of shot peened with 9.9 A intensity value and un-shot peened samples with $125 \mathrm{~Hz}$ magnetizing frequency, magnetization 20, amplification 20, general purpose probe (Figure 4.8 right). ( $\mu$ scan channel)

Table 4.3 MBN measurement results of shot peened 9.9 A and un-shot peened samples.(5 random data) $125 \mathrm{~Hz}$, magnetization 20, amplification 20, general purpose probe (Figure 4.9 right). (Rollscan channel)

\begin{tabular}{|l|l|l|l|}
\hline Name & Max & Min & Average \\
\hline USP & 102 & 97 & 99 \\
\hline SP(9.9A) & 73 & 70 & 71 \\
\hline
\end{tabular}

\subsubsection{Barkhausen Measurement Calibration:}

Some calibration tests were performed in order to find the optimum measurement parameters for the inspections. The $\mathrm{Y}$, which is used for the response in 6 Sigma methodologies, Magnetic Barkhausen Noise response obtained from the material. The Xs, which is used as affecting parameters on Y, are variables of the equipment. 
Those are amplification and magnetization which are changed manually on the equipment. By increasing magnetization and amplification values gradually some curves are obtained which show the change in magnetic Barkhausen responses in unshot peened (Figure 4.8) and shot peened samples (Figure 4.9). The criteria is to choose the best setting by comparing that curves an optimum parameter setting was chosen that are in linear region in magnetization process and have good resolution for showing the difference in un-shot peened and shot peened samples. Therefore, 60 Amplification and 10 Magnetization were chosen for the inspections.

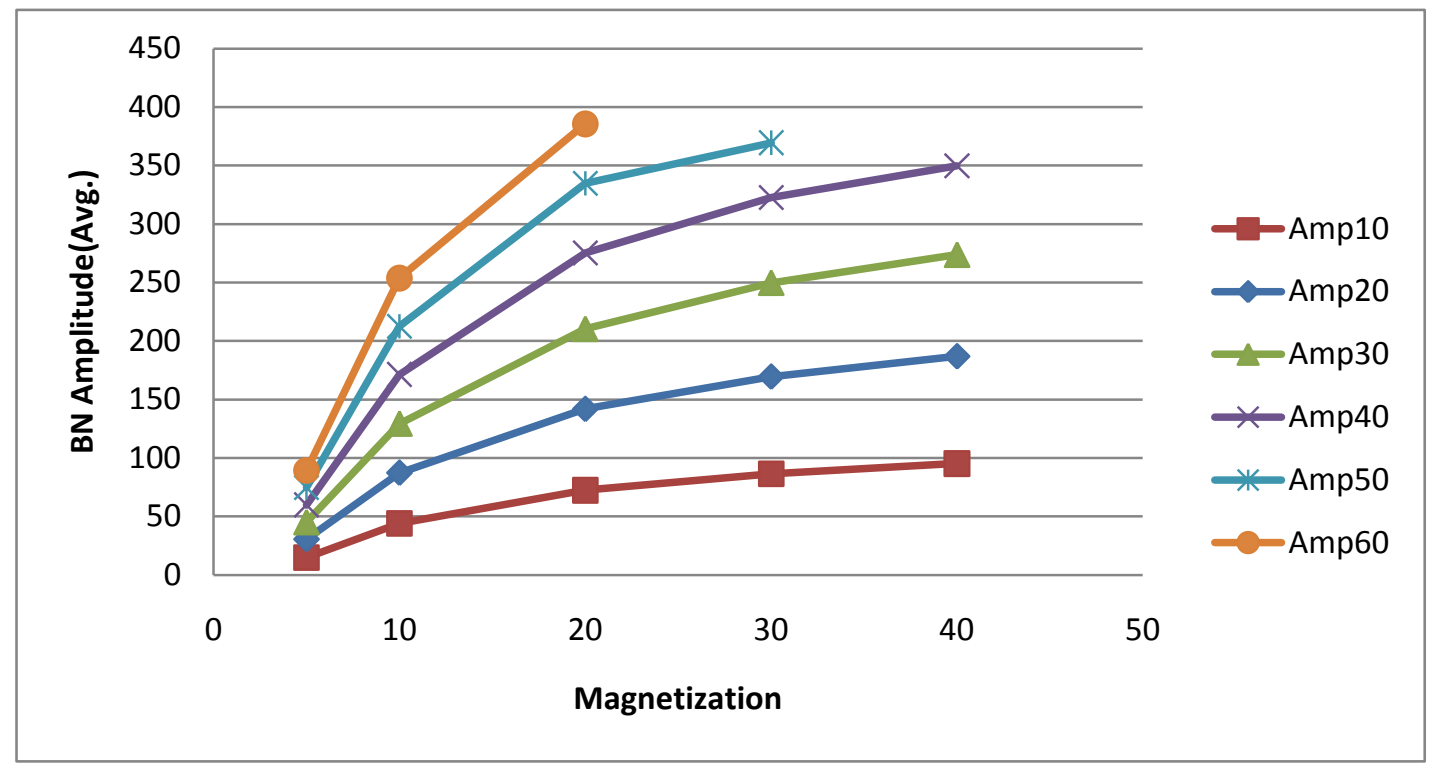

Figure 4.8 MBN response change according to magnetization and amplification (Amp: Amplification) (Un-shot peened sample) 


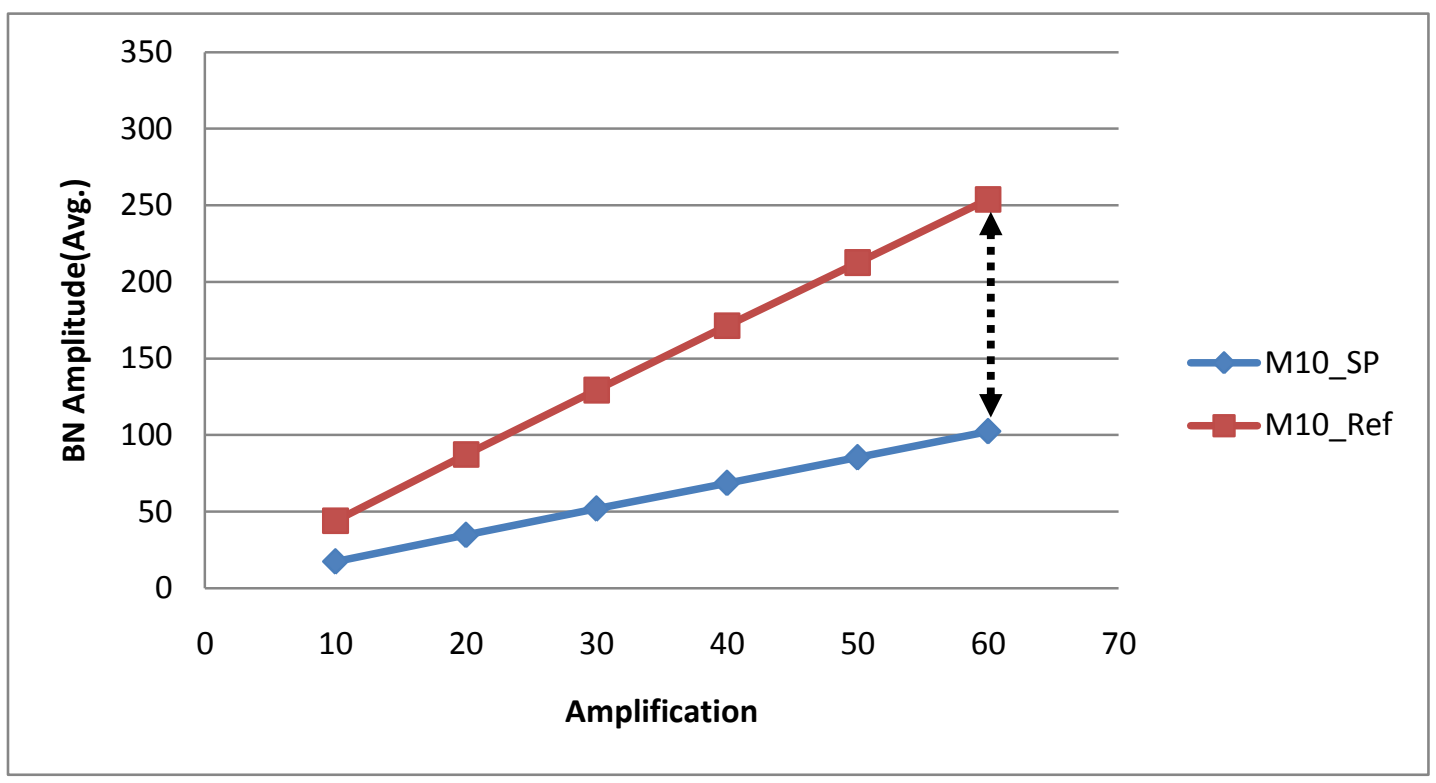

Figure 4.9 (M: Magnetization) Comparison between un-shot peened and shot peened sample MBN response under different amplification values.

\subsection{Stress versus Barkhausen Curve}

\subsubsection{Calibration Sample: (Test Specimen)}

The test specimen dimensions are $8 \mathrm{~mm}$ in thickness and $115 \mathrm{~mm}$ in length (Figure 4.10). The specimen is loaded in tensile and compressive types of load in elastic range of the material. The elongations of the test specimen were calculated by means of the micrometer in $0.001 \mathrm{~mm}$ sensitivity shown in Figure 4.10. By dividing elongation of the sample to the initial length, strain values were calculated (Formula 4.2). By multiplying the strain values with the Elastic Modulus of the sample, stresses were calculated and calibration curve were plotted (Figure 4.11). Difference between first compressive stress value and unloaded value in the graph is seen is a 
little bit higher than other differences between the points. This difference is obtained due to the sensitivity of the system used in calibration operation.

$$
\varepsilon=\left(\mathrm{L}_{\mathrm{in}}-\mathrm{L}\right) / \mathrm{L}_{\mathrm{in}}
$$

Where $\mathrm{L}_{\mathrm{in}}$ : initial length of the specimen, L: length after loading

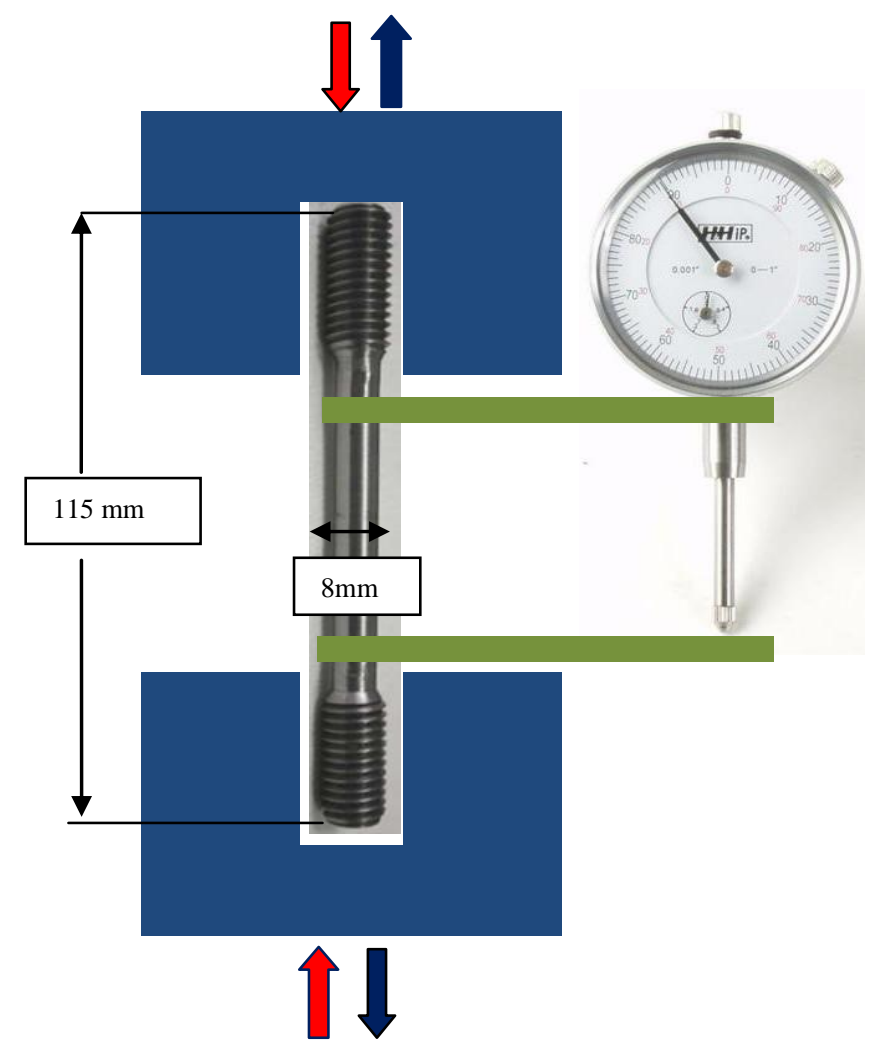

Figure 4.10 System where the calibration sample is applied to tensile and compressive loads in elastic range, a micrometer as $0.001 \mathrm{~mm}$ sensitivity.

Elastic Modulus of the sample was calculated by measuring longitudinal and transverse Ultrasonic velocity of the sample according to equation 4.3 [29] as 232 GPa.

$$
v=\frac{1-2\left(\mathrm{~V}_{\mathrm{T}} / \mathrm{V}_{\mathrm{L}}\right)^{2}}{2-2\left(\mathrm{~V}_{\mathrm{T}} / \mathrm{V}_{\mathrm{L}}\right)^{2}} \quad \mathrm{E}=\mathrm{V}_{\mathrm{I}}{ }^{2} \rho \frac{(1+v)(1-2 v)}{(1-v)}
$$


Where $\rho$ : Density, $v$ : Poisson ratio, E: Elastic Modulus, $\mathrm{V}_{\mathrm{T}}$ : Propagation of transversal velocity, $\mathrm{V}_{\mathrm{L}}$ : Propagation velocity of longitudinal waves.

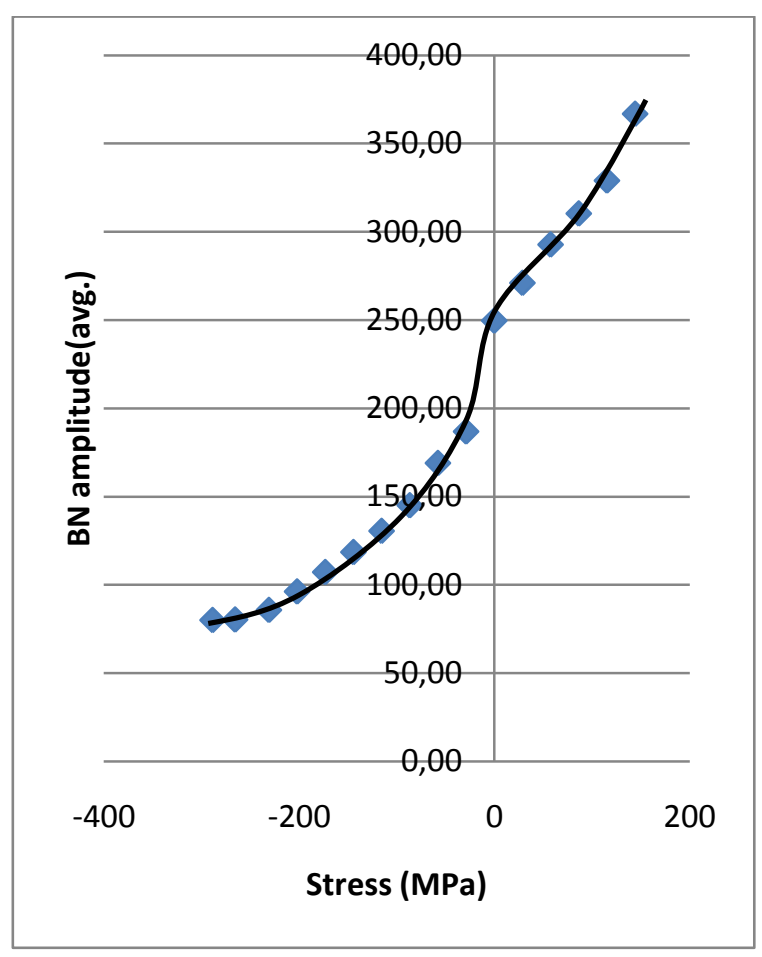

Figure 4.11 Magnetic Barkhausen Noise change according to stress changes in the elastic region which will be used in conversion of Barkhausen responses into residual stress values.

\subsection{X-Ray Diffraction Measurement:}

X-Ray Diffraction (XRD) residual stress measurements were performed in At1lım University. The equipment for XRD measurements was Seifert XRD 3003 PTS XRay Diffractometer System (Figure 4.12). 
In the $\mathrm{XRD}$ residual stress measurements, as a reference material iron $(\mathrm{Fe})$ was selected from the database of the equipment which was the nearest material to the material used in the experiments that is low alloy steel. The properties are shown in Figure 4.13.

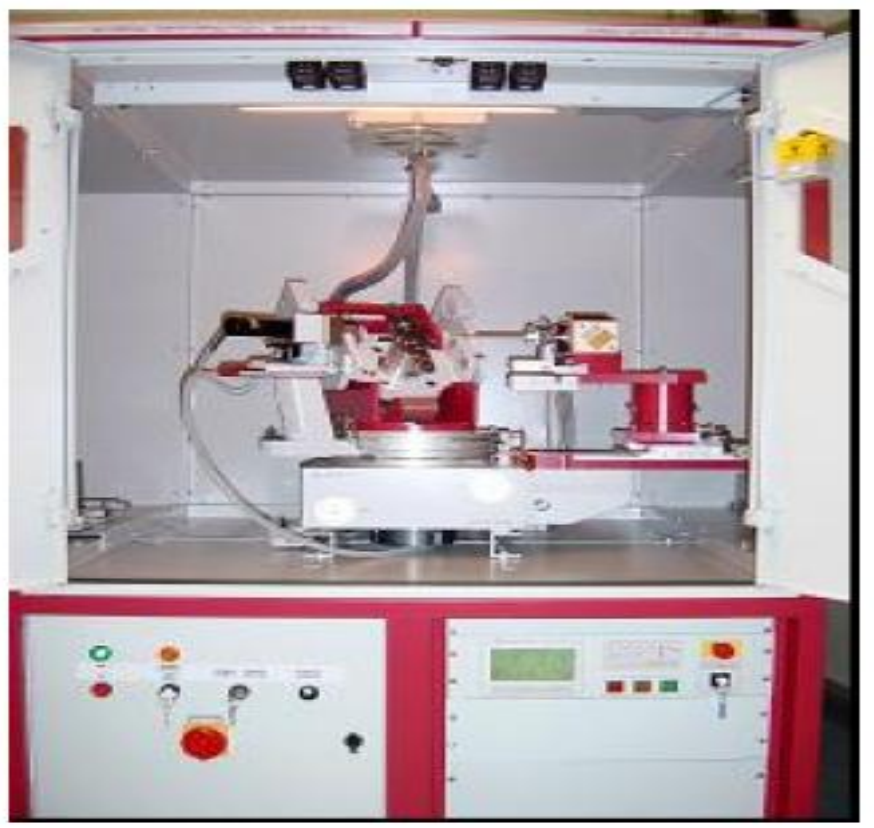

Figure 4.12 Seifert XRD 3003 PTS X-Ray Diffractometer System

\begin{tabular}{|lc|}
\hline \multicolumn{2}{|l|}{ Database Reference } \\
\hline Material: & iron \\
Radiation: & Cr-Ka \\
Bragg Angle: & $156.08^{\circ}$ \\
Lattice Planes: & $(211)$ \\
\hline
\end{tabular}
Young's modulus: $211.996 \quad \mathbf{1 0}^{+3} \mathrm{MPa}$
Poisson's ratio: $\quad 0.29997$
Used constants: Xray

Figure 4.13 Database reference for the XRD residual stress measurements 

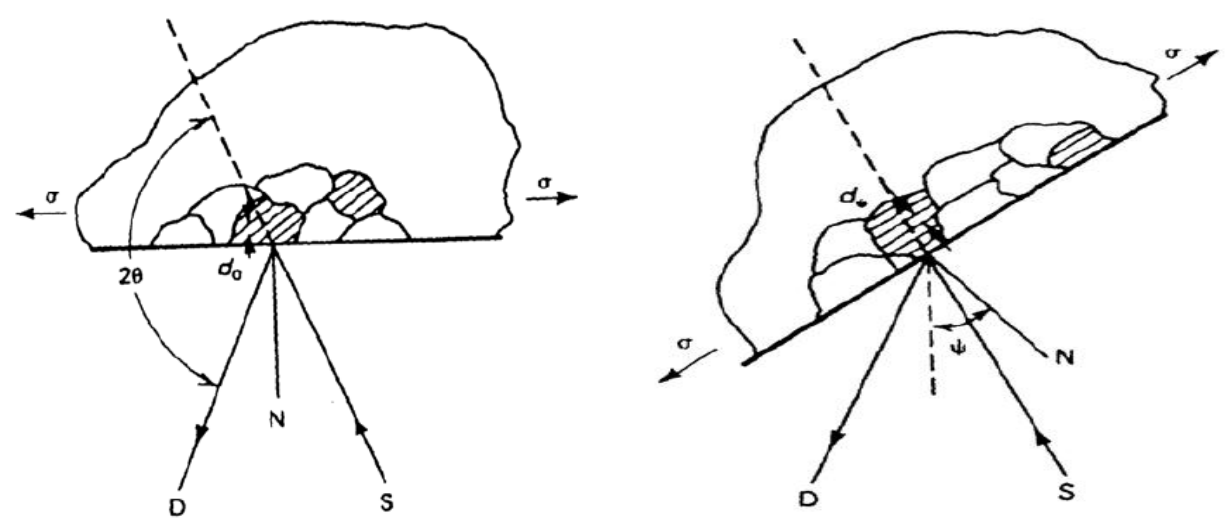

Figure 4.14 Basis of XRD residual stress measurements (S: X-Ray Source, D: XRay Detector, N: Bisector of incident and diffracted beam, $2 \varphi$ : Bragg angle, $\psi$ : Sample is rotated in front of the x-ray source with a known angle $\psi$ [30].

In order to evaluate the residual stresses exist in different directions at the same region, sample was rotated by changing the angle $(\psi)$ between the bisector of the incident and diffracted plane, and normal to the surface of sample [30]. This angle was changed between $-45^{\circ}$ and $45^{\circ}$ in the experiments.

The XRD residual stress measurement method uses the lattice spacing (d) as a strain gauge. Commercial x-ray tubes can produce certain wavelengths. Therefore, choice of the possible planes is limited. The diffraction peak used for residual stress determination is so important for the accuracy of the measurement. In practice, diffraction angle $(2 \varphi)$ is greater than $120^{\circ}$ [30]. In the experiments, it was specified as $156.08^{\circ}$.

As a result, peak point $2 \varphi$ angles of the high angle diffraction peaks at different angles of $\psi$ were recorded and $2 \varphi$ versus $\sin ^{2} \psi$ were obtained. In literature, this plot 
can be seen as d(diffraction plane) versus $\sin ^{2} \psi$ [30]. This is called $\sin ^{2}(\psi)$ technique [31]. The slope of this plot were taken from the best line and stress was calculated by the software of XRD equipment according to the Formula 4.4 [30],

$$
\sigma=(\mathrm{E} /(1+v))_{\mathrm{hkl} \cdot} \cdot\left(1 / \mathrm{d}_{\mathrm{o}}\right) \cdot\left(\mathrm{ad} / \operatorname{asin}^{2} \psi\right)
$$

\subsection{Electrical Conductivity and Magnetic Permeability Measurement:}

For doing frequency analysis, the skin depth formula (Figure 4.12) is used. At which frequency range, what is the depth of the Barkhausen Noise can be analyzed. In order to use this formula, electrical conductivity and magnetic permeability have to be measured. These parameters were measured in METU Central Laboratory. In the figures 4.15 and 4.16, the measurement techniques are shown. At the electrical conductivity measurement, the resistance of a stick of steel sample whose dimensions are $2 \mathrm{~mm} \times 2 \mathrm{~mm} \times 65 \mathrm{~mm}$ is measured by applying electrical current to the sample. Then, from the resistance value is obtained and conductivity is calculated according to Formula 4.5 [32].

$$
\delta=1 /\left(\pi . f . \sigma \cdot \mu_{\mathrm{r}} \cdot \mu_{\mathrm{o}}\right)^{1 / 2}
$$

where $\delta$ : Magnetization depth (m), f: Frequency content of $\mathrm{MBN}(\mathrm{Hz}), \sigma$ : Electrical conductivity $\left(\Omega^{-1} * \mathrm{~m}^{-1}\right), \mu_{\mathrm{r}}$ : Relative permeability, $\mu_{\mathrm{o}}:$ Permeability of vacuum (N.A $\left.{ }^{-2}\right)$

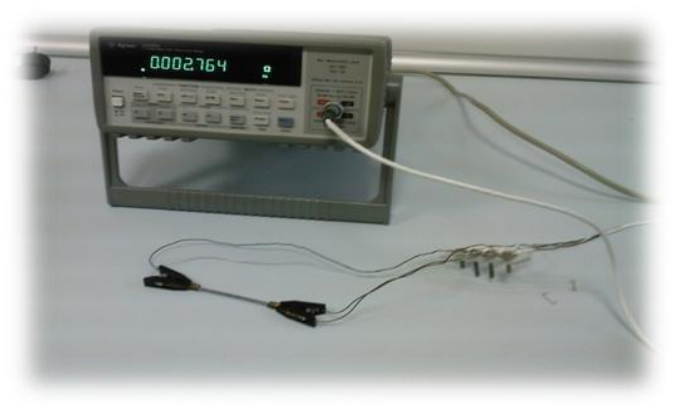

Figure 4.15 Electrical conductivity measurement (Agilent 3458A Digital Nanovoltmeter) 
$\mathrm{R}=2,764 \mathrm{~m} \Omega$ was measured as electrical resistance from the equipment. According to the Formula 4.6 resistivity and electrical conductivity were calculated as $\rho=$ $1,7 * 10^{-7} \Omega * \mathrm{~m}$, and $\sigma=5,64 * 10^{6} \Omega^{-1} * \mathrm{~m}^{-1}$

$$
\rho=\mathrm{R} * \mathrm{~A} / 1 \quad \sigma=1 / \rho
$$

Where R: Resistance $\left(\Omega\right.$, A: Cross sectional area $\left(\mathrm{m}^{2}\right), \quad$ l: Length $(\mathrm{m}), \quad \rho$ : Resistivity $\left(\Omega^{*} \mathrm{~m}\right), \sigma$ : Conductivity $\left(\Omega^{-1} * \mathrm{~m}^{-1}\right)$

For measuring the magnetic permeability, the magnetic inductance of a toroidal shaped sample is measured. By taking its ratio the inductance of vacuum, relative permeability is found.
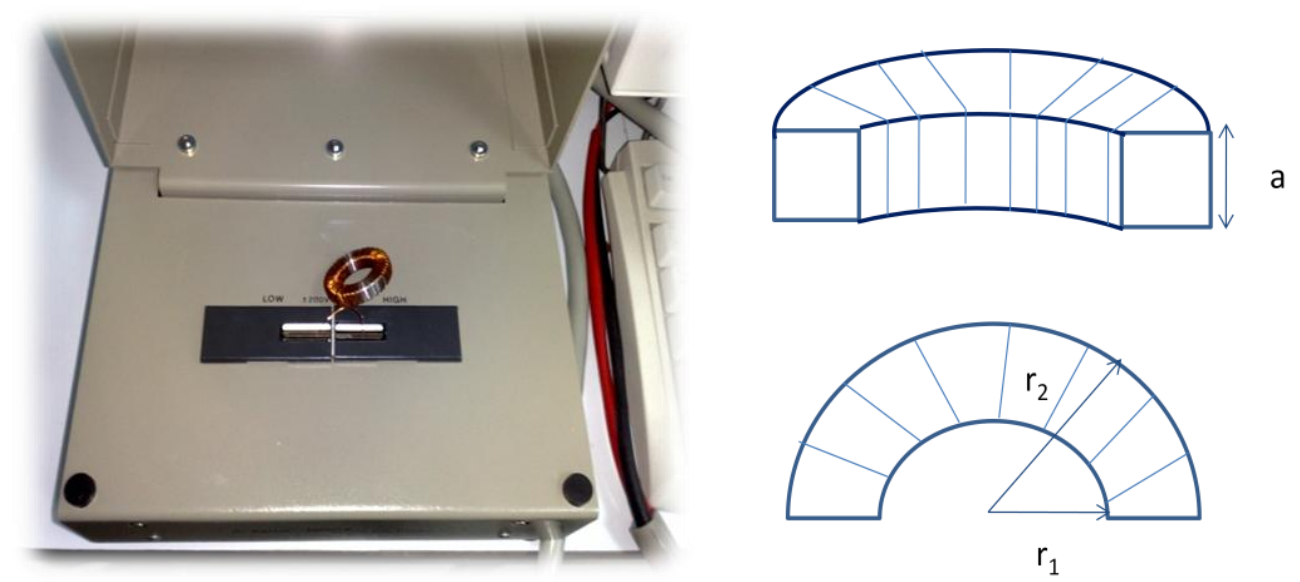

Figure 4.16 Coiled toroid for permeability measurement (Agilent 4294A Impedance Analyzer) 
Calculation is done by using the formula 4.7 [33],

$$
\mathrm{L}=\mu * \mathrm{~N}^{2} * \mathrm{a} * \operatorname{In}\left(\mathrm{r}_{2} / \mathrm{r}_{1}\right) / 2 * \pi
$$

Where L: Magnetic Induction (Henry)(A/m), $\mu$ : Magnetic Permeability $\left(\mathrm{A} / \mathrm{m}^{2}\right)$

$\mathrm{N}$ : Number of Turns, a: Height (m), $\mathrm{r}_{1}, \mathrm{r}_{2}$ : Inner and Outer Diameter (m)

By doing calculations the relative permeability of the sample is found as $\mu_{\mathrm{r}}=80$.

By using the Formula 4.7, the depth of Barkhausen Noise was calculated and shown in Figure 4.17. (Permeability measurement was done according to the $125 \mathrm{~Hz}$ magnetization frequency.)

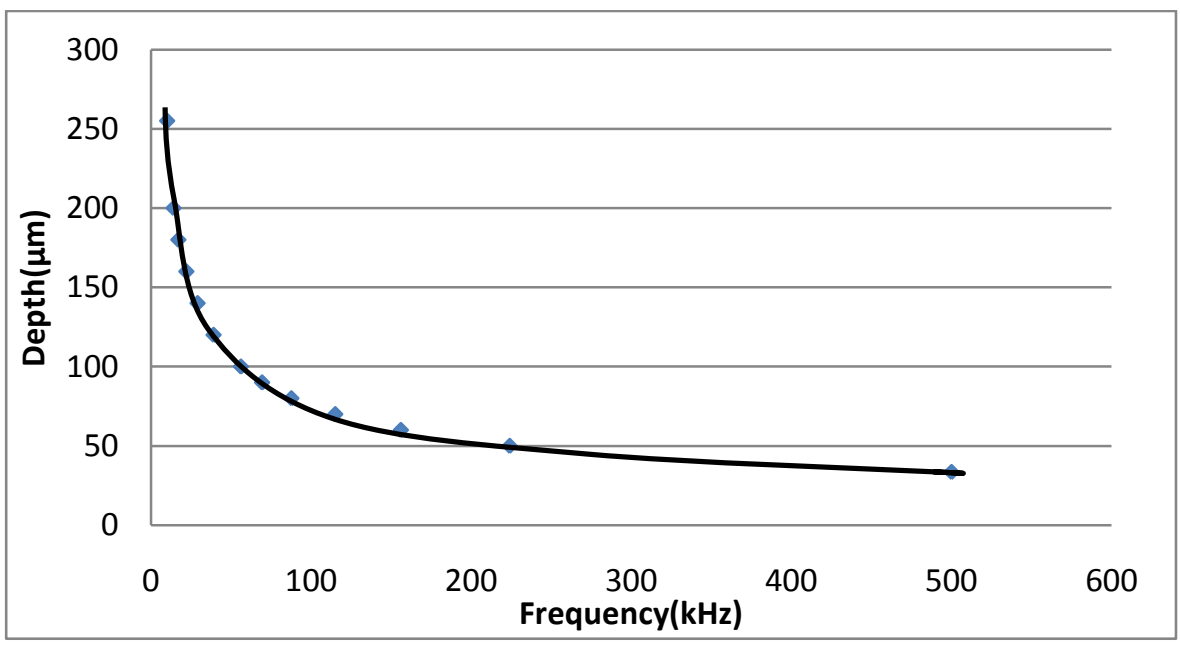

Figure 4.17 Depth of the information vs. Barkhausen Noise frequency

This graph will be used for estimating the depth of the residual stresses in frequency distributions in Chapter 5. 


\section{CHAPTER 5}

\section{RESULTS AND DISCUSSIONS}

\subsection{MBN Measurements with Rollscan System:}

Rollscan channel has real-time measurement capability and it is more useful for industrial applications in order to evaluate the homogeneity of the shot peening process applied to the surface of the material. This channel uses $125 \mathrm{~Hz}$ magnetization frequency. The magnetization and amplification parameters which are the most effective parameters on MBN responses are used as specified in calibration (Chapter 4.7.3). The results show obvious differences between the shot peened samples and reference sample. After collecting random data from the shot peened samples, data is analyzed statistically in order to see their validity.

\subsubsection{MBN Measurements Results of Shot Peened Samples with different Peening Intensity, Coverage and Impact Angles:}

Magnetic Barkhausen Noise measurements were performed at the surface of the samples (random data from each sample) which were obtained by applying four SP intensity values "7A, 8A, 9.8A, 12.3A" (Figure 5.1(a)), three SP coverage values 
"50\%, 100\%, 300\%" (Figure 5.1(b)) and three different SP angle values " $30^{\circ}, 45^{\circ}$, $90^{\circ}$ ' (Figure 5.1(c)).

Intensity is the main parameter to control in shot peening operation in order to control compressive residual stress on the surface and near surface of the material. The intensity values of the shot peening operation were specified by standard Almen strips. Almen strips were peened with different air pressure and shot mass flow values. Coverage is the one of the most important parameters that is affecting compressive residual stresses obtained at the surface of materials [34]. Shot peening angle which is controlled by changing nozzle angles with respect to the surface of the samples. The highest magnitude of compressive stress can be obtained when the nozzle position is perpendicular to the surface of the sample. However, in industrial applications, because of the complicated shapes of the components the nozzle angles can be set as lower values than $90^{\circ}$ in order to provide that all desired areas of the components can be peened homogeneously. Therefore, it will be useful to see the effect of nozzle angle change with respect to the normal of component surface on Magnetic Barkhausen Noise responses. 


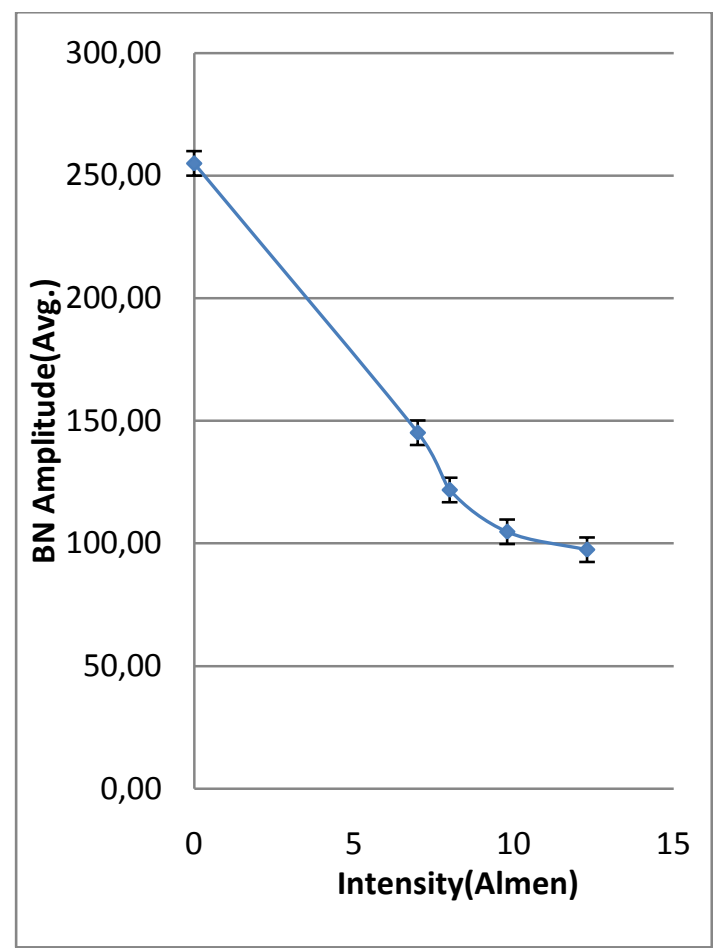

(a)

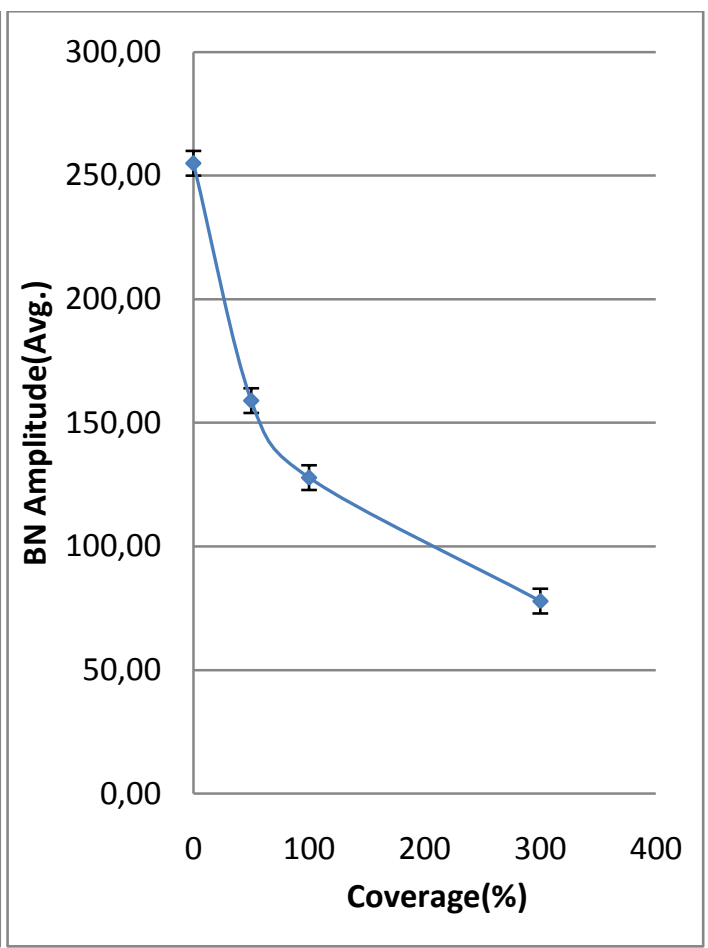

(b)

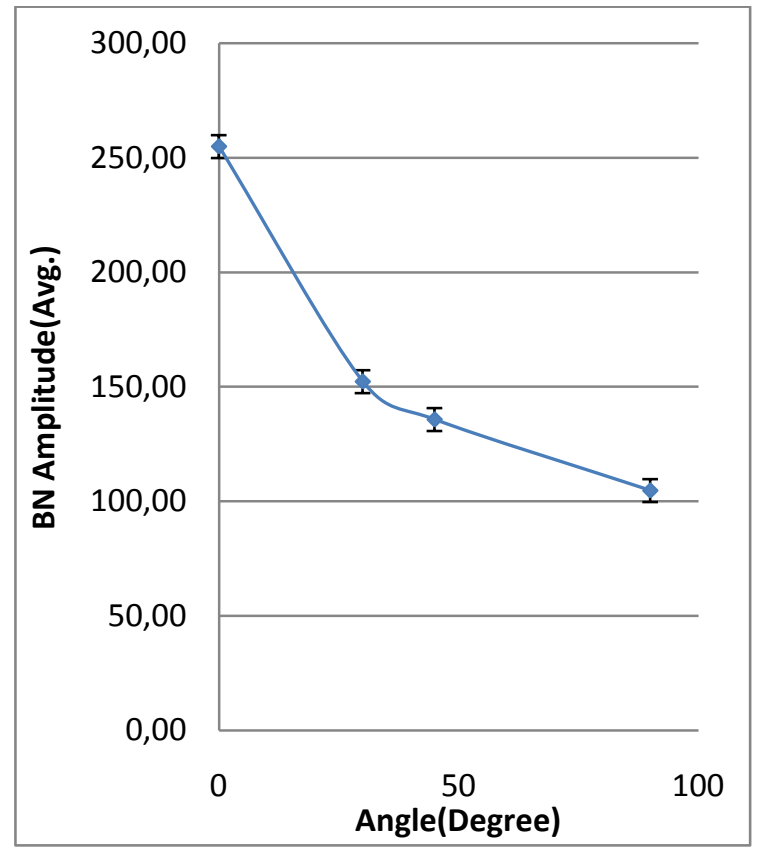

(c)

Figure 5.1 Rollscan BN amplitude for different intensity (a), different coverage (b), and different impact angles (c) shot peened samples. 
The variation in the results is taken as $\pm 5 \mathrm{BN}$ Amplitude change which is calculated from the random collected data maximum variation from the average which is also shown in Table 1 and Table 2.

Table 5.1 Random BN responses taken from shot peened samples with different impact angles and reference samples. (Max var. is max variation from the average)

\begin{tabular}{|l|l|l|l|}
\hline \# of points & Ref. & ShotP.-90 & ShotP.-45 \\
\hline 1 & 253 & 104 & 122 \\
\hline 2 & 255 & 100 & 125 \\
\hline 3 & 254 & 107 & 137 \\
\hline 4 & 268 & 111 & 138 \\
\hline 5 & 248 & 110 & 127 \\
\hline 6 & 272 & 103 & 141 \\
\hline 7 & 260 & 106 & 143 \\
\hline 8 & 246 & 96 & 135 \\
\hline 9 & 238 & 109 & 132 \\
\hline 10 & 255 & 101 & 128 \\
\hline Avg. & 255 & 105 & 133 \\
\hline Max Var. & 5 & 6 & 5 \\
\hline Min Var. & 0 & -1 & 3 \\
\hline
\end{tabular}

Table 5.2 Random BN responses taken from shot peened samples with different coverage and reference samples. (Max var. is max variation from the average)

\begin{tabular}{|l|l|l|l|}
\hline \# of points & USP & $\mathbf{1 0 0 \% C o v e r a g e ~}$ & $\mathbf{3 0 0 \% C o v e r a g e}$ \\
\hline 1 & 253 & 126 & 81 \\
\hline 2 & 255 & 130 & 73 \\
\hline 3 & 254 & 138 & 76 \\
\hline 4 & 268 & 118 & 79 \\
\hline 5 & 248 & 135 & 81 \\
\hline 6 & 272 & 116 & 79 \\
\hline 7 & 260 & 140 & 77 \\
\hline 8 & 246 & 113 & 79 \\
\hline 9 & 238 & 135 & 78 \\
\hline 10 & 255 & 127 & 76 \\
\hline Avg. & 255 & 128 & 78 \\
\hline Max Var. & 5 & 7 & 3 \\
\hline Min Var. & 0 & -1 & 0 \\
\hline
\end{tabular}




\subsubsection{Random MBN Measurement Results in order to Evaluate Homogeneity of the Shot Peening Process:}

In Figure 5.2 and 5.3 random MBN signal collected from surface of shot peened with different coverage and angle values were plotted. This kind of work can be used in the industrial application in order to see the distribution of shot peening effect applied to the surface of the samples. At the end of that work, a general behavior of residual stresses obtained on the surface can be seen.

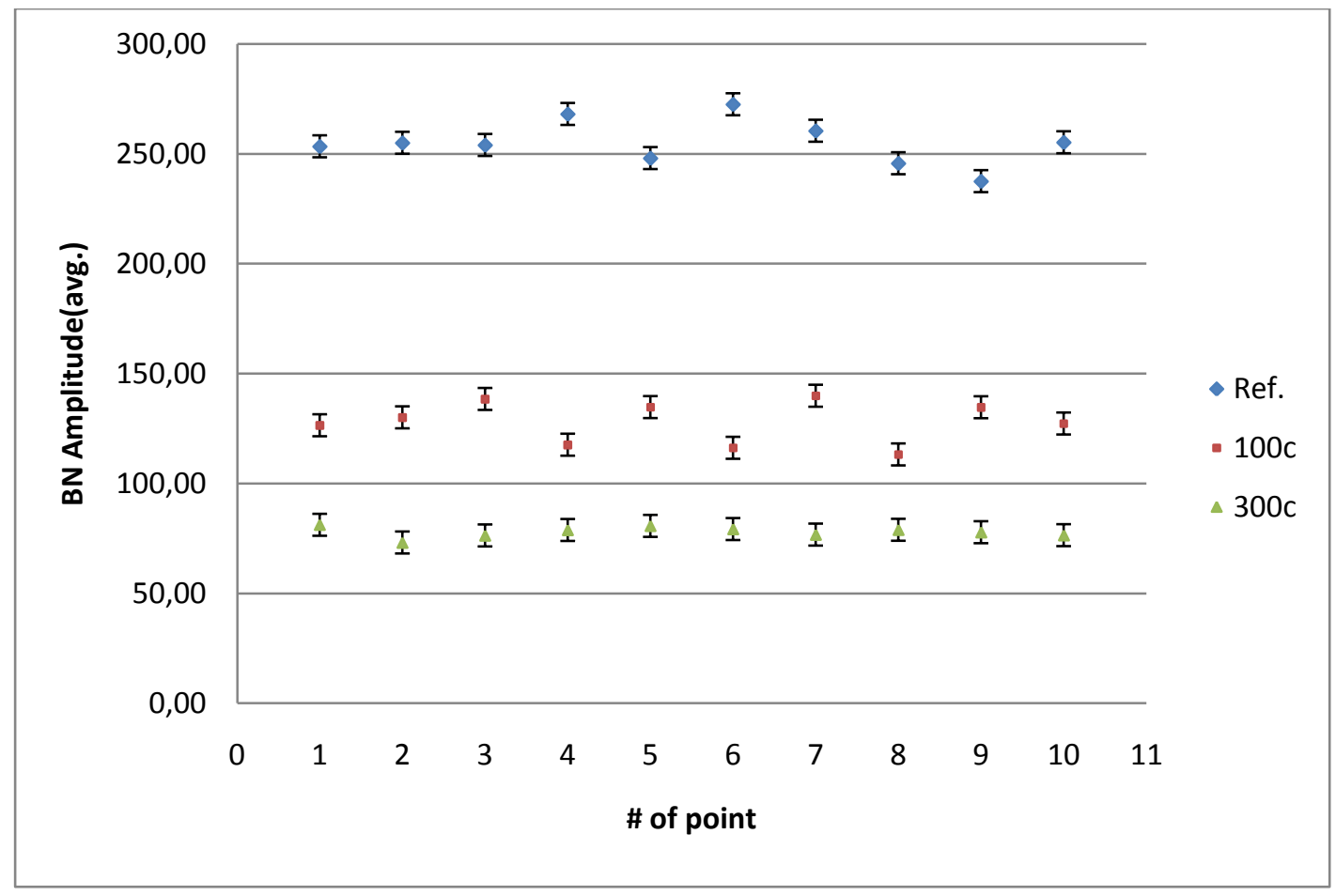

Figure 5.2 Rollscan BN amplitude from different 10 points randomly selected from the different coverage samples and reference sample in order to see the homogeneity of the signal response from the samples. 


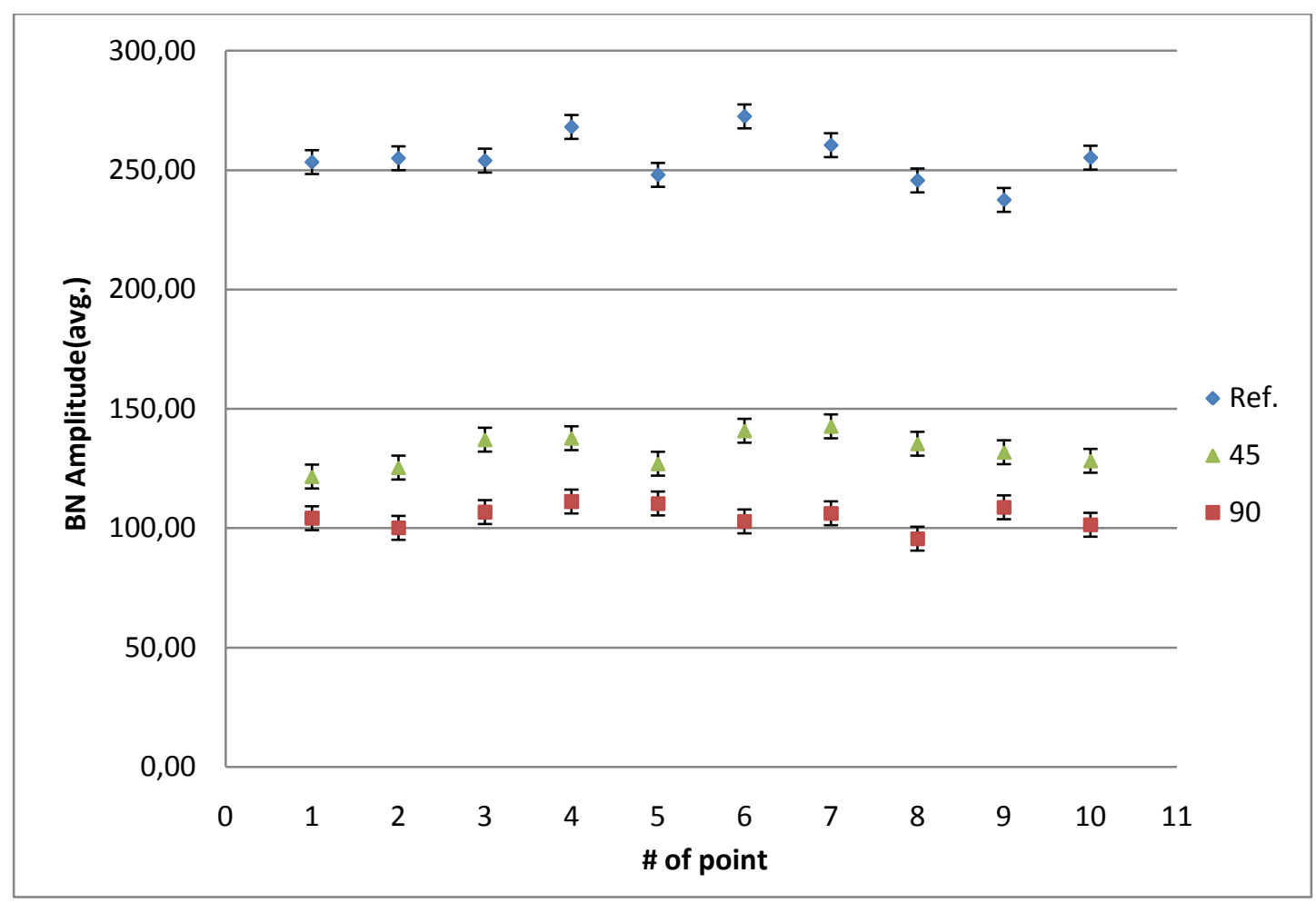

Figure 5.3 Rollscan BN amplitude from different 10 points randomly selected from the different angle samples and reference sample in order to see the homogeneity of the signal response from the samples.

Descriptive statistical analyses and normality tests are performed to the random collected data. Normality tests are performed to the raw data in order to calculate how likely random data is to be normally distributed, so it is used to confirm the validity of the collected data. The data is normal, if the $\mathrm{p}$ value (shown in Figure 5.5 as column name "Statistic") is higher than 0.05 and in normal data sets, average can be used as a result of the whole collected data. As seen in Figure 5.5, according to the values in statistic columns, it is found that all the data sets are normal. Therefore, the average (mean) of the whole data sets can be taken as the measurement result. Histograms and statistical analysis are shown in Figure 5.4 and Figure 5.5. 

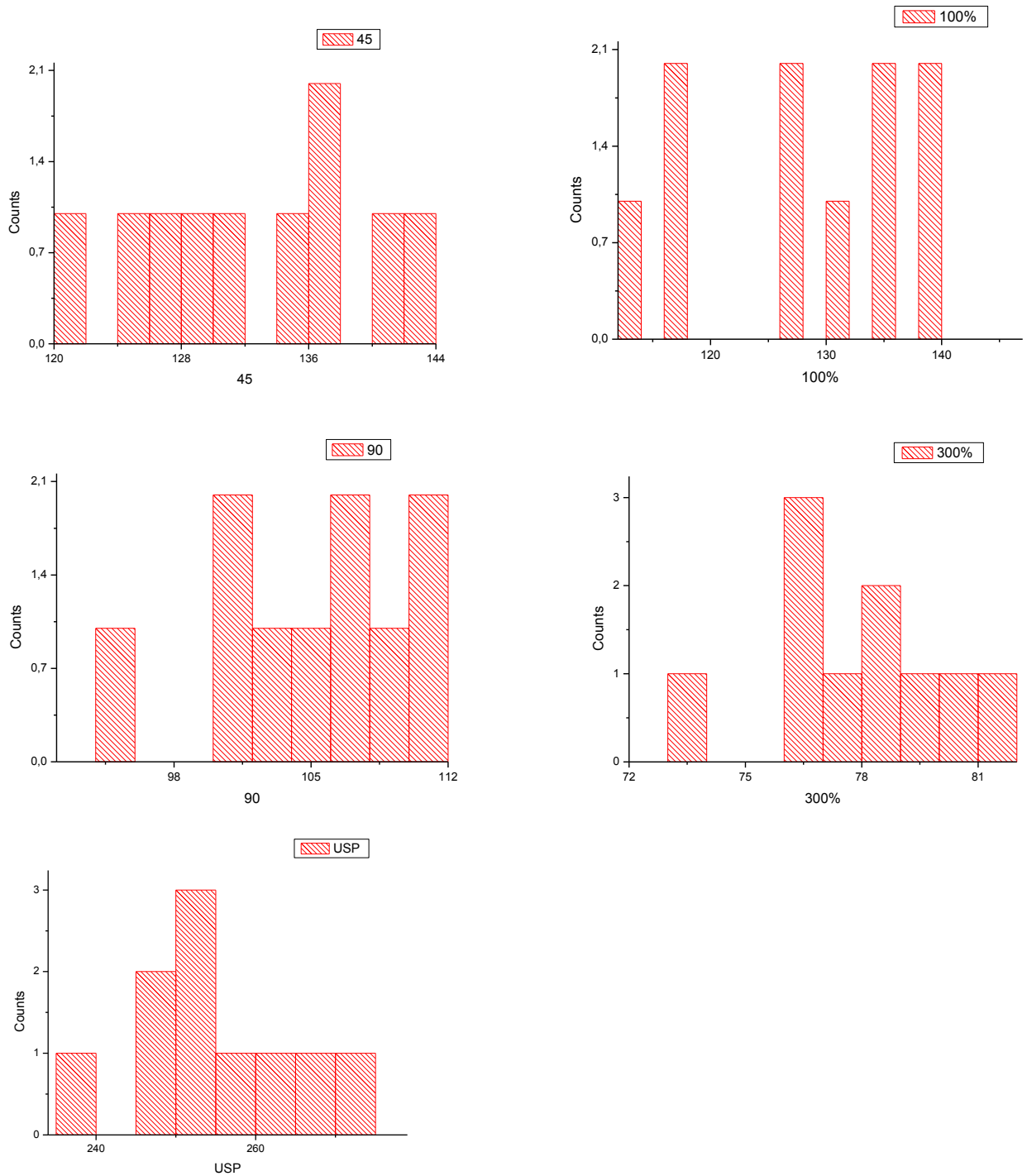

Figure 5.4 Histograms of the random collected data (45, 90 degree; 100\%, 300\% coverage and USP (Un-shot peened) samples) 


\begin{tabular}{|r|r|r|r|}
\hline \multicolumn{5}{|c}{ Shapiro-Wilk } \\
\hline $100 \%$ & 10 & 0,92449 & 0,3959 \\
\hline $300 \%$ & 10 & 0,95127 & 0,68354 \\
\hline 45 & 10 & 0,95819 & 0,76506 \\
\hline 90 & 10 & 0,9687 & 0,87858 \\
\hline USP & 10 & 0,96883 & 0,87977 \\
\hline
\end{tabular}

$100 \%$ : At the 0.05 level, the data was significantly drawn from a normally distributed population $300 \%$ : At the 0.05 level, the data was significantly drawn from a normally distributed population 45: At the 0.05 level, the data was significantly drawn from a normally distributed population 90: At the 0.05 level, the data was significantly drawn from a normally distributed population USP: At the 0.05 level, the data was significantly drawn from a normally distributed population

\begin{tabular}{|r|r|r|r|} 
Lilliefors \\
\hline $100 \%$ & 10 & 0,16306 & 0,2 \\
\hline $300 \%$ & 10 & 0,15194 & 0,2 \\
\hline 45 & 10 & 0,1442 & 0,2 \\
\hline 90 & 10 & 0,11958 & 0,2 \\
\hline USP & 10 & 0,19081 & 0,2 \\
\hline
\end{tabular}

$100 \%$ : At the 0.05 level, the data was significantly drawn from a normally distributed population $300 \%$ : At the 0.05 level, the data was significantly drawn from a normally distributed population 45: At the 0.05 level, the data was significantly drawn from a normally distributed population 90: At the 0.05 level, the data was significantly drawn from a normally distributed population USP: At the 0.05 level, the data was significantly drawn from a normally distributed population

Kolmogorov Smirnov
\begin{tabular}{|r|r|r|r|}
\hline & DF & Statistic & Prob $>$ D \\
\hline $100 \%$ & 10 & 0,16306 & 1 \\
\hline $300 \%$ & 10 & 0,15194 & 1 \\
\hline 45 & 10 & 0,1442 & 1 \\
\hline 90 & 10 & 0,11958 & 1 \\
\hline USP & 10 & 0,19081 & 0,85722 \\
\hline
\end{tabular}

$100 \%$ : At the 0.05 level, the data was significantly drawn from a normally distributed population $300 \%$ : At the 0.05 level, the data was significantly drawn from a normally distributed population 45: At the 0.05 level, the data was significantly drawn from a normally distributed population 90: At the 0.05 level, the data was significantly drawn from a normally distributed population USP: At the 0.05 level, the data was significantly drawn from a normally distributed population

Figure 5.5 Normality analyses were done with three models and in all types models data were found as normal.

Table 5.3 Descriptive statistical analyses of random collected data

\begin{tabular}{|c|c|c|c|c|c|c|c|c|c|}
\hline ID & Ntotal & $\begin{array}{c}\text { Mea } \\
\mathbf{n}\end{array}$ & $\begin{array}{c}\text { Standard } \\
\text { Deviatio } \\
\mathbf{n}\end{array}$ & $\begin{array}{c}\text { Lower } \\
\mathbf{9 5 \%} \mathbf{C l} \text { of } \\
\text { Mean }\end{array}$ & $\begin{array}{c}\text { Upper } \\
\mathbf{9 5 \%} \text { Cl } \\
\text { of Mean }\end{array}$ & $\begin{array}{c}\text { Coefficient } \\
\text { of } \\
\text { Variation }\end{array}$ & $\begin{array}{c}\text { Min } \\
\text {. }\end{array}$ & Median & Max \\
\hline $\mathbf{1 0 0 \%}$ & 10 & 128 & 10 & 121 & 135 & 0,074 & 113 & 129 & 140 \\
\hline $\mathbf{3 0 0 \%}$ & 10 & 78 & 2 & 76 & 80 & 0,031 & 73 & 78 & 81 \\
\hline $\mathbf{4 5}$ & 10 & 133 & 7 & 128 & 138 & 0,053 & 122 & 134 & 143 \\
\hline $\mathbf{9 0}$ & 10 & 104 & 5 & 101 & 108 & 0,046 & 96 & 105 & 111 \\
\hline USP & 10 & 255 & 10 & 248 & 262 & 0,04 & 238 & 255 & 273 \\
\hline
\end{tabular}




\subsubsection{Conversion of MBN Measurement Results to Residual Stresses:}

After doing MBN measurements from the surface of the samples, MBN responses should be converted into residual stresses by using a calibration curve (see in Chapter 4). The calibration curve (Figure 4.11) shows the MBN variation with respect to the stress values that is obtained from a sample which residual stress value is taken as 0 .

The best fitted line and error was calculated from the data collected showing the MBN variation with respect to stress changes (Table 3). The stress values were calculated by using the formula regarding the best fitted line to the calibration data (Figure 5.6)

Table 5.4 MBN data versus Stress value collected from the calibration sample.

\begin{tabular}{|c|c|c|c|c|c|c|}
\hline $\begin{array}{c}\text { BN } \\
\text { Amplitud } \\
\text { e(Avg.) }\end{array}$ & $\begin{array}{c}\text { Stress(From } \\
\text { Strain) }\end{array}$ & $\begin{array}{c}\text { Stress(From } \\
\text { fitted line) }\end{array}$ & Error & & $\begin{array}{l}\text { Absolute of error } \\
\text { in stress due to } \\
\text { curve fitting }\end{array}$ & $\begin{array}{l}\text { Absolute of } \\
\text { error in } \\
\text { stress due to } \\
\text { MBN } \\
\text { measurement }\end{array}$ \\
\hline 80 & -289 & -265 & -24 & & 24 & 37 \\
\hline 80 & -265 & -264 & -2 & & 2 & 36 \\
\hline 86 & -231 & -244 & 13 & & 13 & 35 \\
\hline 96 & -202 & -210 & 8 & & 8 & 31 \\
\hline 107 & -173 & -177 & 4 & & 4 & 28 \\
\hline 119 & -144 & -148 & 3 & & 3 & 25 \\
\hline 131 & -115 & -120 & 4 & & 4 & 22 \\
\hline 145 & -87 & -91 & 4 & & 4 & 18 \\
\hline 169 & -58 & -53 & -5 & & 5 & 14 \\
\hline 187 & -29 & -31 & 2 & & 2 & 11 \\
\hline 250 & 0 & 22 & -22 & & 22 & 7 \\
\hline 271 & 29 & 38 & -9 & & 9 & 8 \\
\hline 293 & 58 & 55 & 2 & & 2 & 9 \\
\hline 310 & 87 & 73 & 14 & & 14 & 11 \\
\hline 329 & 115 & 95 & 20 & & 20 & 13 \\
\hline \multirow[t]{3}{*}{367} & 144 & 159 & -15 & & 15 & 21 \\
\hline & & & & Average Error & 10 & 20 \\
\hline & & & & Total error & 30 & \\
\hline
\end{tabular}




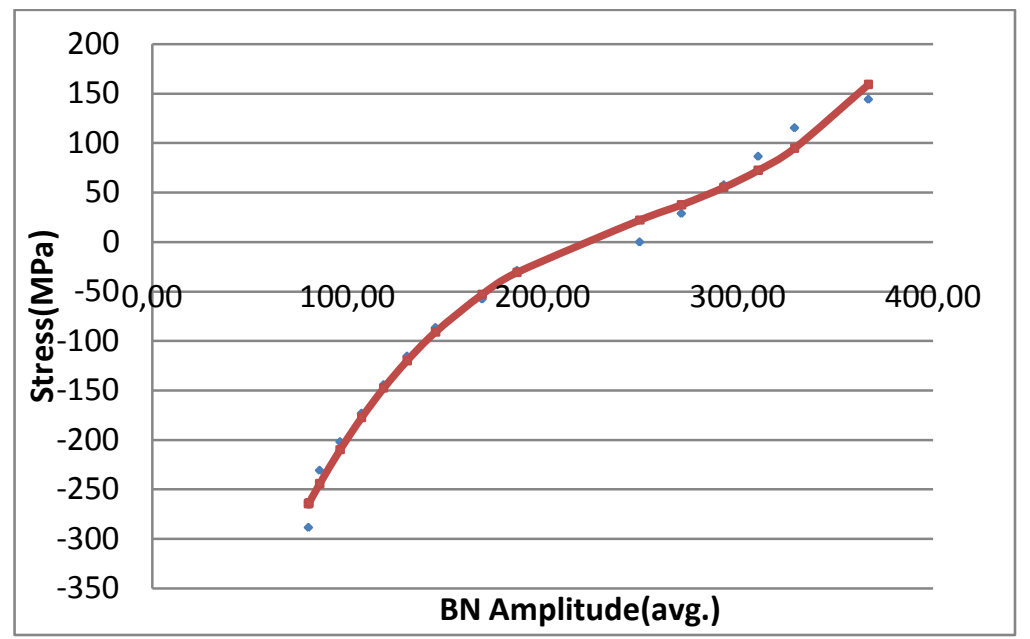

Figure 5.6 Best fitted line as Stress versus MBN in order to calculate the formula by taking MBN responses as $\mathrm{x}$ of the formula.

In Table 5.3, the stresses calculated from strain values collected during calibration after applying stresses in elastic range to the calibration sample and the stresses calculated from the best fitted line. Variation from two stress values was written as error. Also, the variation coming from MBN measurements was taken into account and the total variation is calculated as $60 \mathrm{MPa}$.

According to the calibration curve data (Figure 4.11) the MBN measurements from different shot peened samples with different intensity, coverage and impact angles (Figure 5.7, 5.8, 5.9) Maximum compressive residual stress was obtained at $300 \%$ coverage as -270 MPa. In maximum intensity -210 MPa and in $90^{\circ}$ angle $-180 \mathrm{MPa}$ residual stress values were measured with an error $\pm 30 \mathrm{MPa}$. The amount of residual 
stresses are reasonable for an low alloy steel. The residual stress measurements were confirmed by XRD residual stress measurements (Chapter 5.3).

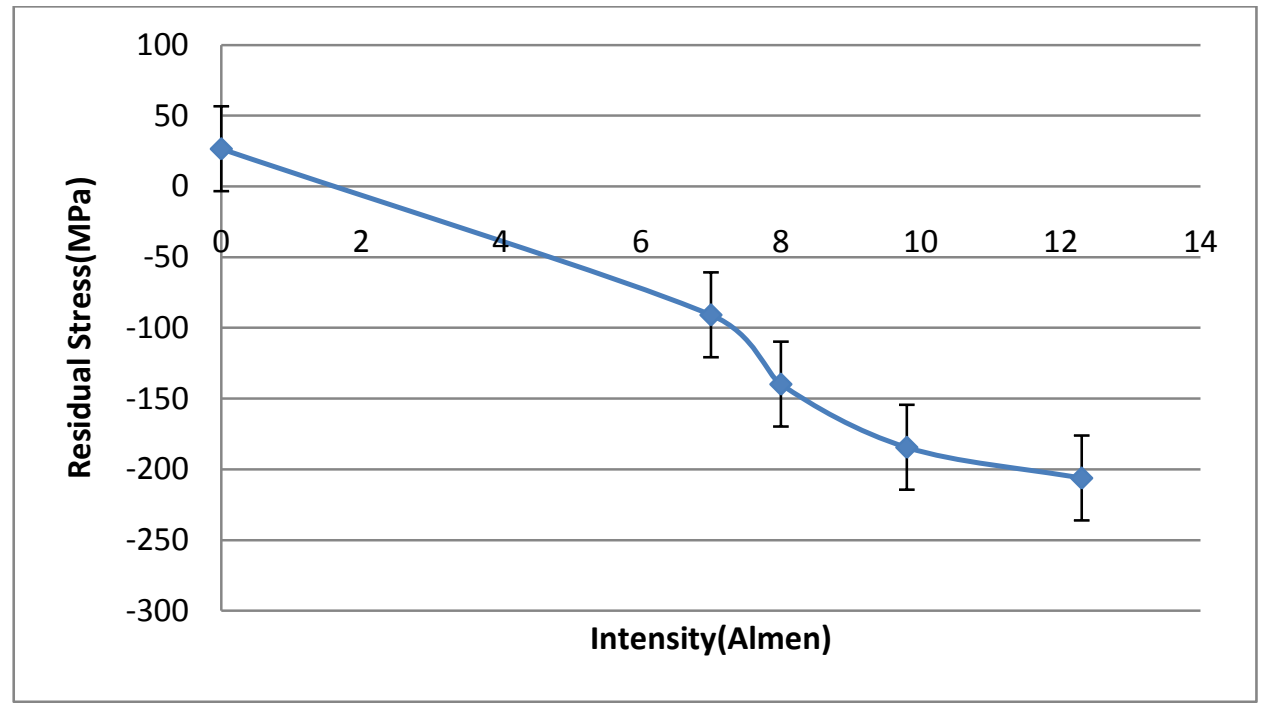

Figure 5.7 The graph is plotted as Stress versus MBN to show intensity effect of shot peening.

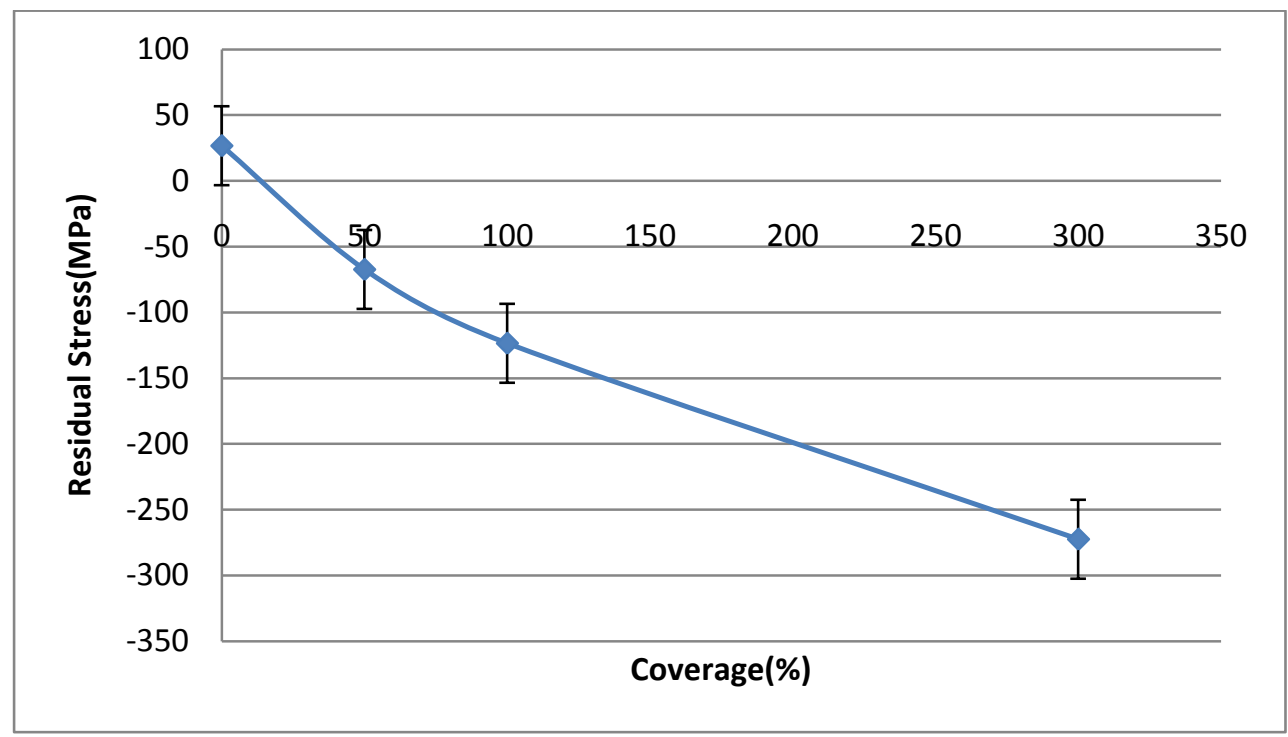

Figure 5.8 The graph is plotted as Stress versus MBN show coverage effect of shot peening. 


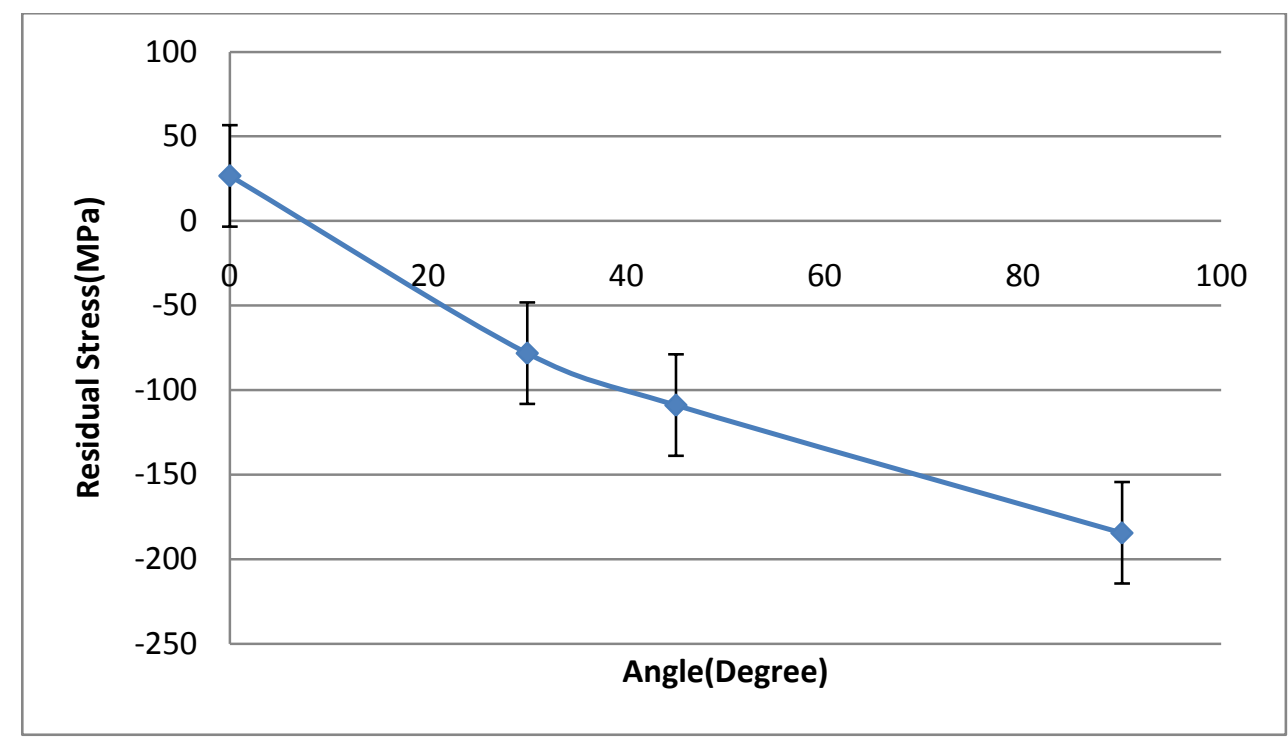

Figure 5.9 The graph is plotted as Stress versus MBN to show impact angle effect of shot peening (The result for 0 degree shows MBN response of reference sample)

Desvaux et al. measured the residual stresses from the M50 bearing samples with the same approach [27, 35]. They confirmed their measurements with the X-Ray measurement method and found results which are very close with the MBN measurement results. In addition to that work, Wojtas has confirmed the MBN measurements in shot peened samples with the X-Ray measurements and showed the potential of the MBN technique as a qualitative and quantitative evaluation method of residual stresses [25].

\subsection{MBN Measurements with $\mu$ scan System:}

$\mu$ scan channel outputs are RMS (Root Mean Square) of MBN, by performing FFT (Fast Fourier Transformation) to the time domain MBN data, Amplitude versus Frequency graph is obtained which shows at which frequency of $\mathrm{BN}$ the highest amount of $\mathrm{BN}$ is coming; and a representative hysteresis curve which can also show 
a difference between different amount of shot peened samples. All of these outputs can be used as detection criteria to the effect of shot peening.

\subsubsection{MBN RMS Profiles of the Samples:}

In Figure 5.10 shows the MBN RMS (Root Mean Square) profiles, which are obtained from the $\mu$ scan channel of MBN equipment, of the shot peened samples with different intensity values that are $7 \mathrm{~A}, 8 \mathrm{~A}, 9.8 \mathrm{~A}, 12.3 \mathrm{~A}$ and there is also the MBN profile of un-shot peened sample as a reference signal. When the intensity value of the SP process increases, the compressive residual stresses obtained at the surface of the sample will increase. As the theory, it is expected a decrease from the MBN signal response of the samples in the sequence of increasing intensities. That's why; compressive residual stresses have a decreasing effect on the MBN response from the fact movement capability of $180^{\circ}$ domain walls decrease [6]. So the figure 5.10 shows an expected behavior. When the intensity of SP increases the MBN response decreases. The MBN profiles of the 9.8A and 12.3A intensities are closer than the other intensities. It can be explained with calibration curve at which the region of the compressive stresses is less that the tensile stresses, so after a value of the compressive stress, the MBN profiles start to become closer in each other. This behavior is the same as those in literature [36]. Besides, the peak positions of the MBN profiles are shifted to the higher magnetic field strengths because the effect of compressive residual stresses makes the magnetization behavior of the sample harder.

The resolution of the MBN measurement is capable of detecting 1 Almen intensity change such as between 7A and 8A. The resolution is getting worse when the Almen intensities increases that is also the fact related to $\mathrm{BN}$ behavior seen in the calibration curve. 
Coverage parameter causes clear changes in MBN amplitude (Figure 5.11). Also, peak positions shift to the higher magnetic field strengths as seen in the intensity changes.

The resolution of the system is capable to detect the effect of angle lower than $45^{\circ}$ but it cannot be obtained good resolution between $45^{\circ}$ and $90^{\circ}$ angles (Figure 5.12). However, a good resolution can be obtained if the average peak values are determined as the evaluation criteria (Figure 5.1(c))

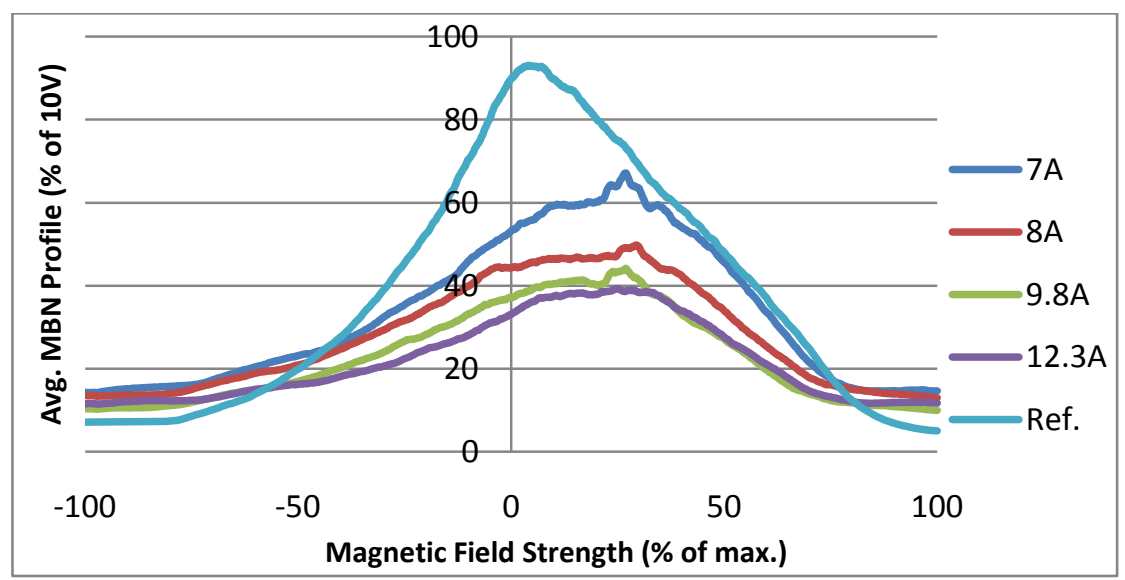

Figure 5.10 RMS MBN Profiles of shot peened samples with different intensity

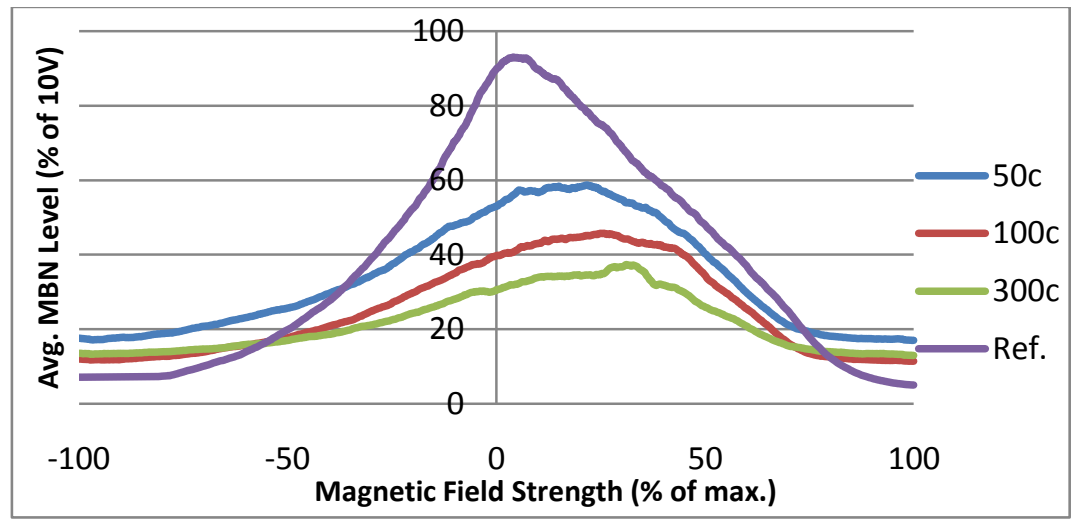

Figure 5.11 RMS MBN Profiles of shot peened samples with different coverage 


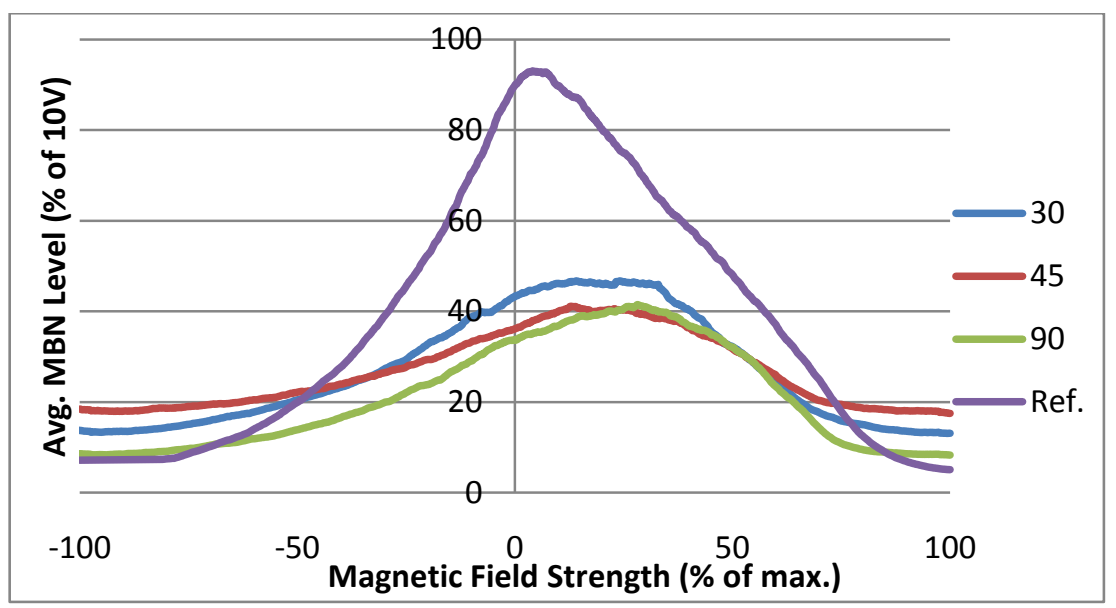

Figure 5.12 RMS MBN Profiles of shot peened samples with different impact angle

\subsubsection{MBN Frequency Distribution Profiles of the Samples:}

Frequency distributions are obtained from MBN signal in time domain by FFT Analysis that is performed automatically by the software available at the equipment. At that distribution, it can be seen that at which frequency the highest amount of MBN response comes. By using Formula 4.5, depth estimation can be performed regarding the frequency range of $\mathrm{MBN}$ response. The frequency distribution profiles are shown in Figure 5.13.

The frequency band where the biggest decrease in amplitude of $\mathrm{BN}$ occurs will give an estimated at what depth residual stresses are most effective. In order to do an estimation regarding the depth where the compressive residual stresses show the most significant effect, difference between the amplitude versus frequency distributions with respect to reference sample are plotted for different intensity shot peened samples (Figure 5.14). As seen in the graph, maximum difference point is located at $14 \mathrm{kHz}$ frequency, which is corresponding to around $200 \mu \mathrm{m}$ depth (Figure 4.17). This kind of estimation was done by Moorthy [37] and Zagar et al. [28] in order to detect the case hardening depth in the steels and he did confirmation that estimation by micro hardness test from the cross section of case hardened steels. By 
this estimation it can be also concluded that used intensity values provide different stress values at the same depth.

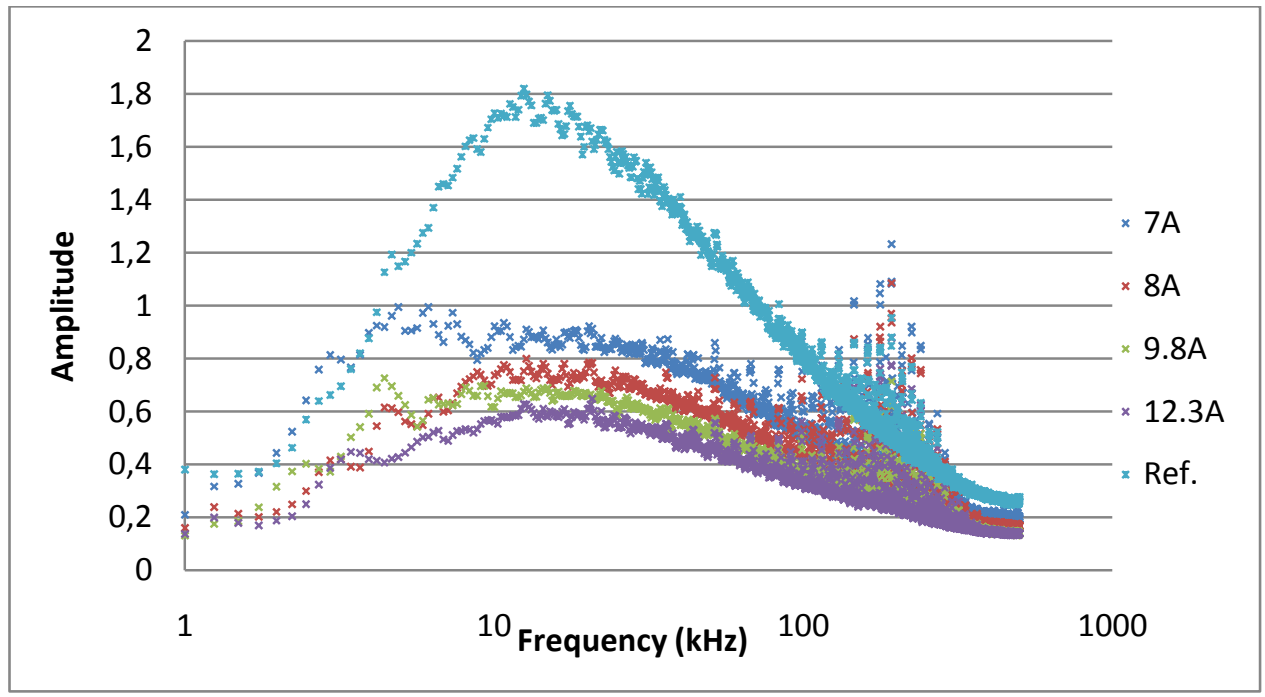

Figure 5.13 Frequency distributions of the samples with different intensity and the reference sample.

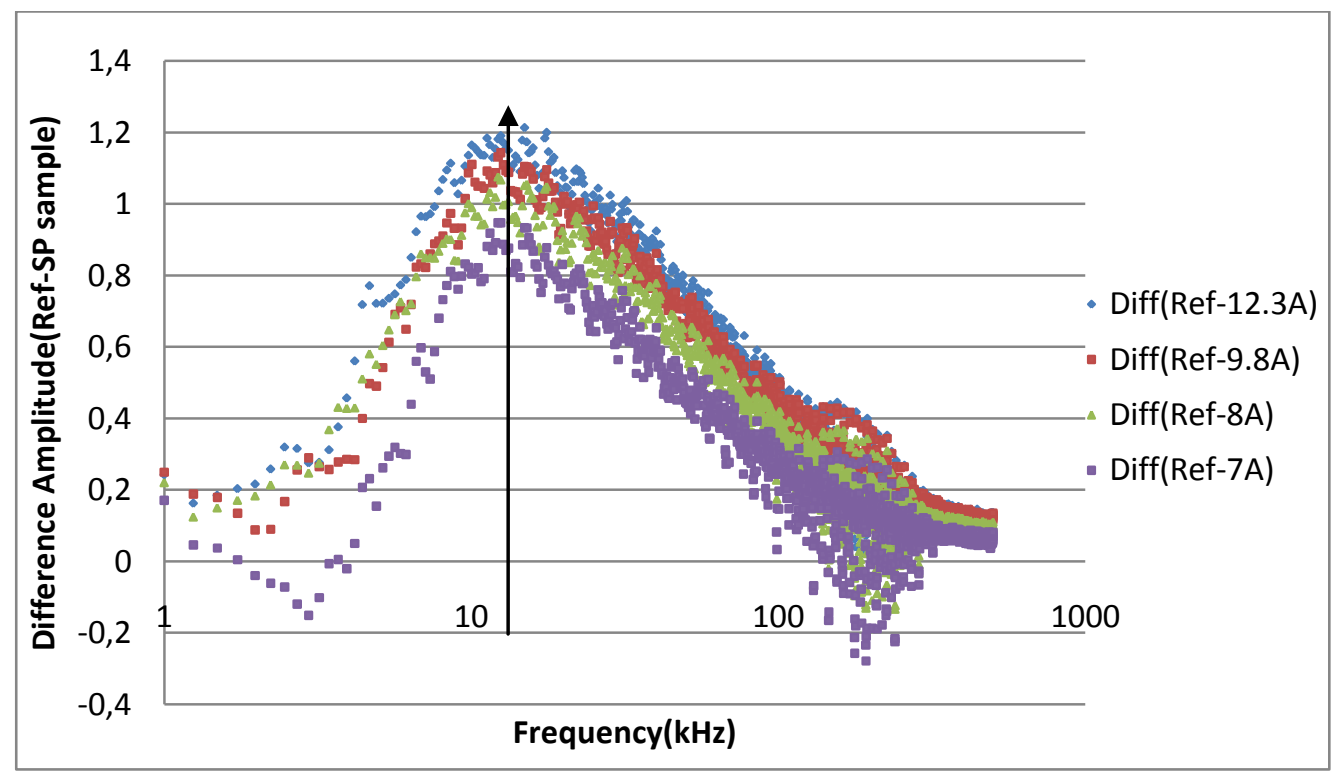

Figure 5.14 Difference between the samples with different intensities and the reference sample in amplitude with their distribution regarding frequency. 
Significant decrease in MBN signal amplitude was detected with increasing coverage (Figure 5.15).

The difference plot of the amplitude versus frequency of the shot peening coverage parameters with respect to reference samples is shown in Figure 5.16.

Results are similar with intensity value that the most significant decrease in $\mathrm{BN}$ amplitude at nearly $11 \mathrm{kHz}$, which is corresponding to in depth $200-255 \mu \mathrm{m}$ range (Figure 4.17). The significant difference shows different amount of residual stresses at the same depth in the 50\%, $100 \%$ and $300 \%$ coverage shot peened samples.

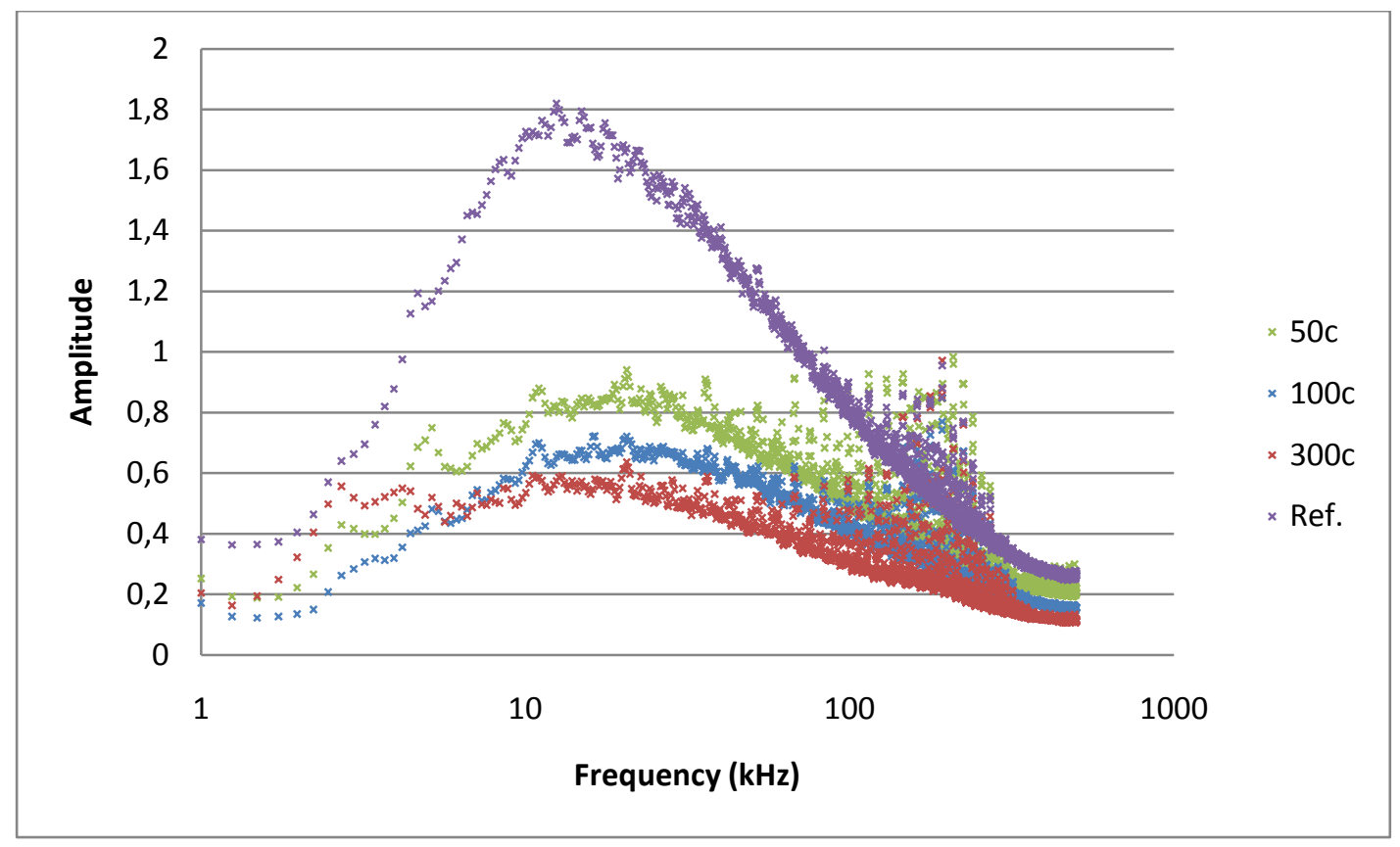

Figure 5.15 Frequency distributions of the samples with different coverage and the reference sample. 


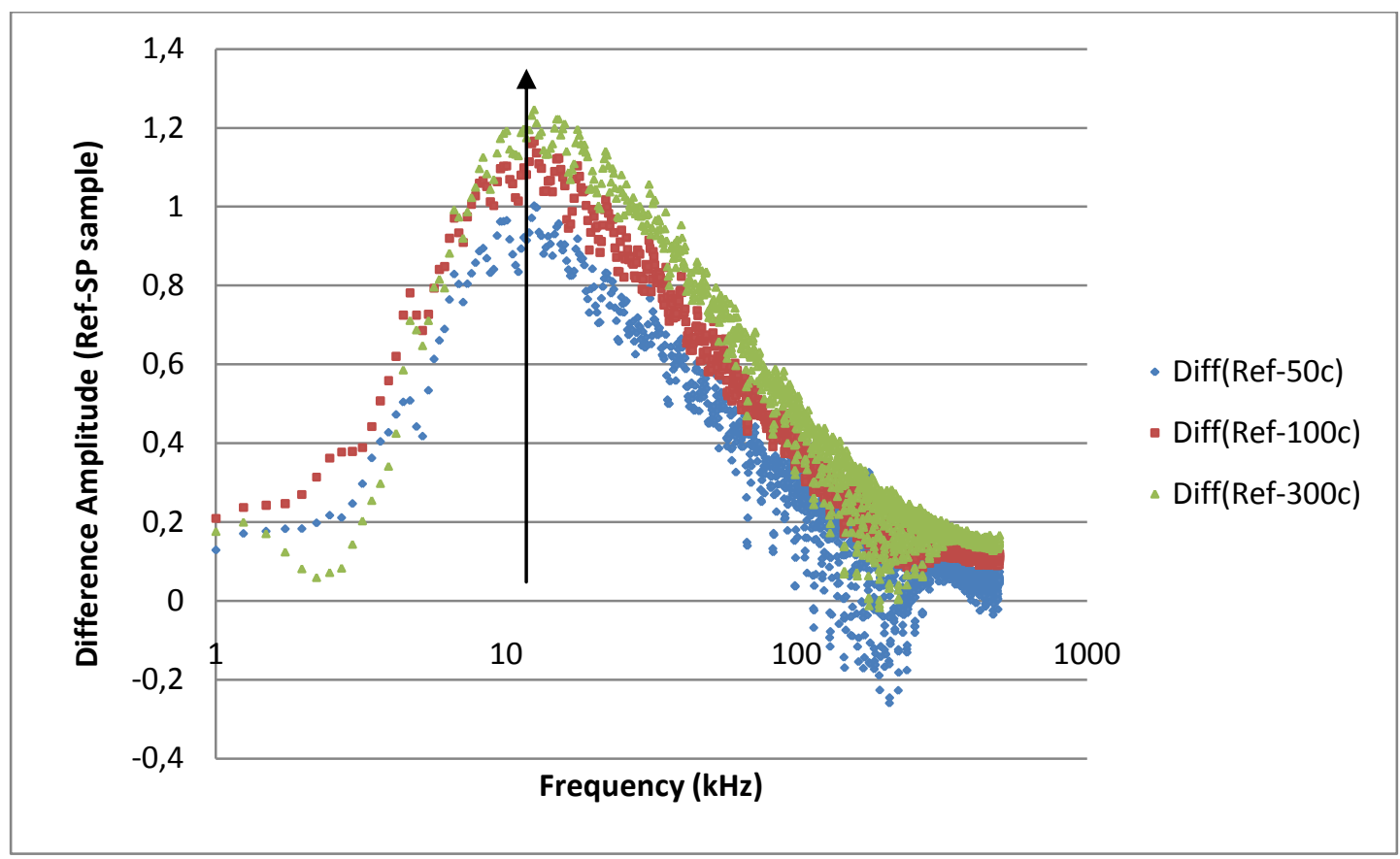

Figure 5.16 Difference between samples with different coverages and the reference sample in amplitude with their distribution regarding frequency.

Frequency distributions of the different impact angle shot peened samples is shown in Figure 5.17. As found in the RMS MBN profiles, the resolution for $45^{\circ}$ and $90^{\circ}$ shot peened samples is not seen sufficient but there is a difference obtained for $30^{\circ}$ angle.

When the difference plot is observed, $30^{\circ}$ angle shot peened sample gives the maximum decrease from the reference sample at higher frequencies than $45^{\circ}, 90^{\circ}$ (Figure 5.18). $30^{\circ}$ angle makes the maximum decrease at $20 \mathrm{kHz}$ frequency which is corresponding to a $160 \mu \mathrm{m}$ depth. On the other hand, $45^{\circ}$ and $90^{\circ}$ angles makes the maximum decrease at $11 \mathrm{kHz}$ which corresponding to $200-255 \mu \mathrm{m}$ depth range (Figure 4.17). This result shows us to see the effect of higher angles on shot peening depth in an expected manner. 


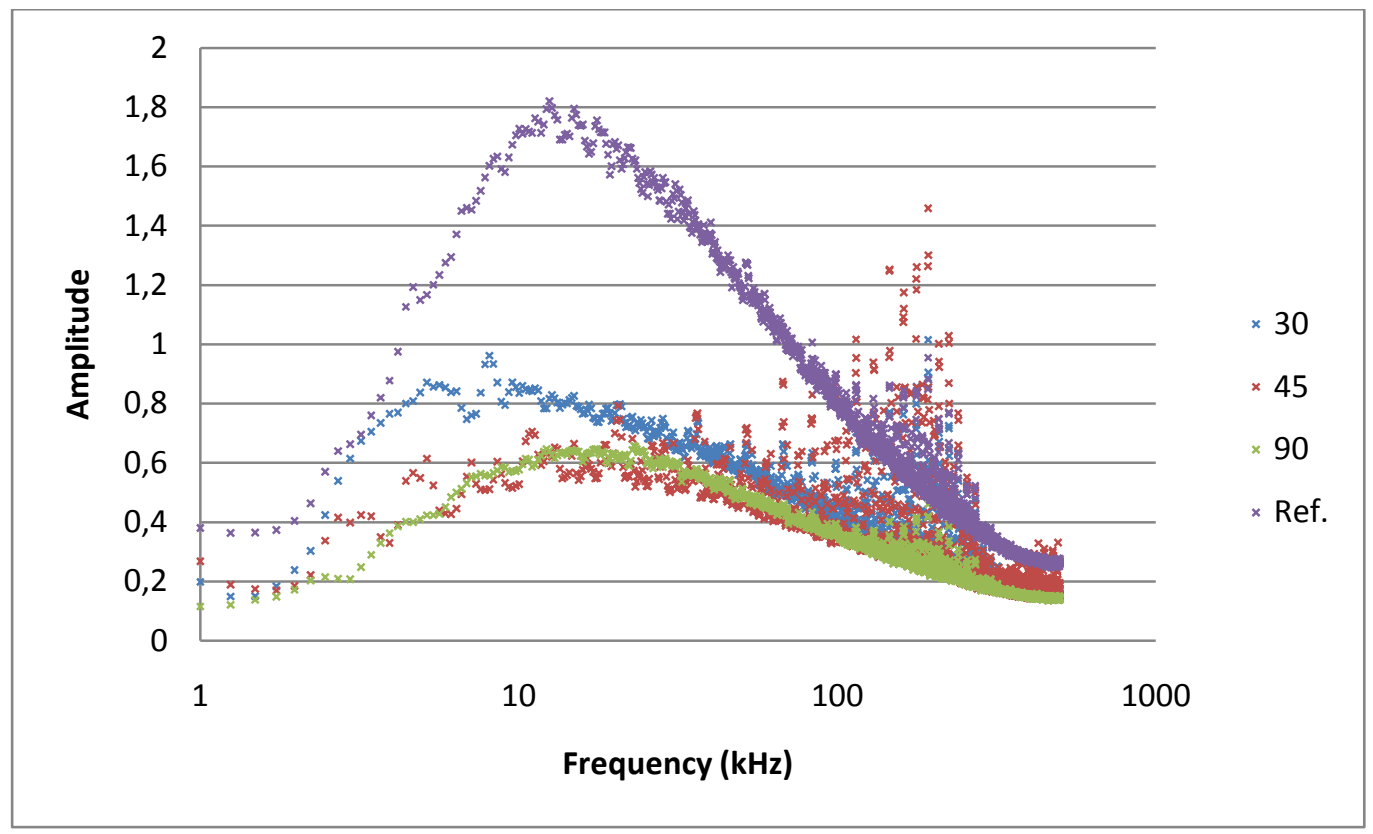

Figure 5.17 Frequency distributions of the samples with different impact angle and the reference sample.

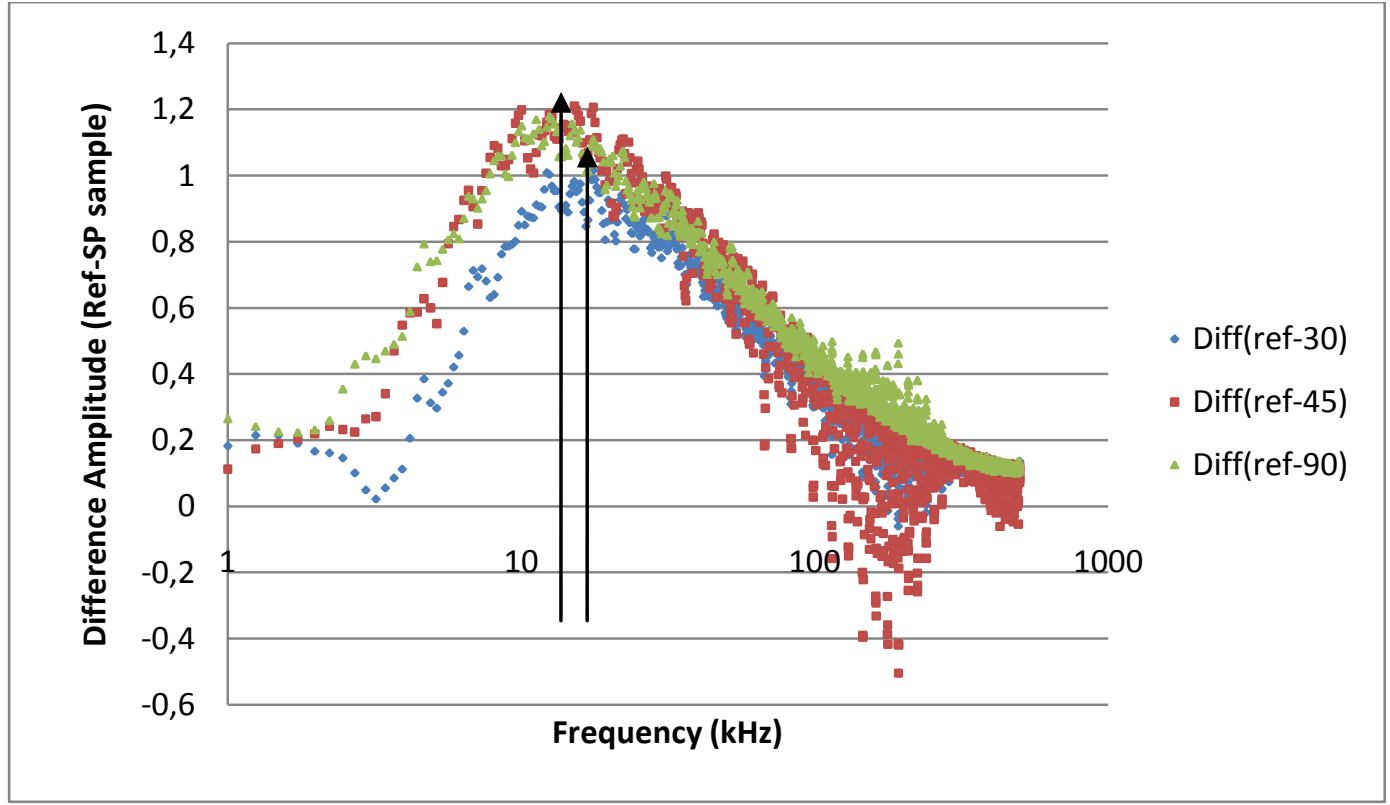

Figure 5.18 Difference between the samples with different impact angles and reference sample in amplitude with their distribution regarding frequency. 
In Figure 5.19, RMS MBN Profiles taken by using different filtering options from the reference sample can be seen. As seen in the frequency distributions, the effect of filtering options to MBN response amplitude can be analyzed with the profiles. The highest amplitude is obtained in $0.1-100 \mathrm{kHz}$ filtering option. The frequency where the maximum MBN response is obtained is in the range of this filtering option.

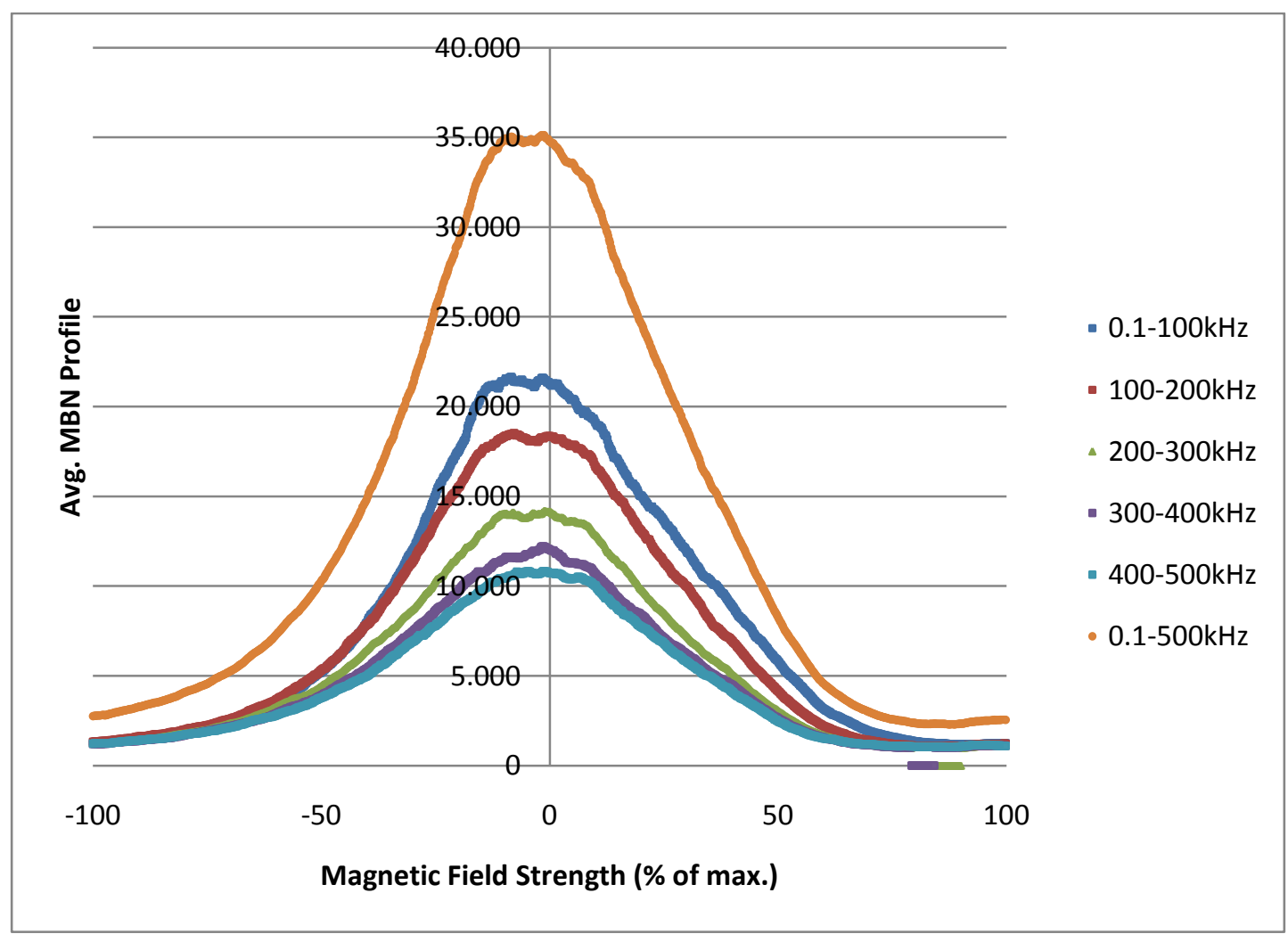

Figure 5.19 RMS MBN Profiles taken by using different filtering options from the reference sample.

By cutting one of the samples which were shot peened in the most severest conditions, microhardness measurements were performed from the cross section in order to see the effect of shot peening (Figure 5.20). The results showed that there is not a significant increase in hardness and the depth of shot peening effect goes up to 
$400 \mu \mathrm{m}$. This can verify the depth estimations performed in frequency distributions of MBN.

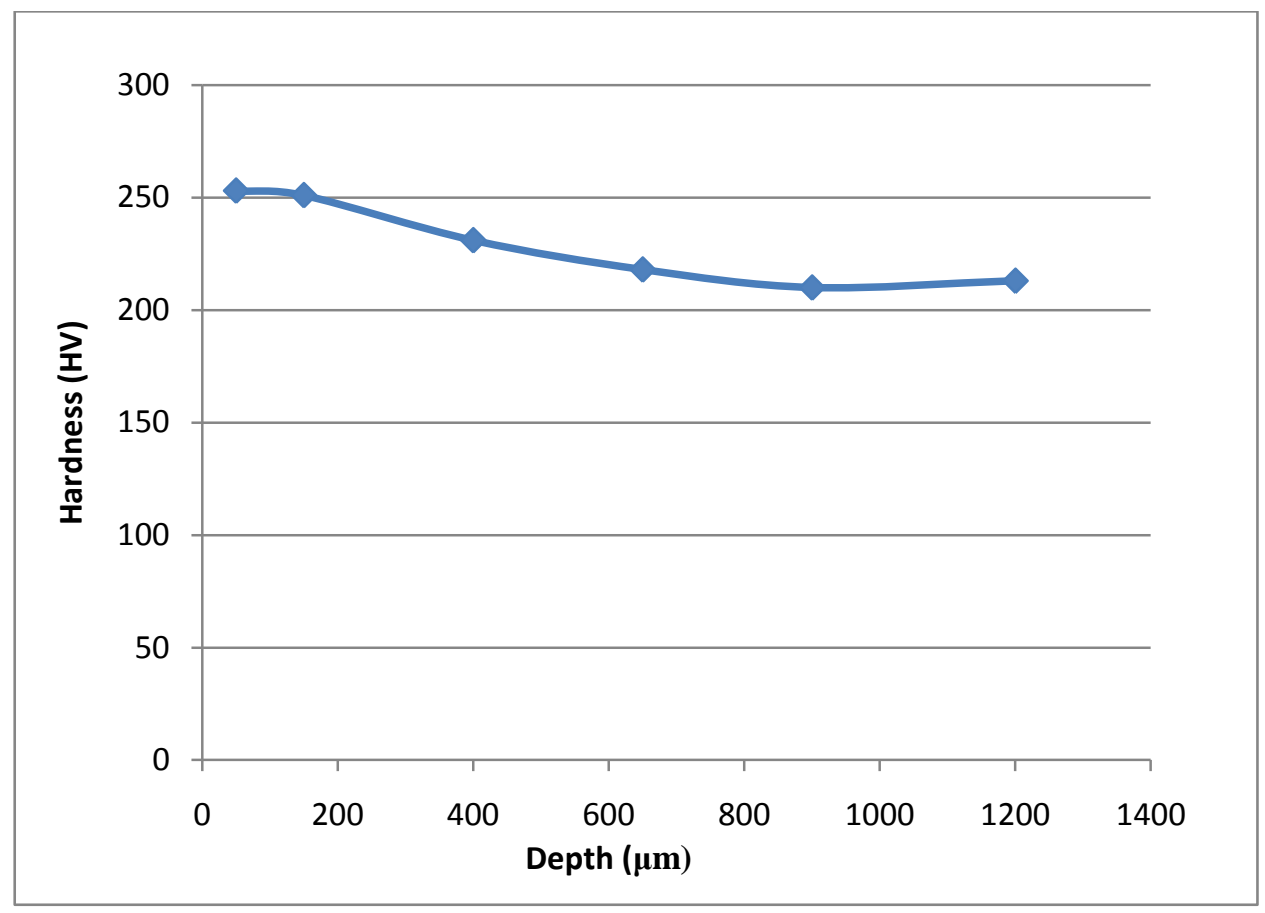

Figure 5.20 Microhardness measurement taken from the most severest shot peened sample.

\subsubsection{Representative Hysteresis Curves of the Samples}

In MBN measurements, a representative magnetic hysteresis loop is obtained in a small volume of specimen because of the irreversible magnetization with applied alternating magnetic field by the probe to the material [32]. In Figure 5.21, 5.22 and 5.23 , the representative hysteresis curves of the reference sample and the samples shot peened with different intensity, coverage and impact angle values shot peened samples with a comparison to reference sample. 


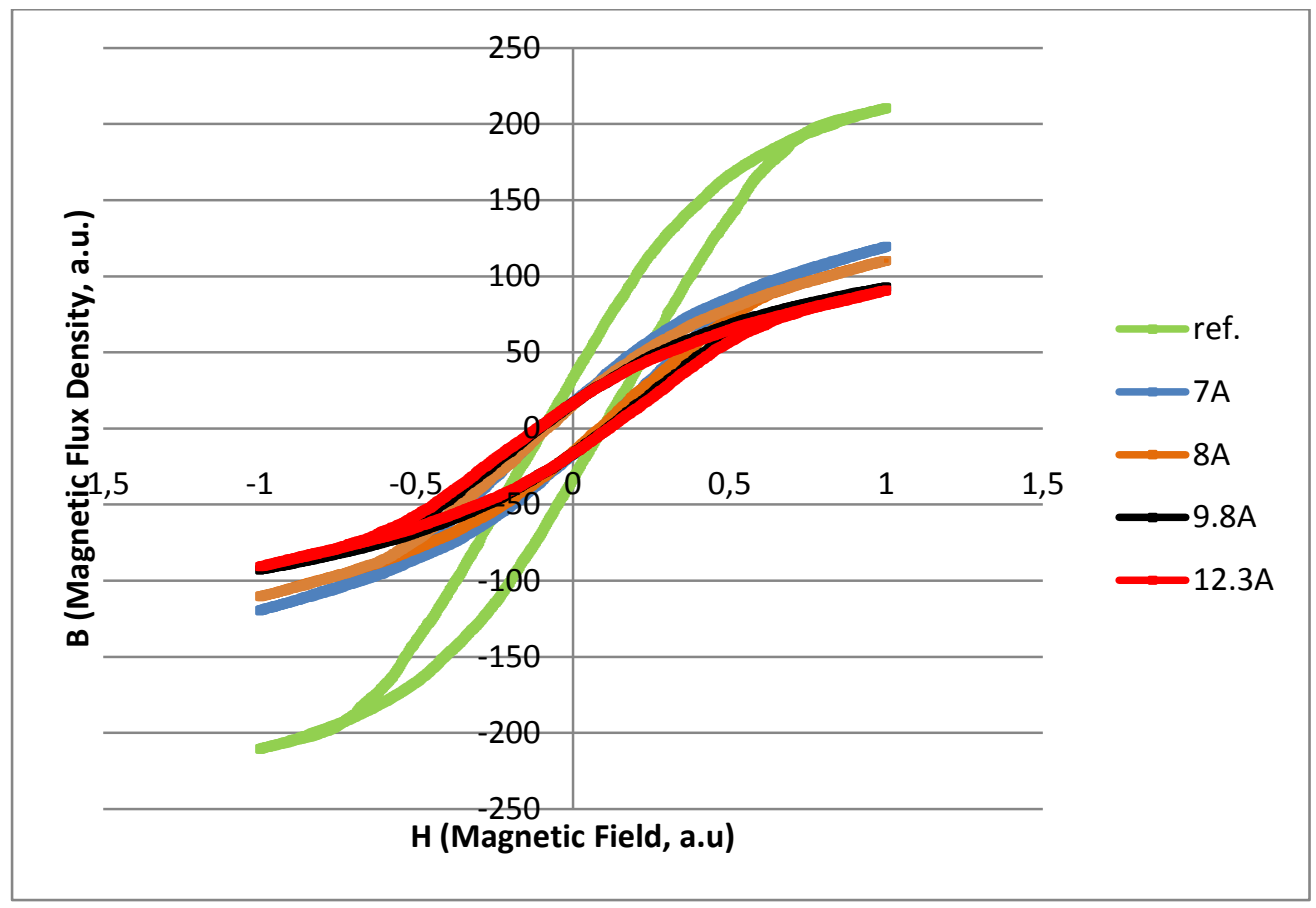

Figure 5.21 Hysteresis curves of the samples shot peened with different intensities.

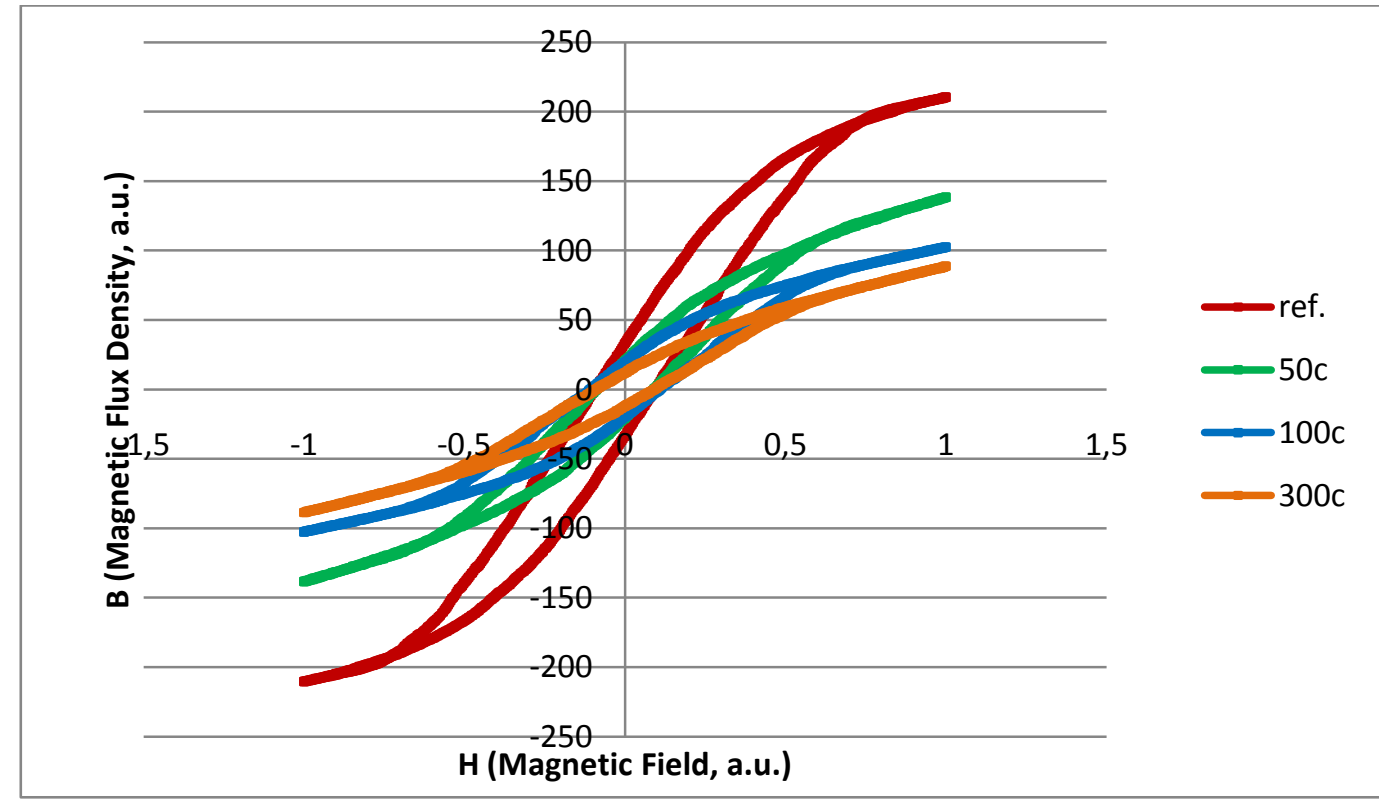

Figure 5.22 Hysteresis curves of the samples shot peened with different coverages. 


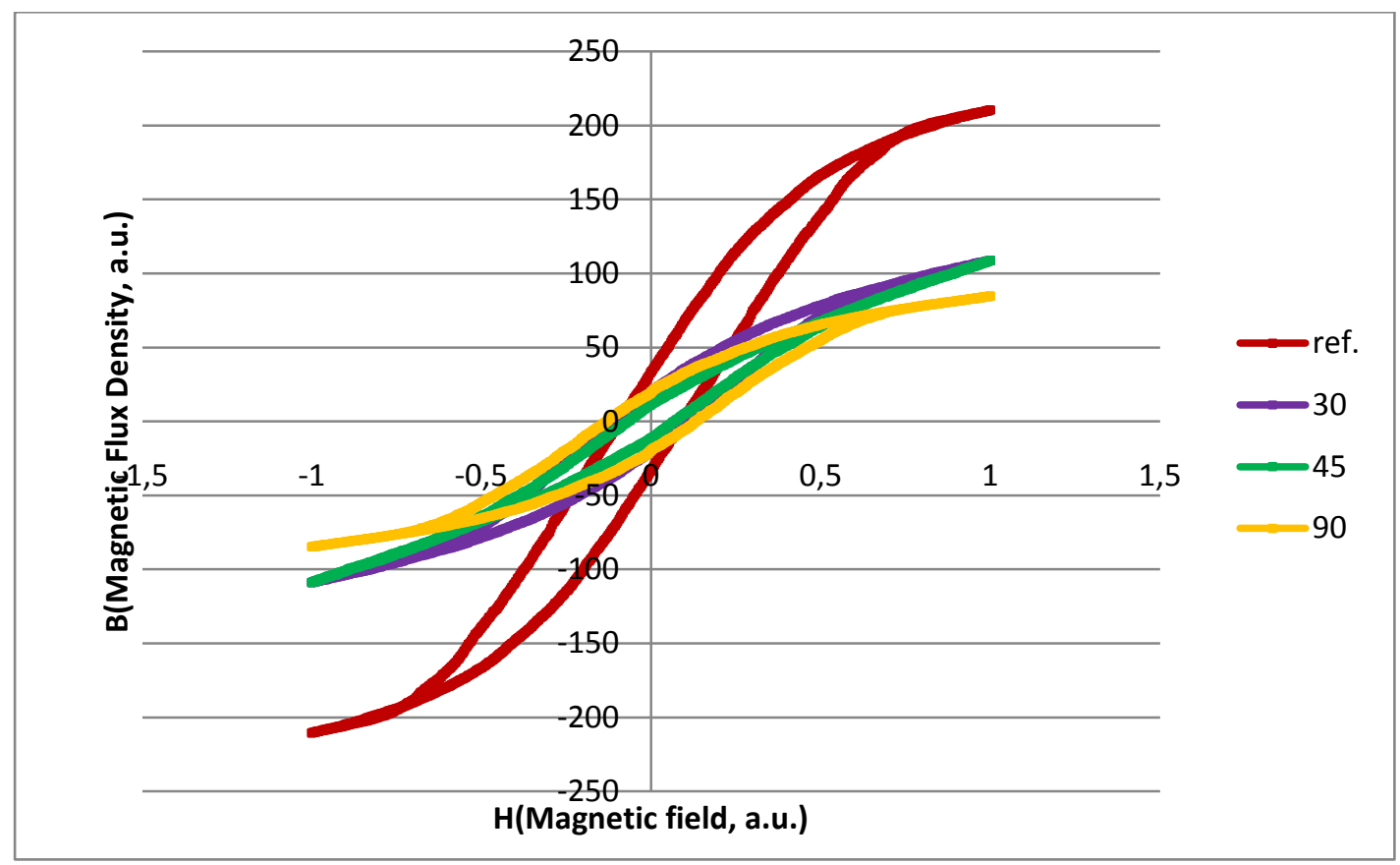

Figure 5.23 Hysteresis curves of the samples shot peened with different impact angles

This representative hystresis curves should not be confused with the real hysteresis curves which is measured by magnetizing all sample. Significant changes can be seen in the representative hysteresis plots of intensity, coverage and impact angle that are correlated with the results of RMS MBN and, frequency distribution plots of the samples. There are differences between samples with respect to their saturation magnetic flux density values. However, the coercive forces of the representative hysteresis curves do not show significant changes in the samples. Same behavior can be seen also in the literature. When AISI 410 stainless steel shows an increase compressive residual stress, SAE 4340 steel shows only difference in saturation magnetic flux density in the same way with the shot peening samples used in the experiments [38]. Therefore, it is better to evaluate shot peening effect of different shot peening parameters with saturation magnetic flux density. 


\subsection{Verification of MBN Results with XRD Residual Stress Measurement Results:}

XRD residual stress measurements were performed on three samples which are reference, shot peened with $9.8 \mathrm{~A}$ and $12.3 \mathrm{~A}$ intensities. First of all, two measurements were performed from the 9.8A shot peened sample at the same point in order to check the repeatability of the measurements. The measurements gave two results which are $-312 \mathrm{MPa}$ and $-316 \mathrm{MPa}$. After doing repeatability check, 5 random measurements were taken from each sample. The mean of the 5 measurements were taken as the overall residual stress value at the surface of the samples. A screen shot taken from the XRD measurement is shown in Figure 5.24. It includes the peaks obtained at high angle, $2 \varphi$ versus $\sin ^{2}(\operatorname{Psi}(\psi))$ plot and the calculated residual stress values. The stress is calculated by taking the lop of the fitted line from $2 \varphi$ versus $\sin ^{2}(\operatorname{Psi}(\psi))$ plot (Chapter 4.8).

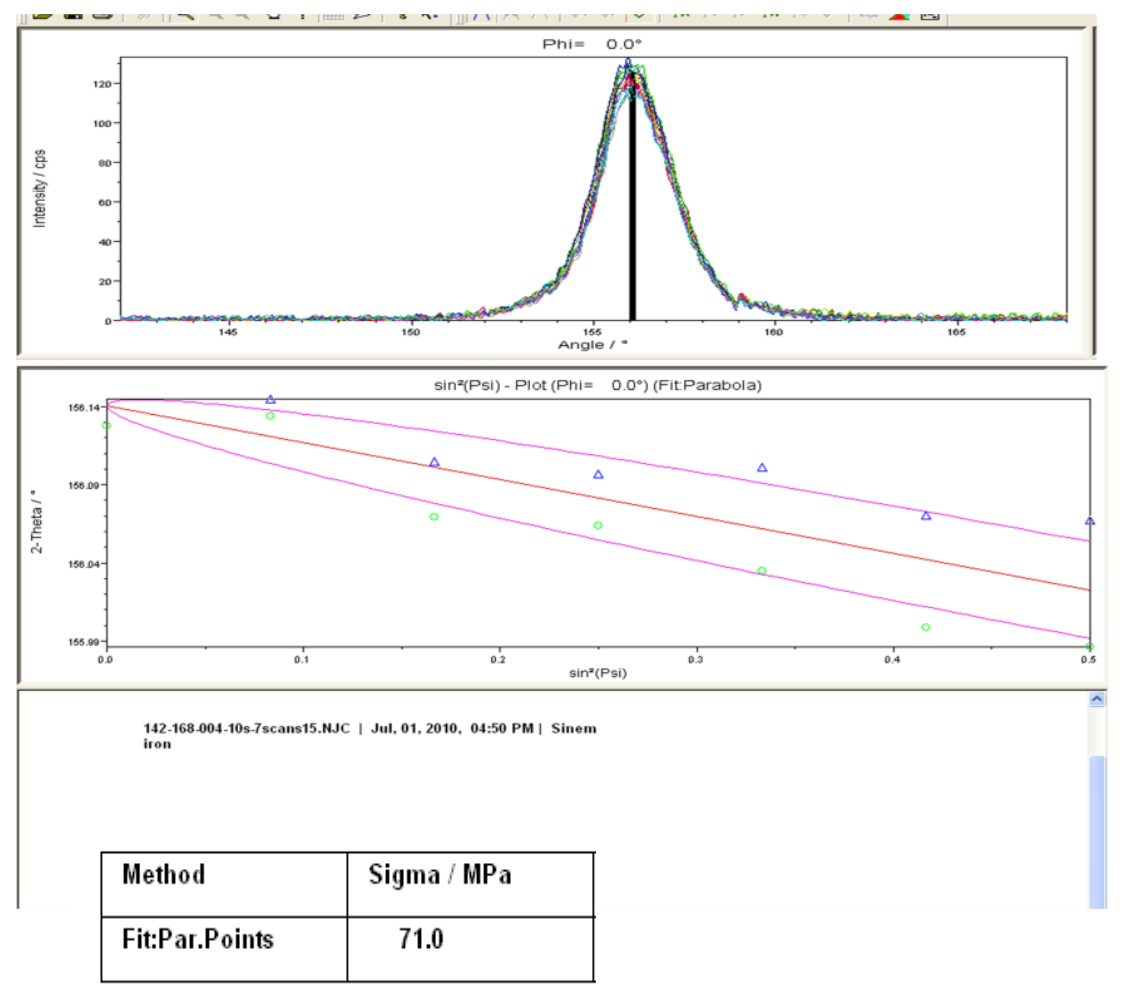

Figure 5.24 XRD residual stress measurement results 
The results of MBN and XRD were plotted in Figure 5.25. MBN results are $26 \mathrm{MPa}$, $-184 \mathrm{MPa}$ and $-206 \mathrm{MPa}$ with $\pm 30 \mathrm{MPa}$ error in reference, 9.8A and $12.3 \mathrm{~A}$ shot peened samples. XRD results are $71 \mathrm{MPa},-286 \mathrm{MPa}$ and $-340 \mathrm{MPa}$ in the same samples. The measurements taken from reference sample show results very close in each other. In shot peened samples, XRD and MBN measurements show near 100 $\mathrm{MPa}$ difference. MBN can take informatin from more deeper regions from the surface of the sample. However, XRD can penetrate near $5 \mu \mathrm{m}$ depth from the surface. The difference between two techniques can be explained with this basis. It is expected lower compressive residual stresses at deeper parts than surface.

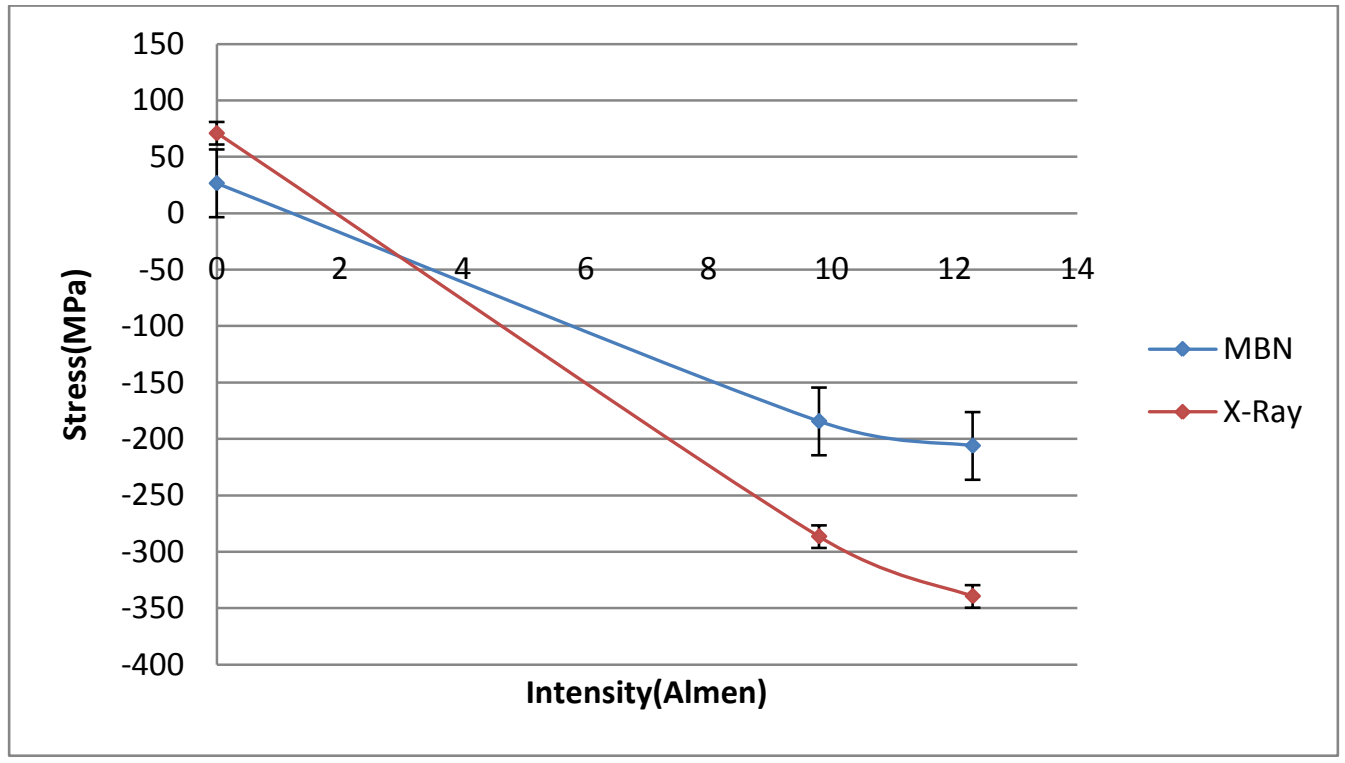

Figure 5.25 Validation of MBN with XRD measurements 


\section{CHAPTER 6}

\section{CONCLUSIONS}

Magnetic Barkhausen Noise(MBN) measurements of the shot peened samples with application of different shot peen intensity, coverage on the surface and different nozzle angles with respect to the normal of material surface were carried out. For this purpose, MBN and residual stress calibration and shot peen effect control procedures were developed. The expected results were found according to the current calibration and control method of shot peening operation that are Almen strip calibration of the peening operation.

The following conclusions can be drawn from the results of the thesis work.

- Shot peening operation introduces beneficial compressive residual stresses on the samples in an increasing amount with the increasing intensity, coverage and noozle angle close to $90^{\circ}$.

- Magnetic Barkhausen Noise method can be used as a very fast scanning method to the shot peened surfaces for sorting and/or evaluation of the shot 
peening coverage by obtaining homogeneous signal distribution in a predetermined range.

- MBN method can be use to evaluate the residual stresses obtained after shot peening operation. By doing frequency analysis, an estimation regarding the depth can be performed.

- MBN method gives correlated results with XRD method which is most commonly used residual stres evaluation technique.

- All the parameters of shot peened process used in the experimental work has a significant effect on $\mathrm{MBN}$ response of the samples.

- Magnetic Barkhausen Noise technique has a good resolution (1 Almen difference) for determining the shot peening effect on different samples with shot peened different intensities, but when going to higher intensities in other words to higher compressive residual stresses resolution of the technique starts to decrease. Calibration of MBN before measurement and statistical analysis on collected data are very important in order to obtain reliable and good resolution measurements.

- MBN probe magnetization ability is important if the compressive type of residual stresses is trying to be evaluate because a decreasing effect of the signal is wanted to evaluate.

For further studies, high hardness ferromagnetic materials can be used as a shot peening substrate material in order to simulate the shot peening operation in real parts such as crackshafts. High hardness ferromagnetic materials have lower MBN responses when compared to the soft materials. This is caused by the decreasing effect of the hardness on MBN. Compressive residual stresses decrease MBN 
emission. In order to see the resolution of the MBN technique in hard ferromagnetic materials an experimental work can be conducted by changing the process parameters of the shot peening and MBN measurements.

By performing these kind of capability studies, establishing calibration and inspection procedure, MBN technique can used in the production sites as a continuous residual stress evaluation method with periodic confirmations by X-Ray diffraction method. 


\section{REFERENCES}

[1] Franck Petit-Renaud, Wheelabrator Group Ltd, Impact Finisher, www.wheelaboratorgroup.com

[2] Withers P.J., Bhadeshia H. K. D. H., Residual Stress Measurement Techniques, Material Science and Technology, April 2001, Vol.17 p. 355-365

[3] ASM Handbook, Vol. 17, p. 327-328

[4] C-G. Stefanita, Ph.D. Thesis, Department of Physics, Queen's University, Kingston, Ontario, Canada, 1999

[5] Chikazumi S., Physics of Magnetism, Wiley, New York, (1964).

[6] Gathier Julie, Magnetic Barkhausen Noise and Acoustoelasticity: A Comparasion of two NDT Methods of Measuring Residual Stress, 1994, p. 20-21

[7] Neelkanta P.S., Handbook of Electromagnetic Materials: Monolithic and Composite Versions and Their Applications, CRC Press, Boca Raton, Florida, 1995.

[8] K. Tiito, in Nondestructive Evaluation: Application to Materials Processing, ed. by O. Buck, S.M. Wolf, ASM, Materials Park, Ohio, 1984, p. 161

[9] Yardley V, Magnetic Properties in NDT, University of Cambridge, Department of Material Science and Metallurgy, 2003, p. 6 
[10] Shot Peener, Vol 21, 2007, p. 20.

[11] Niku-Lari A., "Shot Peening", CETIM, 1st International Conference on Shot Peening (ICSP1), France; 1980

[12] http://www.mechanicalengineering.cc/mechanical-engineering-archives/40Shot-Peening.html, 03.03.2008

[13] ASM Metals Handbook, Vol.5, p.278-291

[14] Shot Peener, Vol 13. p. 5

[15] Plaster H.J., Technical Aspects of Shot Peening Machinary and Media,

Chairman British Impact Treatment Association.

[16] Shot Peener, Vol 21, p.10-11

[17] www.wikipedia.com

[18] Klemenz M., Zimmermann M., Schulze V., Löhe D., Numerical Prediction of the Residual Stress State after Shot Peening, Institude für Werkstoffe I, Universitaet Karlsruhe.

[19] Meo M., Vignjevic R., Finite Element Analysis of Residual Stress Induced by Shot Peening Process, Advances in Engineering Software 34, 2003, p. 569-575.

[20] Floyd T., Use shot peening to toughen welds, Welding Design and Fabrication Sep. 1985 , p. $68-70$

[21]www.aviationdatabase.com/Wheelabrator_Group_Aerospace_shot_peening.htm, 10.04.2008

[22] Duchazeaubeneix Jm., Stresssonic Shot Peening (Ultrasonic Process), The 7th International Conference on Shot Peening, Poland, p. 444-452 
[23] Breuer D., Laser Peening - Advanced Residual Stress Technology, Industrial Heating, The International Journal of Thermal Technology, 2007

[24] Suominen L., Tiitto K., "Use of X-ray diffraction and Barkhausen noise for the evaluation of stresses in shot peening", Proceedings of the Fourth International Conference on Residual Stresses; Baltimore, Maryland; USA; 8-10 June 1994. pp. 443-448. 1994

[25] Wojtas A., "Surface and Subsurface Residual Stresses after Shot Peening Their Qualitative and Quantitative Analysis by X-Ray Diffraction and Barkhausen Noise Analysis", Metal Finishing News; 2004

[26] Jacob P, Marrone S, Suominen L, Honkamaki V. Non-destructive evaluation of residual stress depth profiles by Barkhausen noise analysis and their validation by $X R D$ method combined with electrochemical (destructive) surface removal, Proceedings of the fourth international conference on Barkhausen Noise and micromagnetic testing; 2003. p. 361-8.

[27] Desvaux S., Duquennoy M., Gualandri J., Ouaftouh M., Ourak M., Evaluation of residual stress profiles using the Barkhausen noise effect to verify high performance aerospace bearings, Nondestructive Testing and Evaluation, Vol. 20, No. 1, March 2005, p. 9-24

[28] Zagar S., Zerovnik P., Grum J., Surface Layer Analysis after Shot Peening by Barkhausen Noise Signal, The 10th International Conference of the Slovenian Society for Non-Destructive Testing Application of Contemporary Non-Destructive Testing in Engineering September 1-3, 2009, Ljubljana, Slovenia,p. 539-548

[29] McIntire P., Birks A. S., Green, Jr. R. E., Nondestructive Testing Handbook, Volume 7, Ultrasonic Testing, ASNT, 1991, p.830 
[30] Prevey P., X-Ray Diffraction Residual Stress Technique, American Society for Metals, 1986, p. 380-392.

[31] Hilley M.E, Residual Stress Measurement by XRay Diffraction, Society of Automotive Engineers, Warrendale, PA, 1971, p. 20

[32] Davut K. Characterization of Steel Microstructures by Magnetic Barkhausen Noise Technique, MSc Thesis (Middle East Technical University, 2006).

[33] Terman, Frederick E., Radio Engineers Handbook, McGraw-Hill, New York, 1943, p. 58

[34] S.A. Meguid, G. Shagal, J.C. Stranart, J.Daly, Three-dimensional dynamic finite element analysis of shot-peening induced residual stresses, Finite Elements in Analysis and Design 31,1999,p. 179-191

[35] Desvaux S., Duquennoy M., Gualandri J., Ourak M., The evaluation of surface residual stress in aeronautic bearings using the Barkhausen noise effect, NDT\&E International 37, 2004, p. 9-17

[36] A.S. Wojtas, L. Suominen; B.A Shaw, J.T. Evans, Detection of Thermal Damage IN Steel Components After Grinding Using the Magnetic Barkhausen Noise Method, NDT.net - September 1998, Vol.3 No.9

[37] Moorthy V., Shaw B.A., Evans J.T., Evaluation of tempering induced changes in the hardness profile of case-carburised EN36 steel using magnetic Barkhausen noise analysis, NDT\&E International 36, 2003, p. 43-49

[38] ASM Metals Handbook, Vol. 17, P. 272-333 